\title{
Identification of distinct characteristics of antibiofilm peptides and prospection of diverse sources for efficacious sequences
}

\author{
Bipasa Bose $^{1}$, Taylor Downey ${ }^{2}$, Anand K. Ramasubramanian ${ }^{3, \bigotimes}$, and David C. Anastasiu ${ }^{2, \bigotimes}$ \\ ${ }^{1}$ Department of Biomedical Engineering, San Jose State University, San Jose, CA 95192 \\ ${ }^{2}$ Department of Computer Science and Engineering, Santa Clara University, Santa Clara, CA 95053 \\ ${ }^{3}$ Department of Chemical and Materials Engineering, San Jose State University, San Jose, CA 95192
}

\begin{abstract}
A majority of microbial infections are associated with biofilms. Targeting biofilms is considered an effective strategy to limit microbial virulence while minimizing the development of antibiotic resistance. Towards this need, antibiofilm peptides are an attractive arsenal since they are bestowed with properties orthogonal to small molecule drugs. In this work, we developed machine learning models to identify the distinguishing characteristics of known antibiofilm peptides, and to mine peptide databases from diverse habitats to classify new peptides with potential antibiofilm activities. Additionally, we used the reported minimum inhibitory/eradication concentration (MBIC/MBEC) of the antibiofilm peptides to create a regression model on top of the classification model to predict the effectiveness of new antibiofilm peptides. We used a positive dataset containing 242 antibiofilm peptides, and a negative dataset which, unlike previous datasets, contains peptides that are likely to promote biofilm formation. Our model achieved a classification accuracy greater than $98 \%$ and harmonic mean of precision-recall (F1) and Matthews correlation coefficient (MCC) scores greater than 0.90; the regression model achieved an MCC score greater than 0.81 . We utilized our classification-regression pipeline to evaluate 135,015 peptides from diverse sources and identified antibiofilm peptide candidates that are efficacious against preformed biofilms at micromolar concentrations. Structural analysis of the top 37 hits revealed a larger distribution of helices and coils than sheets. Sequence alignment of these hits with known antibiofilm peptides revealed that, while some of the hits showed relatively high sequence similarity with known peptides, some others did not indicate the presence of antibiofilm activity in novel sources or sequences. Further, some of the hits had previously recognized therapeutic properties or host defense traits suggestive of drug repurposing applications. Taken together, this work demonstrates a new in silicio approach to predicting antibiofilm efficacy, and identifies promising new candidates for biofilm eradication.
\end{abstract}

antimicrobial | antibiofilm | machine learning | MBEC | MBIC

Correspondence: anand.ramasubramanian@sjsu.edu,danastasiu@scu.edu

\section{INTRODUCTION}

Many microbes in their natural habitats are found not as freefloating (planktonic) organisms, but as three dimensional aggregates encased in a polymeric matrix called biofilms [1]. Biofilms are responsible for $65-80 \%$ of recalcitrant infections in humans. Once established, biofilms have the potential to initiate or prolong infections by providing a safe sanctuary from which organisms can invade local tissue, seed new infection sites and resist eradication efforts. Both bacteria and fungi form biofilms on abiotic (e.g., catheters and implants) or biotic (e.g., skin, wounds) surfaces [2, 3]. Cells within the biofilms display high levels of resistance against clinicallyadministered antibiotics, which often leads to morbidity and mortality [4]. Therefore, there is an urgent need to develop agents that are effective against biofilm infections [5, 6].

The traditional antibiotic screening paradigm first established during the 'golden era' of antibiotics (1940-1960), which has continued until very recently, was heavily biased towards the discovery of 'magic bullets' that have either bacteriostatic or bactericidal properties but elicited waves of antibiotic resistance. This approach has had little success against multidrug resistant (MDR) highly virulent Enterococcus faecium, Staphylococcus aureus, Klebsiella pneumoniae, Acinetobacter baumannii, Pseudomonas aeruginosa, and Enterobacter spp (ESKAPE) pathogens [7]. Antimicrobial peptides (AMP) have emerged as a promising alternative or complement to chemical compounds in treating microbial infections [8]. More than 4,700 such peptides have been identified in all forms of life, and are deposited in the Antimicrobial peptide database (APD) [9]. Compared to chemical antibiotics, AMPs are particularly attractive for several reasons: (i) AMPs appear to have a lower rate of inducing bacterial resistance and they continue to be developed clinically [10]; (ii) AMPs appear to be the last resort for recalcitrant infections as exemplified by Polymyxin B, colistin, daptomycin against the MDR ESKAPE pathogens [11]; (iii) AMPs can work synergistically with antibiotics [12].

In the recent past, several Machine Learning (ML)-based approaches have been developed for the characterization and prediction of novel AMPs including AntiBP - for predicting antibacterial peptides [13], iAMP-2L - for identifying antimicrobial peptides [14], iAMPred - for predicting antimicrobial peptides by using physico-chemical and structural properties [15], AmPEP - for sequence based prediction of antimicrobial peptides [16]. These studies have clearly demonstrated that pattern-based computational approaches to establish structure-function relationships are a powerful alternative or augmentation to experimental biochemical assays, which are inherently lower throughput, and expensive. More importantly, ML approaches have been used to discover new 
AMP sequences [17], predict unknown peptides from known ones [18], identify peptides with multiple functions [19], and to discover previously unknown interrelationships between existing peptides [17].

While a vast majority of work has focused on AMPs effective against microbial infections in general, relatively fewer experimental or computational efforts have been invested on discovering peptides that are effective against biofilm infections. These peptides, called Antibiofilm peptides (ABP) are a subset of AMPs that inhibit biofilm formation or eradicate previously formed biofilms. Nearly 200-300 peptides have been identified to be effective against biofilms and are listed in the antibiofilm peptide database, BaAMPs [20]. ABPs can be particularly attractive as a strategy to limit microbial virulence without necessarily killing the organisms, or risking the development of antibiotic resistance. ABPs can be used as an alternative to antibiotics in microbial infections [21].

Previous ML approaches have focused on establishing patterns from existing antibiofilm peptides that enable the classification of candidate peptides for potential antibiofilm activity [22-24]. Gupta et al. developed sequence-based support vector machine (SVM) and random forest (RF) models to predict antibiofilm activity using the peptides listed in the BaAMP database. Their model achieved reasonable success with a Matthews's correlation coefficient (MCC) score of 0.84 [22]. Sharma et al. developed SVM- and Wekabased models using BaAMP data as their positive dataset, and quorum-sensing peptides as their negative set. They achieved an MCC of 0.91 [23]. Another web-based model, BIPEP, was developed by Atanaki et al., wherein peptides from the APD and BaAMP databases were used as the positive set, along with a negative dataset consisting fewer quorum sensing peptides that in the positive set. Their SVM model achieved an MCC value of 0.89 [24]. While these studies developed important quantitative structure and activity relationships in ABPs, they suffered from some drawbacks which may affect the model performance. The model of Atankai et al. did not account for the lower abundance of ABPs in nature. The model of Gupta et al. might have used the pattern recognition sequences ('motifs') as a privileged information prior in the classification model, while the model of Sharma et al. considered a smaller negative set compared to their positive data set. Most importantly, these models can only classify ABPs but do not provide any insights into the efficacy of these peptides against biofilms.

The objectives of this work are three fold: first, we seek to improve the classification algorithm for ABPs by using a more realistic, curated negative dataset with mostly biofilmfavoring peptides which is ten-fold larger than the positive dataset; our model identifies the most useful amino-acid composition features and short-repeating patterns ('motifs') indicative of antibiofilm activity; second, we seek to develop a regression model using the minimum biofilm inhibitory concentration (MBIC) and minimum biofilm eradication concentration (MBEC) of ABPs to predict the effectiveness of the novel peptides classified as antibiofilm candidates; third, we seek to understand the putative mechanisms of action of the peptide hits using their previously known properties, secondary structure, and similarity with known antibiofilm peptides.

\section{METHODS}

A. Dataset Preparation. In this work, we collected data with the aim to improve the performance of antibiofilm prediction models. While creating the dataset, we simulated the probability of finding an $\mathrm{ABP}$ in nature, which are rather rare. We therefore used ten times more non-ABP data to mimic the lower prevalence of ABP in nature. We chose to work with real peptides instead of randomly generated peptides so that a more realistic performance may be obtained from our classifier models. Therefore, we collected peptides which directly or indirectly could play a role in biofilm formation as elaborated in Section A.1. For establishing the efficacy, we performed an extensive literature search to obtain peptides with minimum biofilm inhibitory concentration (MBIC), and minimum biofilm eradication concentration (MBEC).

A.1. Dataset 1. We extracted ABPs from the Antimicrobial Peptide Database (APD), and the Biofilm-active Antimicrobial Peptide database (BaAMP). After removing duplicates, we obtained 242 ABPs, which served as our positive dataset (Tables 17-21 in supplementary note 6). For the negative dataset, we curated peptides from different databases such as UniProt [25], Quorum Sensing Peptide Prediction Server (QSPProd) [26] and NCBI protein database [27]. The peptides from the UniProt database were screened for their direct or indirect contribution to biofilm formation, including regulation, association with biofilm matrix polysaccharide or proteins, and association with the cells themselves. For example, we added protein Q59U10, which is a biofilm and cell wall regulator in Candida albicans. We also screened the proteomic profiles of different biofilm-forming bacteria like Staphylococcus aureus and Escherichia coli, and included peptides from the NCBI and UniProt databases that promote biofilm formation. For example, we included fibronectin-binding protein $\mathrm{B}$, which promotes the accumulation and surface attachment of biofilm by Staphylococcus aureus. We also included quorum sensing peptides, which promote biofilm formation, from QSPProd in our negative dataset. To have a similar sequence length distribution in the negative dataset, we considered either only the signal peptide length of the original protein, or we divided the whole sequence into several sequences of length 70-75, depending on the protein length. The negative dataset has peptides of length 4-75.

Given the scarcity of ABPs in nature, the negative dataset was chosen to be ten times larger than the positive dataset. Eighty percent of the positive and negative datasets were used for training and ten-fold cross-validation while the remaining $20 \%$ was kept aside as a test/validation set. The performances of different machine learning algorithms were evaluated on this out-of-scope test dataset. 
A.2. Dataset 2. We manually curated the minimum biofilm inhibitory concentration (MBIC), and the minimum biofilm eradication concentration (MBEC) for our positive dataset against different gram-positive and gram-negative bacteria. We did an exhaustive literature search to find out peptides which clearly show inhibition and eradication of biofilm. In cases where these values were not listed in the source publication, the approximate values were obtained from images or graphs in the articles. For example, for LL-37, we consider the case where $P$. aeruginosa biofilm were grown previously and then peptides were added in various concentration [28]. The bacteria was tagged with green fluorescent protein and the killed biofilm appeared as red in the result. We analyzed the figures, which indicate that the killing starts at 20 $\mu \mathrm{M}$ concentration. Therefore, we considered $20 \mu \mathrm{M}$ as the MBEC value of LL-37 against $P$. aeruginosa. Likewise we did the search of all the ABPs from our positive dataset. Of the 242 peptides in our positive dataset, we obtained MBIC and MBEC values for 178 and 57 peptides (Table 22 in supplementary note 4 ), respectively.

We did not consider the peptides which showed inhibition/eradication against fungal pathogens like Candida and others.

A.3. Candidate Dataset. In addition to the labeled dataset we used to train and evaluate the performance of our computational antibiofilm prediction models, we constructed a large candidate dataset from various sources, including 74 anticancer peptides, 220 antiviral peptides, and more than 4770 antimicrobial peptides from the Data Repository of AntiMicrobial peptides (DRAM) [29]. Additionally, we collected all 202,716 peptides from UniProt of sequence length 1120. After removing duplicates, our candidate dataset contains 109,807 unique UniProt peptides. We also included peptides from the Swiss-Prot section of UniProt with sequence length 4-10 \& 20-80. In total, we tested our model against 135,015 unique peptides from different data sources.

B. Feature Extraction. We used the 'propy3' [30] and the 'protParam' [31] software packages to extract different peptide features, which are numerical representations of the peptide sequence, structure, and physicochemical properties.

B.1. Amino Acid Composition. The Amino Acid Composition (AAC) features represent the percentage of each amino acid present in the peptide sequence. The python package returns a 20 -element vector of the naturally occurring amino acids. Equation 1 provides the formula for computing the AAC of a given amino acid $i$ :

$$
A A C(i)=\frac{\# \text { amino acids of type }(i)}{\# \text { amino acids }} \times 100
$$

B.2. Dipeptide Composition. Dipeptide Composition (DPC) represents the percentage of the dipeptides present in the peptide sequence. The DPC feature returns 400 named vectors with a non-zero value for any amino acid pair (dipeptide) present in the peptide.

$$
D P C(i, j)=\frac{\# \text { dipeptide }(i \text { and } j)}{\# \text { possible dipeptides }} \times 100
$$

B.3. Composition, Transition, Distribution. The Composition, Transition, Distribution (CTD) descriptor is a 147element vector representing different physio-chemical properties of the peptides [32]. The properties of peptides that are part of the CTD descriptor include 'hydrophobicity', 'normalized van der Waals volume', 'polarity', 'polarizability', 'charge', 'secondary structure' and 'solvent accessibility'. The amino acids are divided into three groups depending on their property and functionality. The 'composition' features represent the percentage of each group of amino acids in the peptide. The 'transition' features represent the relative frequencies of a given amino acid from one group being followed by an amino acid from a different group. Finally, the 'distribution' features represent the percentage residue of each attribute present in the peptide in their first, $25 \%, 50 \%$, $75 \%$, and $100 \%$ of residues, respectively.

B.4. Motif. 'Motifs' are maximal length amino acid sequences present in peptides which may represent a unique biological or chemical function. We used the 'MERCI' software [33] to identify distinct patterns in ABPs that are not present in non ABPs (non-antibiofilm peptides). The MERCI software provides two scripts to extract motifs. One script can essentially find all the motifs that are present in the positive dataset and absent in the negative dataset, which was used to discover and store, in each experiment, motifs found in our training dataset. We then used the second script to identify which of those training set motifs were present in the test samples. Finally, we used the number of identified motifs found in a given peptide as the motif-based single-variate feature.

B.5. Other Features. We extracted other critical, global features, such as sequence length, molecular weight, aromaticity, and isoelectric point, using the 'ProteinAnalysis' module of the 'ProtParam' software.

C. Machine Learning Models. We developed our prediction model using several machine learning algorithms, including Support Vector Machines (SVM), Random Forest (RF), and Extreme Gradient Boosting (XGBoost) classifiers. Our goal was to select the algorithm that provides the best predictive performance for antibiofilm activity on out-ofsample data. We used the 'Scikit-learn' [34] package to train and test models for our work.

C.1. Support Vector Machine. Support Vector Machine (SVM) is one of the most commonly used classifiers for peptide prediction [35]. SVM works particularly well for binary classification problems. The model works by separating samples in different classes using a hyperplane, which can be expressed in a high dimensional space through kernel transformations. Since our dataset is not relatively large, we used a nonparametric method that SVM supports and a 
radial basis function (RBF) kernel. SVM is a robust model that can be used for both classification and regression. Literature shows that SVM has performed exceptionally well in predicting peptide function [36].

C.2. Support Vector Regressor. The Support Vector Regressor (SVR) model uses the same principle as SVM, but for regression problems. Instead of separating samples into different classes using a hyperplane, the hyperplane is used to create a best fit line that has the maximum number of points between the decision boundaries. Like the classifications models, we used a radial basis function (RBF) kernel to create a nonlinear hyperplane. The SVR was used to predict minimum biofilm eradication/inhibitory concentration (MBEC/MBIC).

C.3. Random Forest. The Random Forest (RF) model is an ensemble prediction model, which also supports both regression and classification. RF has been used to classify peptides and to solve other biological problems [37]. Although RF may not be the best choice as a classifier for an imbalanced dataset, we used this algorithm to compare the performance with other classification algorithms.

C.4. Extreme Gradient Boosting. The Extreme Gradient Boosting (XGBoost) model is comparatively a new prediction method used in machine learning, which can also be used for both classification and regression problems. In our work we used the XGBClassifier. The XGBoost algorithm has regularization parameters that can be tuned to reduce overfitting in an imbalanced dataset. This algorithm is also used in prior work for the prediction of peptides with an accuracy greater than $98 \%$ [38].

D. Cross-Validation and Stratified Sampling. To address potential overfitting problems, we performed ten-fold crossvalidation of our training dataset, wherein one part of the dataset, called the validation set, was used for testing, and the other nine were used for training. This process was iterated over ten times, using, in turn, each of the ten parts as the validation set. Since our dataset is imbalanced, having ten negative peptides for every positive one, we used stratified sampling to ensure that each fold receives an equal percentage of positive and negative peptides while doing cross-validation. Additionally, we used stratified sampling to ensure that the out-of-sample test dataset also has precisely $20 \%$ of the positive data, i.e., 48 peptides, and $20 \%$ of the negative data, i.e., 485 peptides. The details of the distribution of dataset is available in Table 4 in supplementary note 1.

E. Performance Evaluation. We used several standard metrics to evaluate our models' performance, including sensitivity (Sen), specificity (Spec), accuracy (Acc), Matthews's correlation coefficient (MCC), and harmonic mean of the precision-recall (F1) Score. The metrics are defined as,

$$
\text { Specificity }=\frac{T N}{F P+T N}
$$

$$
\begin{gathered}
\text { Sensitivity }=\frac{T P}{T P+F N} \\
\text { Accuracy }=\frac{T P+T N}{T P+F P+T N+F N} \\
F 1=\frac{T P}{T P+\frac{F P+F N}{2}} \\
M C C=\frac{(T P)(T N)-(F P)(F N)}{\sqrt{(T P+F P)(T P+F N)(T N+F P)(T N+F N)}}
\end{gathered}
$$

where, $\mathrm{TP}=$ True Positive, $\mathrm{TN}=$ True Negative, $\mathrm{FP}=$ False Positive, and FN = False Negative. For each model we tested, we used 10-fold cross-validation to tune meta-parameters and find the best model performance on the training set. We report the effectiveness of that model on the out-of-sample test set in the following section.

F. Principal component analysis (PCA). During feature selection, the samples were transformed into a lower dimensional space via Principal Component Analysis (PCA). Several hyperparameters were tuned, namely the regularization parameter (C) and kernel coefficient $(\gamma)$ for the SVM/SVR models, and the number of principal components for the dimensionality reduction. We employed 5-fold stratified cross validation for classification and 5-fold cross validation for regression to ensure we trained a generic enough model that would not overfit the training set.

G. Sequence Alignment. Sequence alignment of peptides was performed to identify structural similarities between peptides using Clustal Omega, and visualized using Jalview [39].

\section{RESULTS AND DISCUSSION}

Our pipeline to predict peptides active against biofilms may be grouped into four key steps: identification of positive and negative datasets; development of a robust machine learning algorithm for classification of ABPs; collection of candidate potential ABPs from diverse habitats; and prediction of the efficacy of the novel peptides using our antibiofilm peptide classification model and a regression model based on known MBEC data. In the following, we will describe each of these tasks, which are also portrayed in Fig. 1.

\section{H. Characteristics of peptides in the positive dataset.}

H.1. Sequence length. The number of amino acids in our positive dataset varies between 4-70 (Fig. 2A). Almost all the peptides have a sequence length less than 50 . Only 2 peptides have a sequence length between 50-60 and 2 peptides have a sequence length between 60-70. Most of the ABPs were relatively short, i.e., two-thirds of the peptides contain less 20 amino acids with half of the peptides containing between 11-20 amino acids. 
bioRxiv preprint doi: https://doi.org/10.1101/2021.09.28.462235; this version posted September 28, 2021. The copyright holder for this preprint (which was not certified by peer review) is the author/funder, who has granted bioRxiv a license to display the preprint in perpetuity. It is made available under aCC-BY-NC-ND 4.0 International license.

$\mathrm{H}$ Characteristics of peptides in the positive dataset

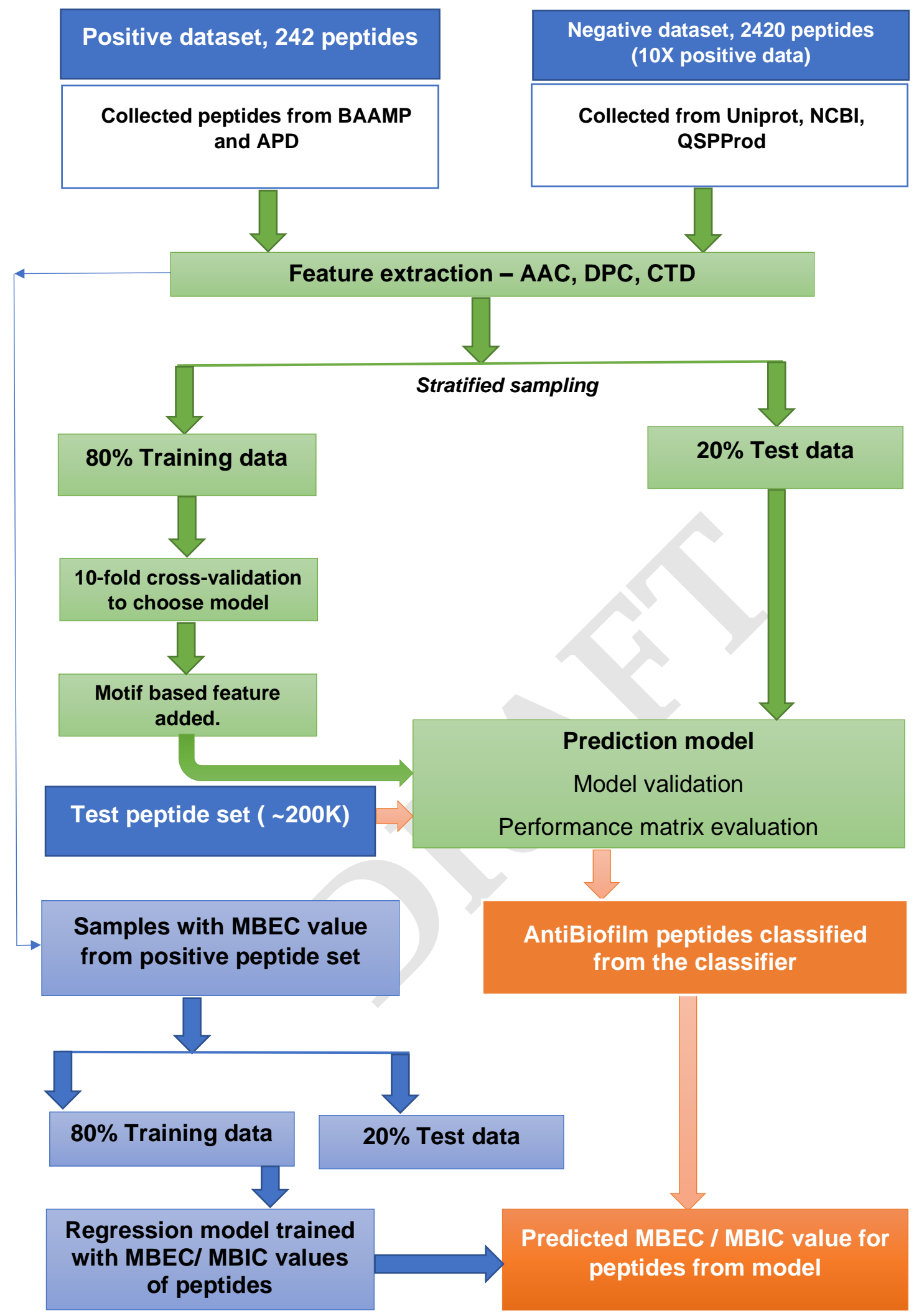

Fig. 1. Process flow for the classification of antibiofilm peptides and prediction of antibiofilm activity. The process consists of two distinct, sequential steps. In the first step, a binary classification model was trained using a dataset with 242 peptides with reported antibiofilm activity and 2420 peptides with no known or suspected antibiofilm activity. In the second step, two regression models were trained using a subset of the peptides with known minimum biofilm eradication concentration (MBEC) and minimum biofilm inhibitory concentration (MBIC) values. Candidate peptides will be first evaluated for plausible antibiofilm activity using the classification model, and then their effectiveness will be predicted using the regression model. 
bioRxiv preprint doi: https://doi.org/10.1101/2021.09.28.462235; this version posted September 28, 2021. The copyright holder for this preprint (which was not certified by peer review) is the author/funder, who has granted bioRxiv a license to display the preprint in perpetuity. It is made available under aCC-BY-NC-ND 4.0 International license.

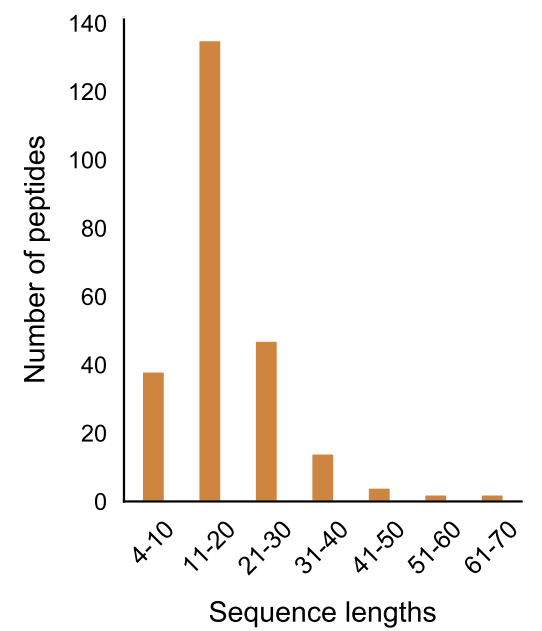

A

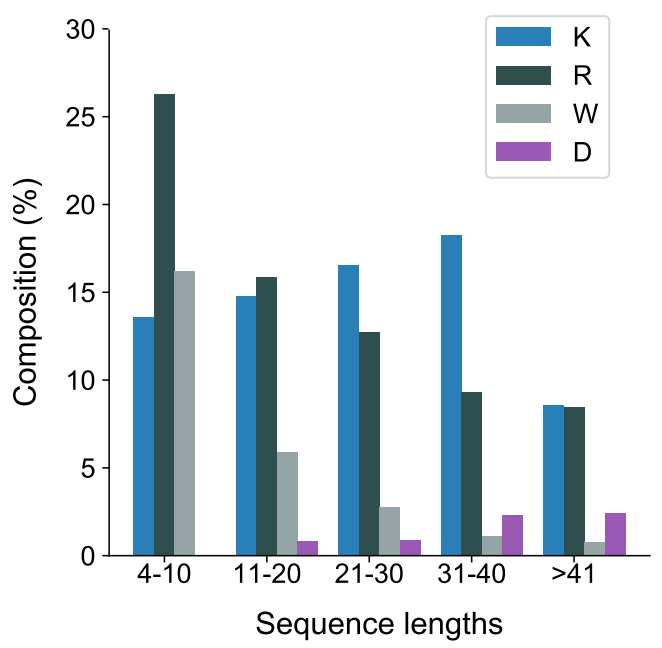

C

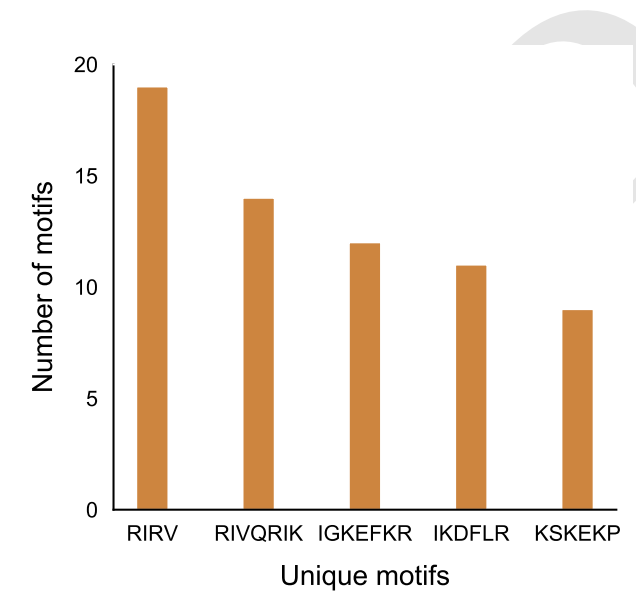

E

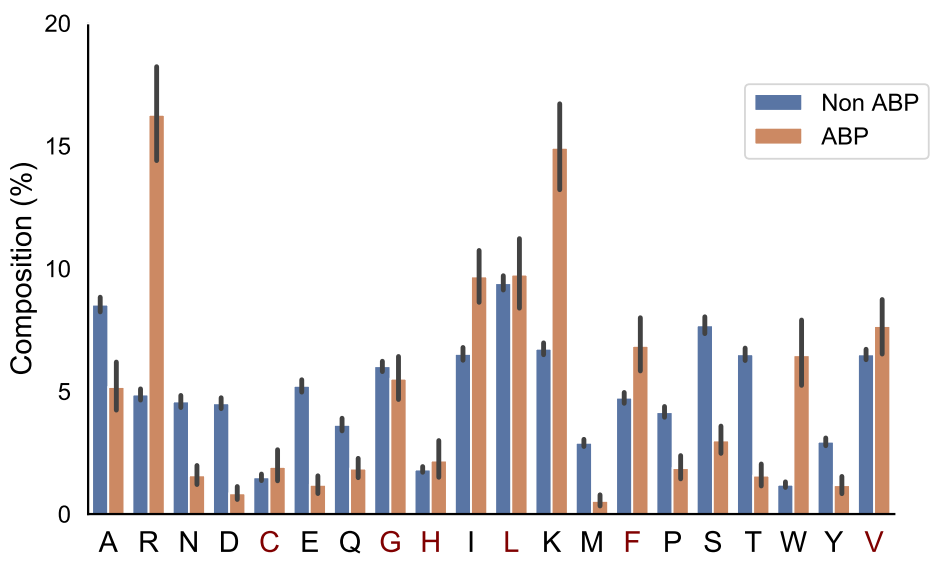

B

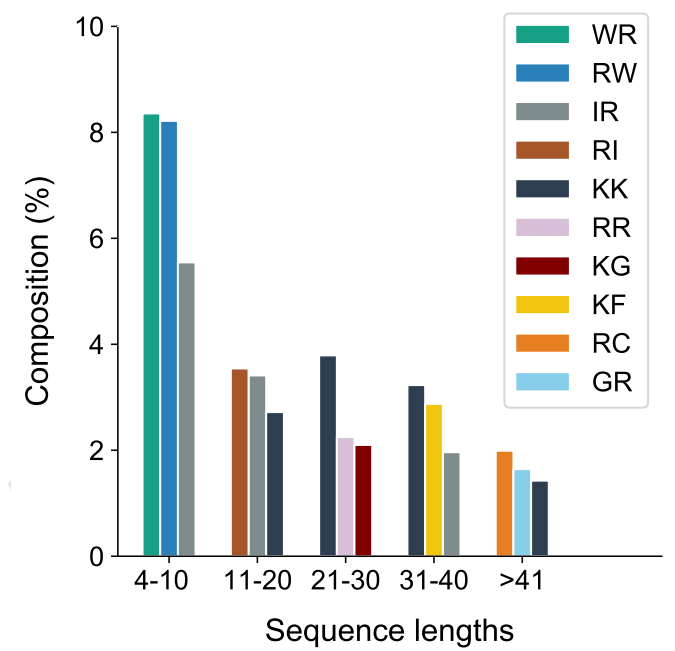

D

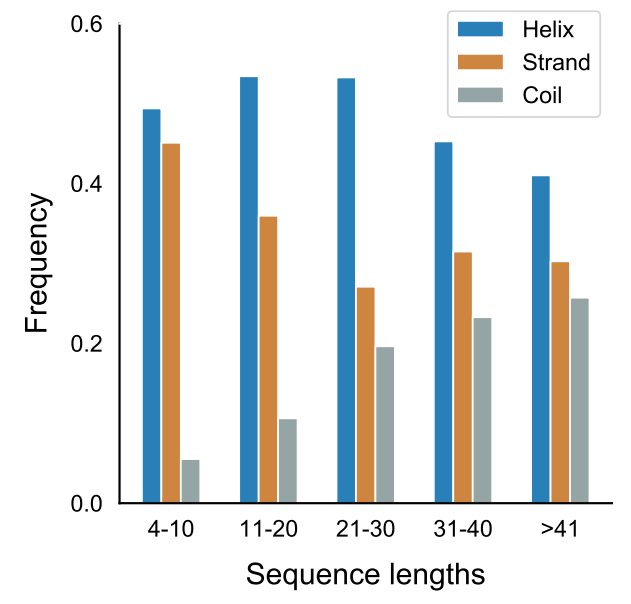

F

Fig. 2. Primary and secondary structural characteristics of antibiofilm peptides. (A) Distribution of antibiofilm peptides over different sequence lengths. More than $50 \%$ of the dataset peptides have length of 11-20 amino acids; (B) Comparison of amino acid distribution in the positive and negative datasets. Cationic amino acids lysine (K), arginine (R), and aromatic amino acids tryptophan (W) are present at significantly higher quantities in antibiofilm peptides; while the anionic amino acids aspartic acid (D), glutamic acid $(E)$ are present more in non-antibiofilm peptides. Statistical significance $(p \leq 0.001)$ was established using Mann-Whitney U-test; Amino acids marked in 'red' on the $\mathrm{x}$-axis of the figure are not statistically significant; $(\mathrm{C})$ Distribution of $\mathrm{K}, \mathrm{R}$, and $\mathrm{W}$, grouped based on the peptide length. On average, $\mathrm{K}$ and $\mathrm{R}$ are equally distributed, and account for $\sim 30 \%$ of the total amino acids in the positive dataset; (D) Dipeptide composition analysis shows IR, RI, WR, RW, and KK are the most common dipeptide sequences present in the antibiofilm peptide database (AA, LL, AL, or LA are most common in the negative dataset); (E) Most commonly found motifs in the antibiofilm peptides. The 'number of motifs' is the count of each motif in the peptide set; (F) Antibiofilm peptides contain more alpha helices than beta sheets or coils; 
H.2. Amino acid composition. We compared the distribution of 20 amino acids in the peptides in the positive and negative datasets (Fig. 2B). We observed that, compared to the negative dataset, the ABPs contained a significantly higher percentage of lysine (K), arginine (R), tryptophan (W), and a significantly lower percentage of aspartic acid (D), glutamic acid $(\mathrm{E})$, threonine $(\mathrm{T})$ serine $(\mathrm{S})$, asparagine $(\mathrm{N})$, and methionine (M). This clearly indicates that the ABPs are positively charged, and contain a lower fraction of polar but uncharged side chains. The higher percentage of $\mathrm{W}$ indicates a higher hydrophobic nature of ABPs. This is further exemplified when the distribution of amino acids in the positive dataset were grouped by sequence length: $\mathrm{K}, \mathrm{R}$, and W make up 50\% of the amino acid composition in the short peptides ( $<20$ amino acids), which make up two-thirds of the positive dataset (Fig. 2C). We also observed that peptides contain non-polar amino acids isoleucine (I), leucine (L), glycine (G), and alanine (A), which provide an amphipathic character to the ABPs.

H.3. Dipeptide composition. Fig. 2D and Fig. 11 in supplementary note 2 show the most commonly encountered dipeptides in our positive and negative datasets, respectively. In our analysis, we focused on the top 3 dipeptide components in different sequence ranges. With the higher prevalence of $\mathrm{K}, \mathrm{R}$, and $\mathrm{W}$ in the ABPs, all the top candidates for dipeptides contained these amino acids. When arranged by sequence length, it can be seen that the majority of the peptides $(>80 \%$, with lengths in the range 4-30) contained 'WR/RW', 'RI/IR', ' $\mathrm{KK}$ ', and 'RR' as the most commonly encountered dipeptides. In contrast, the non-ABPs have non-polar aliphatic amino acid leucine (L) and alanine (A) in the top 5 dipeptide candidates. The dipeptide components most prominent in the positive and negative datasets clearly indicate the presence of a higher percentage of cationic and hydrophobic amino acids, and charge-hydrophobicity as a recurring theme in the antibiofilm (positive) dataset. It is this recurring presence of the charge-hydrophobicity combination exemplified by the dipeptide composition that underscores the amphipathic characteristic typically attributed to the action of ABPs.

H.4. Motifs. Motifs represent short sequences that are commonly found in the datasets. We observed that the motifs 'RIRV', 'RIVQRIK', and 'IGKEFKR' appeared more frequently in the positive dataset (Fig. 2E), indicating a combination of polar and non-polar amino acids as one of the main reasons of amphipathicity. In contrast, the most prevalent motifs in non-ABPs were 'SE', 'ET', and 'VD', mainly consisting of acidic amino acids, i.e., aspartic acids and glutamic acids. This analysis shows that certain motifs, although present in a relatively smaller fraction, can be effective in conferring antibiofilm properties. For instance, human cathelicidin LL-37 prevents biofilm formation of P.aeruginosa at a concentration lower than its MIC value by probably blocking the growth of the extracellular matrix [28]. While the truncated LL19-37 did not affect biofilm growth, the addition of 'IGKEFK' (LL13-37) inhibited biofilm formation at $50 \mu \mathrm{M}$. 'IGKEFK' is one of the motifs we found in high numbers in our positive dataset during motif analysis. As stated in Nagant et al., LL-19 has no activity against bacterial membrane permeability [28], but adding a motif of 'IVQRIK' increases permeability in LL-25. 'IVQRIK' is another motif that we found in our positive dataset.

H.5. Secondary Structure Analysis. We observed that ABPs of any sequence length are more likely to form $\alpha$-helix structures (Fig. 2F). In smaller length peptides, we noticed a prevalence of $\alpha$-helix structures. As the peptide length increases, we noticed a greater percentage of coils in the peptides. The presence of positively charged and hydrophobic amino acids, together with the propensity to form $\alpha$-helices suggests that the predominant mechanism of antibiofilm activity consists of positively charged, amphipathic helical peptides.

H.6. Physicochemical properties. We also compared different physicochemical properties, namely, polarity, hydrophobicity, and solvent accessibility between the positive and negative datasets (Fig. 3). First, as expected from the AAC, the ABPs, compared to the negative dataset, contained a significantly larger fraction of charged polar residues but a smaller fraction of uncharged polar residues. Second, the comparison of hydrophobic properties between ABPs and non-ABPs showed that ABPs in our dataset consisted of a much lower number of hydropathically neutral peptides but significantly higher number of hydrophobic or charged residues. The hydrophobic portion of ABPs leads to insertion of the peptides into the less polar bacterial membrane and to destabilizing membrane barriers [40]. The higher percentage of alanine, valine, leucine, isoleucine, and phenylalanine could be a potential reason for the ABP's hydrophobic nature. Third, ABPs, compared to the negative dataset, had a significantly lower percentage of compounds that were neutral in their interactions with solvent water but contained more residues that will be buried or exposed when exposed to water. This compositional analysis shows that the ABPs are composed of amino acids with strongly polar and hydrophobic tendencies which together provide an amphipathic nature rather than neutral amino acids.

\section{Performance of Machine Learning Models.}

I.1. Classifier Performance. Having characterized the antibiofilm peptide dataset, we used primary and secondary structure information of the peptides to develop machine learning models to identify and understand features that may be unique to ABPs. We used a total of 572 features obtained from AAC, DPC, and CTD analysis, and motifs, in various combinations, to describe our peptide samples numerically and train our machine learning models. For the SVM model, we used a linear kernel with and without recursive feature elimination, and a RBF kernel. Recursive feature elimination is a heuristic method used to select a subset of the features that may lead to superior performance compared to using all initial features; it works by iteratively eliminating the feature whose elimination produces the most improvement in 


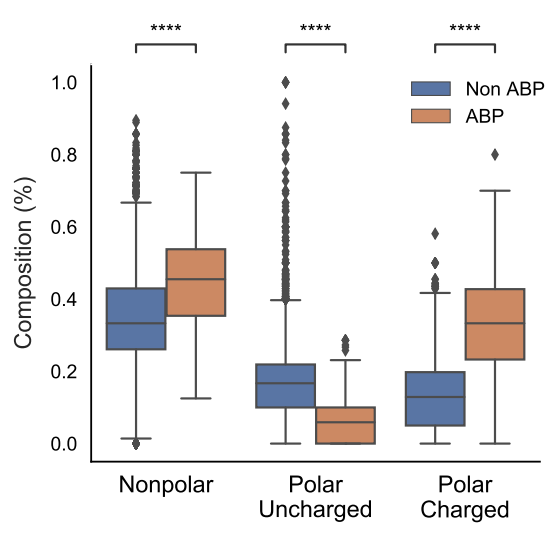

A
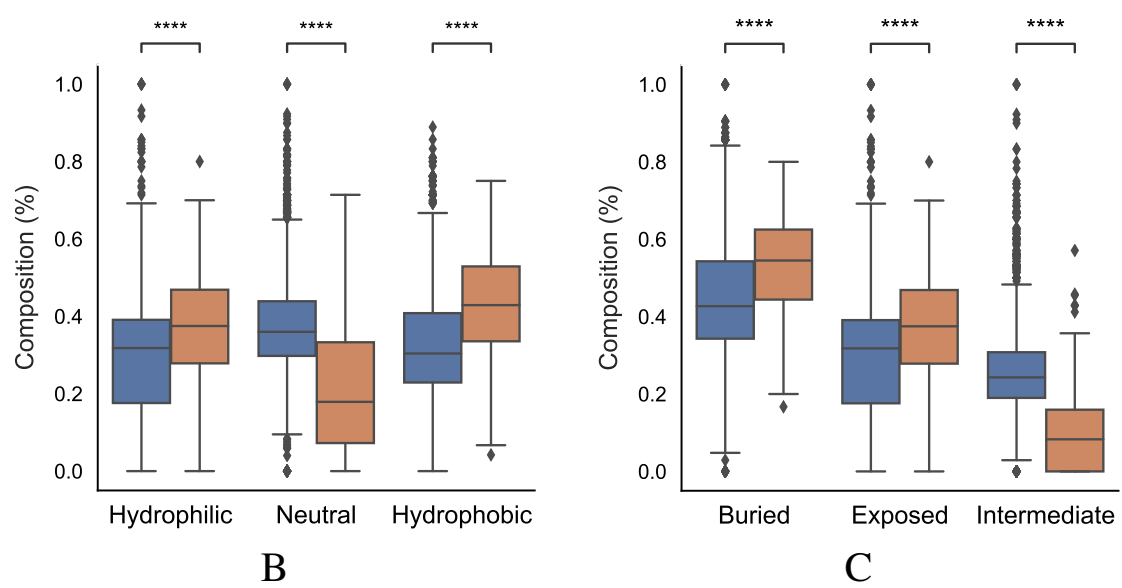

Fig. 3. Physicochemical characteristics of antibiofilm peptides. (A) Polarity; (B) Hydrophobicity; (C) Solvent accessibility; Statistical significance ( $p<=0.001)$ was established using the Mann-Whitney U-test;

performance, until no such performance improvement can be achieved. The linear kernel in SVM did not perform well and only achieved an MCC score less than 0.75. Additionally, recursive feature elimination did not lead to improvements in our classification model performance. Using the radial bias kernel provided the highest model performance. For the XGBoost and Random Forest models, the model parameters, number of estimators and maximum depth, were tuned. The performance of the models are presented in Fig. 4 and Tables 5-7 in supplementary note 3 . The accuracy for all the models was more than $95 \%$ while the model specificity varies between $98 \%-100 \%$. Since our model is a binary classifier and our dataset is not balanced, we used F1 score and MCC as the two key metrics to evaluate the performance of these machine learning models (Fig. 4).

We observed that using either AAC, DPC, or CTD alone resulted in an F1-score between $0.80-0.85$ in all our models. In contrast, using a combination of two of the three sets of features significantly improved the model performance with F1-scores between $0.82-0.88$ in all our models. Using a combination of all three sets of features further, though modestly, improved model performance. We also observed that the addition of motifs as a feature improved the performance of our classifier model with SVM (Fig. 4A). Similar observations have been noticed with MCC scores. While only considering DPC gave an MCC as low as 0.79, adding the remaining features lead to an MCC score of 0.9 (Fig. 4B).

To adequately compare the performance of our model with that of previously published models on ABPs, we applied our best-performing model to the dataset used by Gupta et al. [22]. It is important to mention here that the performance obtained by one model vs. another on the same task cannot be directly compared unless experiments were conducted using the same dataset and evaluation metrics. Our best performing model is SVM with a radial bias kernel that utilizes AAC, DPC, CTD, and motif as features. Our model outperformed the previously reported results by a significant margin as seen by the increase in MCC from the published value of 0.84 in [22] to 0.90 (Table 8 in supplementary note 3 ).
I.2. Distinguishing characteristics of antibiofilm peptides predicted by the SVM model. Next, we ranked features that are distinct in the positive dataset compared to the negative dataset, so that we may be able to ferret out higher level information that may be unique about the ABPs. To this end, the features were ranked in the order of increasing importance, as determined by the SVM with radial RBF kernel model.

There is no available API in the scikit learn RBF kernel SVM package to get the top feature. Therefore, we used a forward selection method to choose the top features. This is a computationally intensive iterative process where we start with zero features and iteratively add each feature that leads to the most performance improvement, until all 572 features are exhausted. In essence, it is the opposite of the recursive feature elimination method. With each iteration, the algorithm identifies the next best performing feature. The performance score was measured using the MCC score.

We observed that the first feature generated an MCC score of 0.61 , and the first four features generated an MCC score of 0.79 . The addition of the next four and eight features generated an MCC score of 0.81 , and 0.82 , respectively; the inclusion of all 572 features generated an MCC score of 0.91 (Fig. 5A). The first four features that contributed most to the MCC score were all associated with the physicochemical properties of the peptides, namely, number of transitions from apolar to polar amino acids, fraction of polar amino acids, fraction of amino acids that are buried and least accessible to solvent, and distribution of solvent accessibility for amino acids that are buried from first residue to $25 \%$ residue. The distributions of these parameters in the positive and negative datasets reveal non-overlapping distributions, which further explains their performance impact in the classification task (Fig. 5B). This analysis confirmed the importance of the alternation between charge and hydrophobicity. The most discerning feature from the forward selection process, 'polarity-transition-group-1-3', is the transition from polar group 1, i.e, from non-polar sequences like Gly, Ala, Val, Leu, Ilu, Pro to group 3, i.e. charged-polar amino acids like His, Lys, and Arg. The other discerning features consist of 'polarity-composition-group-3' or com- 


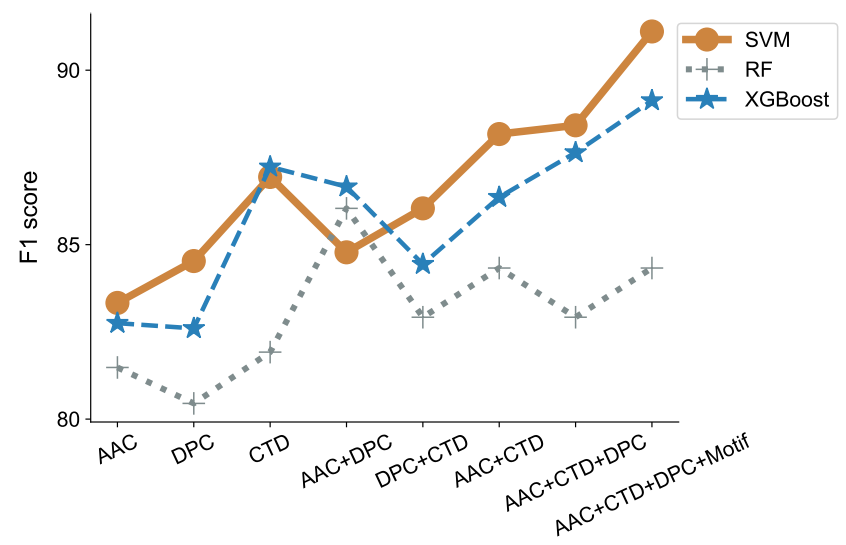

A

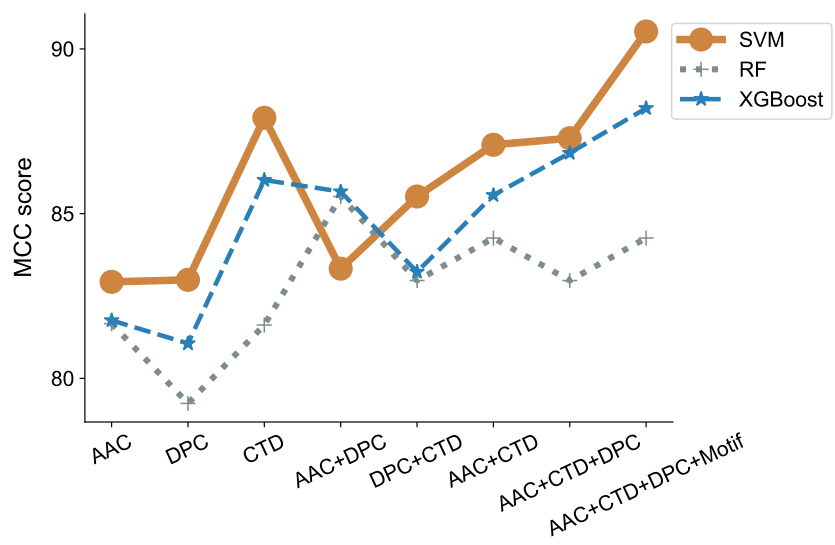

B

Fig. 4. Evaluation of classification models and features. F1 scores (A) and MCC (B) were estimated for three different machine learning algorithms, SVM, RandomForest and XGBoost, incorporating features that contain combinations of amino acid composition (AAC), dipeptide composition (DPC), composition-transition-distribution parameters (CTD), and motifs. SVM performed best when run against all features, including motif.

position of highly charged amino acids like His, Lys and Arg, 'Solvent-Accessibility-composition-group-1' or composition of buried amino acids, and 'Solvent-AccessibilityDistribution-group1' or distribution of amino acids like Ala, Leu, etc.

\section{I.3. Prediction of antibiofilm efficacy using regression mod-} els. The effectiveness of ABPs are evaluated based on their minimum biofilm inhibitory concentration (MBIC) and minimum biofilm eradication concentration (MBEC) levels. The MBIC represents the concentration of the peptide that will prevent biofilm formation, while MBEC represents the concentration of the peptide that can remove preformed biofilms. datasets containing both concentrations were modeled and evaluated for efficacy, with the goal of predicting these values for antibiofilm peptide hits.

Models for the prediction of Minimum Biofilm Inhibitory Concentration. The positive peptide dataset for the classification model contains 242 anti-biofilm peptides, 178 of which we were able to obtain MBIC values for. Although MBIC spanned from 0 to $640 \mu \mathrm{M}$, the data was largely skewed with approximately $80 \%$ of the values less than $64 \mu \mathrm{M}$ and $52 \%$ of the values less than $20 \mu \mathrm{M}$. Given this imbalance, we trained an SVM to classify peptides above or below $64 \mu \mathrm{M}$, and a separate Support Vector Regression (SVR) model to predict the MBIC value of a peptide. Both models used an RBF kernel and a dataset consisting of only those peptides with $\mathrm{MBIC}$ values less than or equal to $64 \mu \mathrm{M}$. Each peptide consisted of 571 features and, due to this large dimensionality, feature selection was implemented using the forward selection algorithm to choose the most effective features. While iterating through forward selection, Root Mean Square Error (RMSE) for the training set peptides was minimized in the case of SVR and MCC was maximized in the case of SVM. Forward selection was halted upon 5 consecutive iterations where RMSE had not decreased or MCC increased. During feature selection, the samples were transformed into a lower dimensional space via Principal Component Analysis (PCA). Several hyperparameters were tuned, namely the reg- ularization parameter $(C)$ and kernel coefficient $(\gamma)$ for the the SVM/SVR models, and the number of principal components for the dimensionality reduction. We employed 5fold stratified cross validation for classification and 5-fold cross validation for regression to ensure we trained a generic enough model that would not overfit the training set. For both models, a grid search between 0.001 to 1000 was used for both $C$ and $\gamma$ and the number of principal components spanned from 1 to the number of forward selection features. The best SVM model we found contained 9 features and was trained with parameters $C=10, \gamma=950$, and 6 principal components. The best SVR model contained 9 features as well and used parameters $C=45, \gamma=40$, and 8 principal components. The final model was able to achieve an MCC of 0.81 and an RMSE of 8.51 on the out-of-sample test sets. Fig. 6A shows several ranges of MBIC values and the number of actual predicted MBIC values in each range.

Models for the prediction of Minimum Biofilm Eradication Concentration. We further evaluated the peptides and found only 57 from literature where the MBEC values have been reported. The analysis of peptides showed almost $85 \%$ of peptides having a sequence length $<30$. These peptides showed a high percentage of positively charged amino acids like arginine and lysine as well as aromatic amino acids like tryptophan. Additionally, secondary structure analysis showed a high percentage of helices present in those peptides (figures in supplementary note 4). After eliminating peptides with MBEC values greater than $64 \mu \mathrm{M}$, our dataset consisted of 42 peptides for further regression analysis.

A Support Vector Regression (SVR) model built with an RBF kernel was found to be the most effective model to predict MBEC values given the limited training dataset. The same dimensionality reduction methodology was used as in the MBIC models in addition to the same hyperparameter grid search. The best SVR model contained 12 features and used hyperparameters $C=900, \gamma=20$, and 7 principal components. It was trained using 5-fold cross-validation and the best performing model had an RMSE of 8.41. When ground 


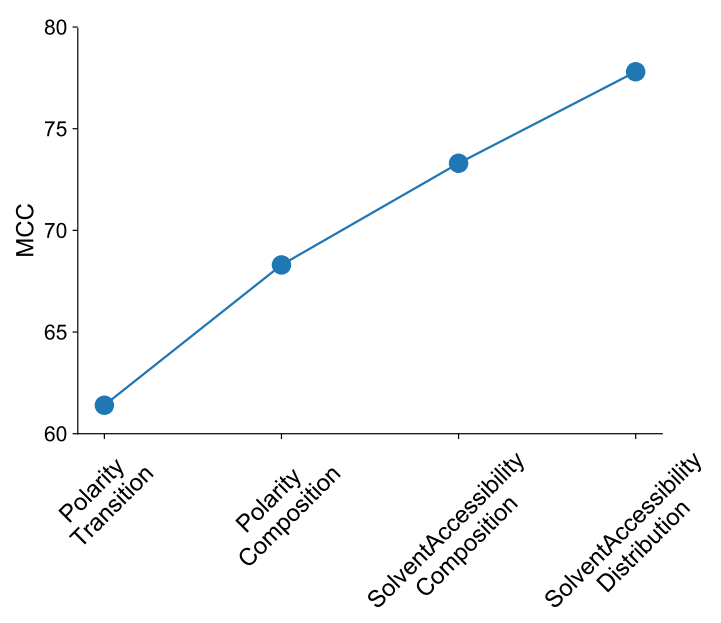

A

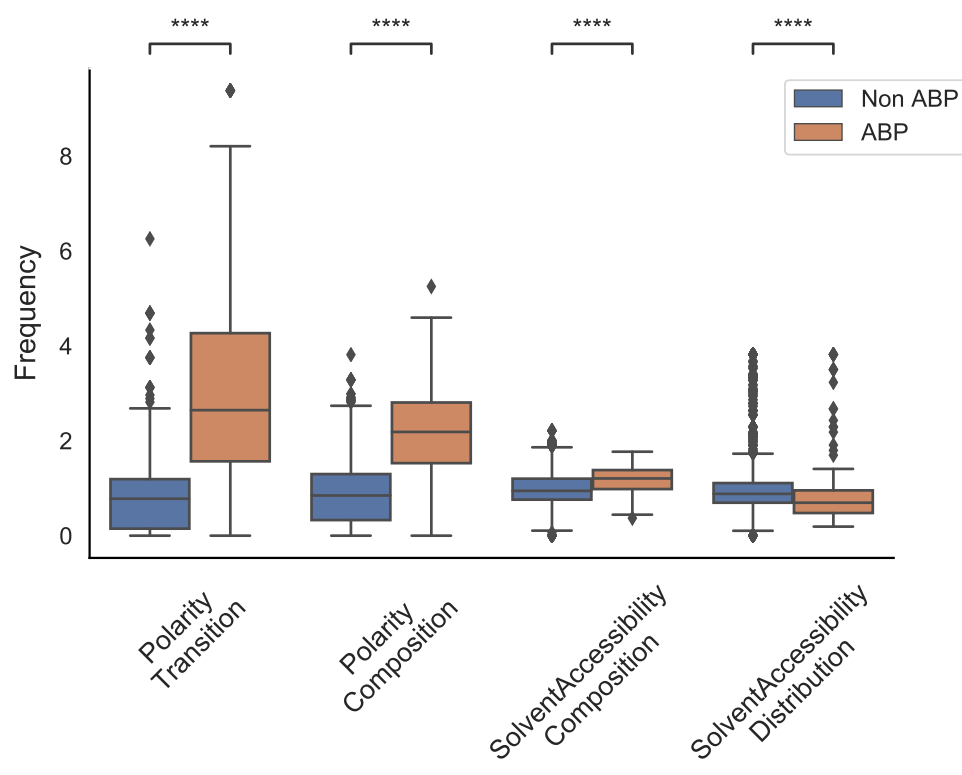

B

Fig. 5. Most discriminant features obtained from the SVM model using Forward Selection. (a) Cumulative increase in MCC with top features shows that polarity and solvent accessibility are sufficient to account for nearly all the differences between the positive and negative datasets; (b) Distribution of top features between the positive and negative datasets; Polarity Transition means transition from group1 (non-charged) to group3 (highly charged) amino acids; Polarity Composition means composition of highly charged amino acids; Solvent Accessibility Composition means composition of buried amino acids; Solvent Accessibility Distribution means the fraction of first $25 \%$ of residues in the sequence are buried amino acids; Statistical significance $(p<=0.001)$ was established using the Mann-Whitney $U$-test;

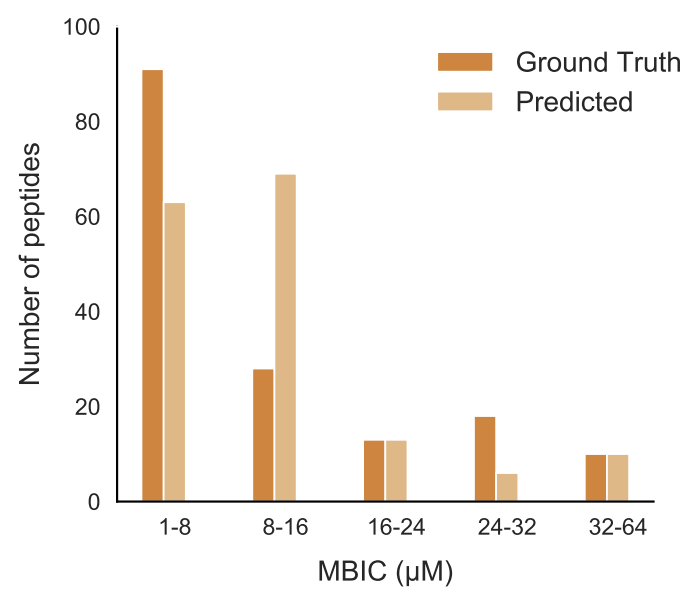

A

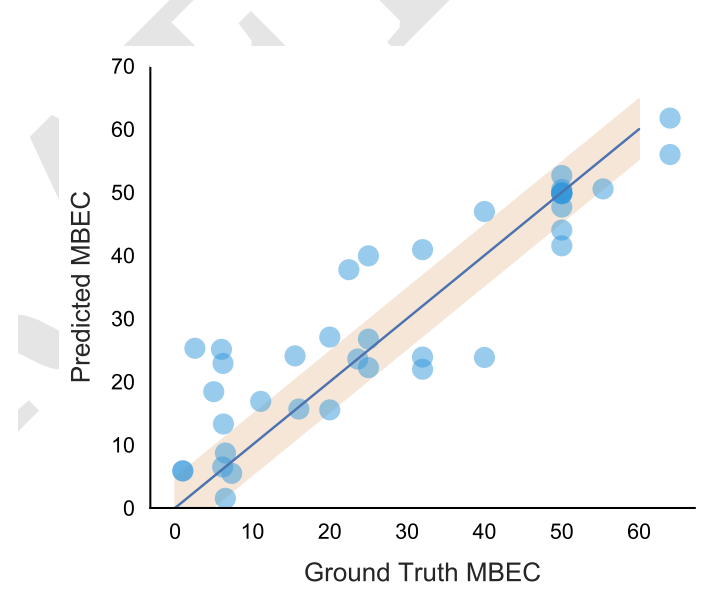

B

Fig. 6. Performance and characteristics of peptides with MBIC/MBEC values; (A) Comparison between original and predicted MBIC values using our best regression model; (B) Performance of our best MBEC regression model;

truth MBEC values were plotted against the regression predictions, we found the R-squared value to be 0.832 (Fig. 6B).

J. Classification of novel antibiofilm peptides. We used our best machine learning models to predict peptides with potential for antibiofilm activity from diverse sources. We queried various peptide databases to identify peptides with antibiofilm activity. We searched 4700 antimicrobial peptides, 74 anticancer peptides, and 212 antiviral peptides in the DRAMP database. We also considered more than 131,298 unique peptides from UniProt which have a sequence length of 4-80. After removing duplicates, we ran our classification model on 135,015 unique peptides from these varied sources, and selected 5468 unique peptides which were predicted as positive or hits by our model. The overall hit rate for this initial set of predicted peptides is $4.04 \%$ while the hit rate only from DRAMP database is $30.49 \%$. This higher value is due to the inclusion of peptides with established antimicrobial activity in the antimicrobial databases, which is likely to be skewed for high antibiofilm activity.

Due to the relatively large number of peptides selected by our classification model, we used the decision function of each of the peptides to narrow down the hits. The decision function estimates the sample position with respect to the discriminating hyperplane of the model. While training our model, we noticed that the peptides with decision function values higher than 0.99 were ABPs, whereas those with a negative deci- 
sion function were non-ABPs (Fig. 7A). More importantly, we noticed a clear discontinuity in the decision function as we transition from the positive to the negative dataset, which further showcases the effectiveness of our computational prediction model. Therefore, we used this confidence value as a filtering criteria to narrow down our list of peptides in the candidate set which were initially predicted as antibiofilm by our classification model and set a cut-off threshold of 0.99 . As a result, we chose candidate peptides with decision function values higher than 0.99 as more likely to have antibiofilm activity, which further narrowed down the hits to 296 peptides or a hit rate less than $0.2 \%$ overall. A vast majority of these peptides have lengths between 6-21 amino acids (Fig. 7B).

\section{K. Prediction of activity in novel antibiofilm peptides.}

Having classified potential ABPs, we used the regression models to predict the MBIC and MBEC values of the 296 peptides. Since we are interested in peptides that are efficacious against preformed biofilms, we used an operational cut-off of decision function $\geq 0.99$, and MBEC $\leq 64 \mu \mathrm{M}$. We obtained 185 peptides (Table 9-16 in supplementary note 5) of interest (Fig. 8A). Among these peptides, 40 showed high effectiveness (MBEC between 1.0-8.0 $\mu \mathrm{M}$ ) and another 48 peptides had comparatively lower effectiveness (MBEC more than $32 \mu \mathrm{M}$ ) (Fig. 8B). We noticed that most of the peptides (67 peptides) had moderate predicted effectiveness between 16.0-24.0 $\mu \mathrm{M}$. When we evaluated the source of the peptides, most of them were synthetic (116), and the naturally occurring peptides were from expected sources such as plants, amphibians, insects, and mammals (Fig. 8C). We grouped the hits into those with known antimicrobial activity as archived in the DRAMP database (Table 9-13 in supplementary note 5), and those that are not archived in the DRAMP database that were obtained from the UniProt database (Tables 14-16 in supplementary note 5). Of the 185 hits, 131 peptides were from the DRAMP database, and 54 were from the UniProt database. We also grouped the peptide hits based on their function. As expected, most of the peptides have some previously reported antibacterial properties. The hits also contained 19 peptides with anti-tumor/cancer activity, 26 peptides with antifungal properties, and 1 peptide with antiplasmoidal activity, suggesting potentially useful dual function therapeutics (Fig. 8D).

Some of these peptide hits have already shown promise as antimicrobial agents (but not as antibiofilm agents). The two anticancer peptides DRAMP03575 and DRAMP03829 are reported to exhibit an MIC of $16 \mu \mathrm{M}$ and $10 \mu \mathrm{M}$, respectively, against Escherichia coli [29]. The sperm protamine peptides from catshark and bat showed activity against 12 pathogens at a concentration of $0.01-20 \mathrm{mg} / \mathrm{mL}$ [41]. Mastoparan- 1 has an MIC value between 2-32 mg/L against Staphylococcus aureus, and is known to have antibacterial and antibiofilm properties [42]. Ponericins, peptides from the Ponerine ant, have structural similarity with well-known antimicrobial and antibiofilm peptide cecropins [43]. While no known antimicrobial activity has been listed for the histamine releasing peptide from the oriental hornet, studies are ongoing for alphaconotoxin obtained from cone snails, mainly used in pain management, to establish its antimicrobial activity [44]. An analog, $\omega$-conotoxin MVIIA shows the peptide is effective against Candida kefyr and Candida tropicalis with moderate MIC values between $28-40 \mu \mathrm{M}$ but it was not effective against any bacterial assay up to $500 \mu \mathrm{M}$ [45].

\section{Prediction of secondary structure of novel an- tibiofilm peptide hits, and alignment of sequences with known antibiofilm peptides. We sought to under-} stand the possible mechanisms of action of newly found antibiofilm hits in the top quadrant of (Fig. 8A). Since we were interested in peptides with previously unreported antimicrobial activities, and therefore novel, we focused on the 54 peptides from the UniProt database. Even amongst these 54 peptides, 14 peptides have been reported to have antimicrobial activities as per the UniProt annotation although they were not listed in any of the antimicrobial databases. For instance, the peptides P0CF03, P82420, and C0HK43 have been reported to have antimicrobial properties as well non-hemolytic properties, and anticancer properties (COHK43) suggesting that these peptides may serve as good antibiofilm candidates. Other peptides such as P30259, P0C424, C0HLM2, Q9U8M9, A0A1C8YA26, P85874, and Q16228 are not reported to have any antimicrobial/antibacterial activity as per their UniProt annotation. Of the 40 peptides that do not have any annotations or references to antimicrobial activity, we found 5 peptides from the mastoparan group, 3 peptides from the poneritoxin group, 2 peptides each from the conotoxin, lasioglossin and protamine groups, and 17 uncharacterized peptides that are mostly derived from plant sources. Of note, our positive dataset did not contain any peptides from the mastoparan, poneritoxin, conotoxin, lasioglossin or protamine groups indicating that these are indeed novel hits. Since the function of peptides from the mastoparan, ponericin, and conotoxin groups is to protect the host organism, they belong the category of host defense peptides (HDPs). Interestingly, we also obtained non-host defense peptide hits which have varied functions - DNA intercalation (protamine), intemediate filaments in neurons (peripherin), and metabolic enzymes (alcohol dehydrogenase, betaamylase).

We chose the 37 novel peptides for further analysis, and their decision function and predicted MBEC values are listed in Table 1. In this Table, the first 16 peptides have been characterized previously, and the next 21 peptides have not been characterized (i.e., listed as uncharacterized in the Uniprot database). We evaluated the secondary structure of these peptides using the PEP2D server [46]. Most of these peptides have largely helical or coil-helix-coil structure, a few have purely coil structure, and only a few contained sheet structures. Fig. 9 and Fig. 10 show the structures of previously characterized and uncharacterized peptides, respectively. Specifically, the mastoparan, poneritoxin, and lasioglossin peptides show helical structure while the conotoxin peptides have a purely coil structure (Fig. 9). Interestingly, one of the protamine hits showed propensity for folding into beta-sheet which may be stabilized by the intracellular bonding through the eight cysteine residues. The peptides not 
bioRxiv preprint doi: https://doi.org/10.1101/2021.09.28.462235; this version posted September 28, 2021. The copyright holder for this preprint (which was not certified by peer review) is the author/funder, who has granted bioRxiv a license to display the preprint in perpetuity. It is made available under aCC-BY-NC-ND 4.0 International license.

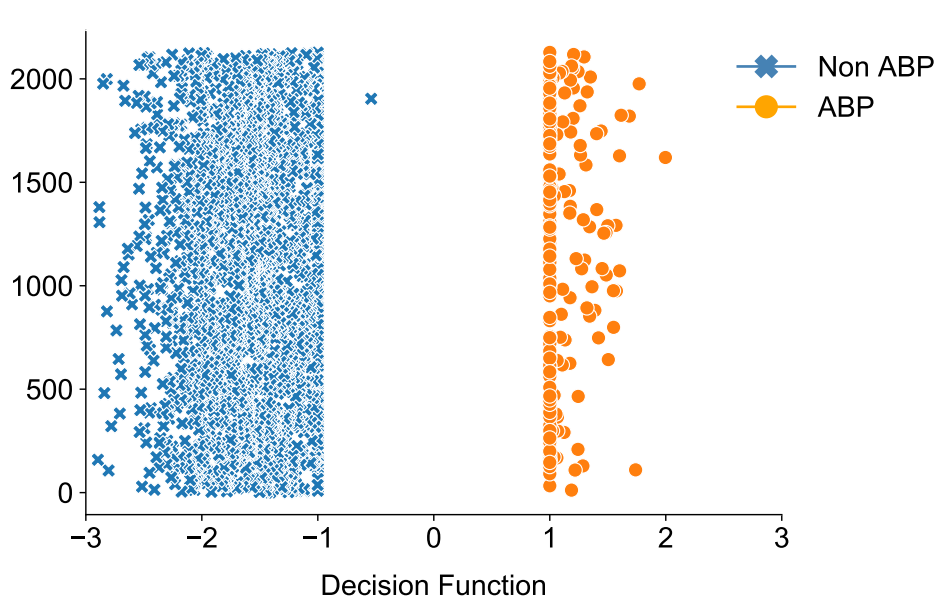

A

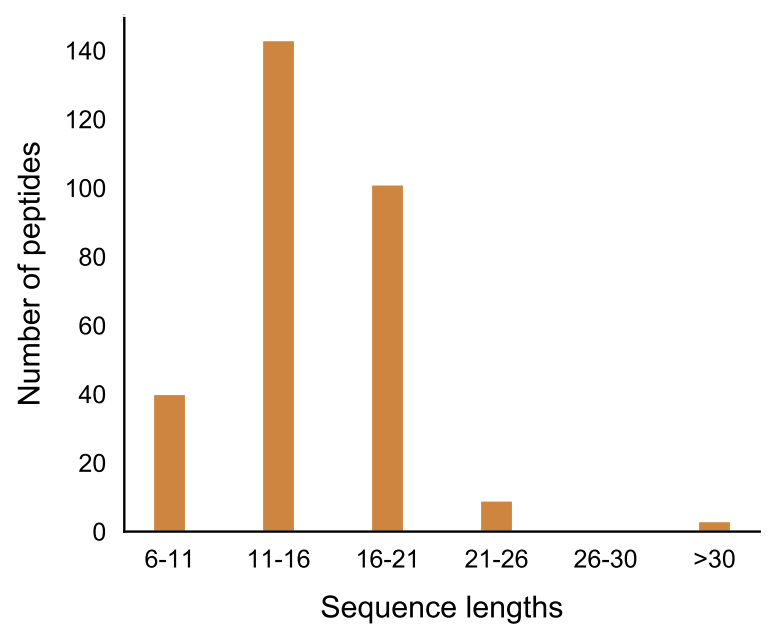

B

Fig. 7. Classification of antibiofilm peptides. (A) Decision Function of the training data, decision function values $>0.99$ are the antibiofilm peptides whereas values $<0$ are the non-antibiofilm peptides; one antibiofilm peptide was misclassified by the model; (B) Distribution of predicted antibiofilm peptides based on sequence length.

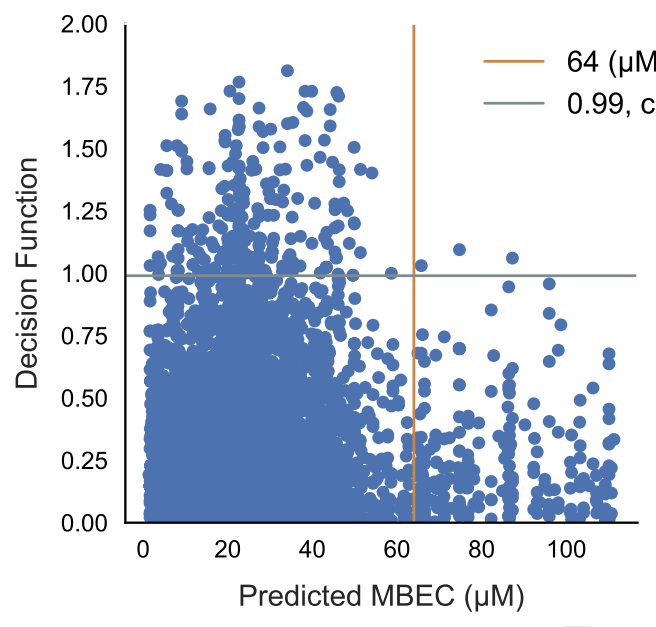

A

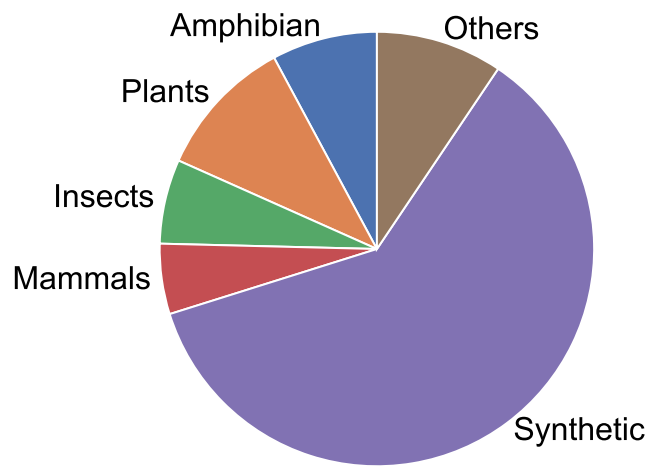

C

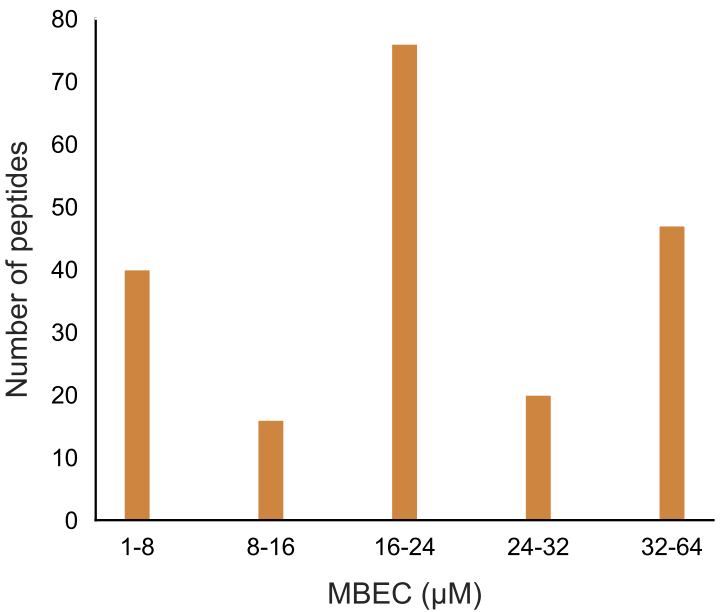

B

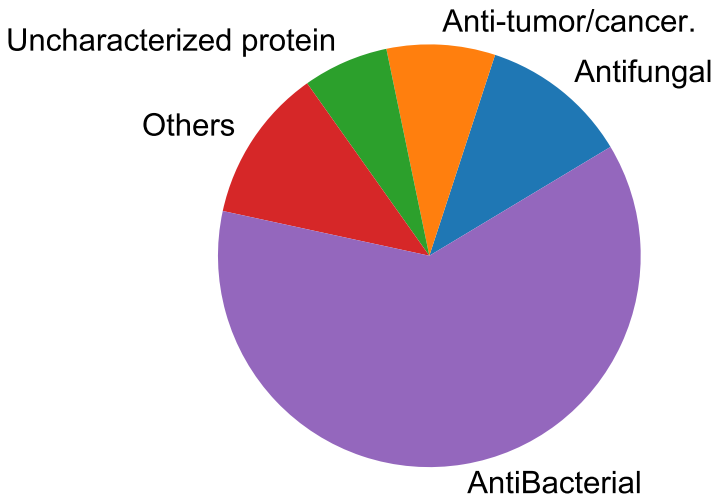

D

Fig. 8. Prediction of antibiofilm activity using an integrated classification-regression scheme. (A) Decision Function of the classifier and Predicted MBEC from the regression model of the peptides; (B) Distribution of $\mathrm{MBEC}$ values in the 1-64 $\mu \mathrm{M}$ range; (C, D) Distribution of the peptides with predicted antibiofilm activity based the source (C), or the function (D); 
belonging to any specific class or uncharacterized peptides as per Uniprot annotation also showed mostly helical or coil structures with only two peptides folding as sheets (Fig. 10).

To obtain insights into the mechanisms of action of these peptide hits, we sought to compare the sequences of these peptides with those in the positive dataset with known low MBEC values $(<64 \mu \mathrm{M})$. Upon sifting through the positive dataset, we identified 5 peptides (LL-37, coprisin, melittin, RT2 and 1018) that have unique sequences and also have well established antibiofilm activity with known mechanisms of action (Table 22 in supplementary note 6). We performed sequence alignment of the 37 peptide hits (16 characterized peptides and 21 uncharacterized peptides) with these 5 antibiofilm peptides using Clustal Omega, and the pairwise alignment score is shown in Table $2-3$. As representative examples, the sequence alignments for the peptide pairs with the highest pairwise alignment scores are presented in Fig. 14 in supplementary note 5 . The alignment scores are relative. The scores depend on both the length of the sequences and the number of identical or similar amino acids in those sequences. For instance, the self-alignment scores for the 37amino acid long LL-37 is 1850 , while the same score for alignment with the first five amino acids of LL-37 is 260 .

Of the previously characterized peptides (Table 2), the hits which have a helical structure encompassing the mastoparan, poneritoxin, and lasioglossin groups showed significant sequence similarity with the melittin and LL-37 peptides. Conotoxin peptides with coiled structure share sequence similarity with coprisin. Interestingly, peripherin shared relatively high sequence similarity with LL-37, 1018 and RT2, demonstrating the highest pairwise alignment score with RT2 amongst all the peptides tested in this work. On the other hand, we notice that a few of the peptide hits (Q8MWD3 and P30259-protamines, Q9U8M9-alcohol dehydrogenase) showed low sequence similarity to the five known antibiofilm peptide sequences. These three peptides have an acceptable MBEC predicted to be less than $20 \mu \mathrm{M}$.

Of the uncharacterized peptides (Table 3), a majority of the peptides shared sequences similar to either melittin or LL37. Among others, A0A0K1NW40 and E9JAR4 showed higher sequence similarity to coprisin, A0A0A9M1Q7 and A0A5K1F988 showed higher sequence similarity to RT2, and E4Z311 showed similarity to the 1018 peptide. A few peptides (A0A5K1FWL9, A0A5K1D9T8, S71KV4, A0A2P2N8A3) showed poor alignment with any of the five known antibiofilm peptides. Of these five peptides, $\mathrm{A} 0 \mathrm{~A} 2 \mathrm{P} 2 \mathrm{~N} 8 \mathrm{~A} 3$ and A0A5K1FWL9 are predicted to have low MBEC values. A0A2P2N8A3 is rich in lysine and hydrophilic residues while A0A5K1FWL9 is rich in arginine and hydrophobic residues, indicating the diversity in the sequences of the hits.

The results from secondary structure prediction and sequence alignment analysis provide insights into the possible mechanisms of action of the novel antibiofilm peptides. Although poorly understood, the antibiofilm peptides work through a variety of mechanisms including membrane disruption, inhibition of motility, disruption of essential proteins, and inter- ruption of genetic elements [47]. The interaction with cell membrane is naturally favored by the amphipathic helices which is commonly found in most antimicrobial peptides. Using helical wheel diagrams, we visualized only the helical regions of the peptides which have a higher percentage of helices in Fig. 13 in supplementary note 5. The helical wheel diagrams show that the poneritoxin peptides form a nearly perfect amphipathic helix with hydrophilic and hydrophobic amino acids on either side of the helix. Along with the poneritoxin peptides, the lasioglossin peptide has higher overall positive charge indicating a favorable interaction with negatively charged membrane. Among the uncharacterized peptides, A0A2P2Q2Y8, A0A5K1D9T8, E9JAR4 form amphipathic helices while some other peptides, such as E4Z311 and A0A0A9FN30, may fold into a helix but do not show amphipathic character. The coiled peptides (conotoxin, peripherin and protamine) may elicit antibiofilm action through mechanisms different from membrane interactions, possibly by interfering with vital cellular processes through specific binding interactions. For instance, the 1018 peptide is believed to interact with the signaling molecule ppGpp, and LL-37 by interfering with several pathways including quorum sensing [48, 49]. Lastly, the biofilm environment is generally acidic with $\mathrm{pH} 5-6$, which may promote a change in secondary structure depending upon the $\mathrm{pI}$ of the amino acids [50]. Therefore, while this work provides some insights into novel peptide sequences and their mechanisms, detailed genetic and molecular biofilm inhibition assays are necessary to confirm the proposed mechanisms or delineate the mechanisms of action of novel peptides identified in this study.

\section{CONCLUSIONS}

In this work, we have developed a machine learning pipeline for the classification of antibiofilm peptides followed by the determination of their efficacy. Using this pipeline, we identified a small set of novel antibiofilm peptides by mining diverse peptide libraries, and evaluated the efficacy of the hits. The peptide hits comprised of both novel peptides and peptides with other reported functions. Classical bioinformatics approaches of sequence alignment showed that some of the peptide hits may act through known mechanisms of antibiofilm activity while some others may follow less understood mechanisms to confer antibiofilm activity.

Unlike many other machine learning applications for antimicrobial peptides, we focused on the smaller subset of antibiofilm peptides instead of the much larger set of antimicrobial peptides because most recalcitrant infections are due to biofilms. Therefore, the drug development strategy should focus on efficacy against the biofilm mode of growth rather than the planktonic mode. Our approach differs from the previous models of antibiofilm peptide discovery in many significant ways. First, our negative dataset was curated as peptides which are likely to directly or indirectly promote biofilm formation rather than randomly generated sequences. Second, our model is built on the idea that the antibiofilm peptides are rarer to find in nature than biofilm-inhibiting peptides. To mimic that concept, we used ten times more peptides in 
bioRxiv preprint doi: https://doi.org/10.1101/2021.09.28.462235; this version posted September 28, 2021. The copyright holder for this preprint (which was not certified by peer review) is the author/funder, who has granted bioRxiv a license to display the preprint in perpetuity. It is made available under aCC-BY-NC-ND 4.0 International license.

Table 1. Ranking of Antibiofilm Peptides Hits

\begin{tabular}{|c|c|c|c|c|}
\hline Name & Type & Sequence & $\begin{array}{l}\text { Decision } \\
\text { Function }\end{array}$ & $\begin{array}{l}\text { Predicted } \\
\operatorname{MBEC}(\mu \mathrm{M})\end{array}$ \\
\hline P17238 & Mastoparan & INLKAIAALVKKVL & 1.142 & 22.669 \\
\hline P85874 & Mastoparan-like-peptide PMM2 & INWKKIASIGKEVLKAL & 1.109 & 22.679 \\
\hline P69036 & Mastoparan & INWLKLGKAVIDAL & 1.065 & 22.679 \\
\hline P69034 & Mastoparan & INWLKLGKKVSAIL & 1.011 & 22.679 \\
\hline P82420 & U1-poneritoxin-Ng3g & GLVDVLGKVGGLIKKLLPG & 1.326 & 27.710 \\
\hline P82419 & M-poneritoxin- $\mathrm{Ng} 3 \mathrm{f}$ & GLVDVLGKVGGLIKKLLP & 1.299 & 28.502 \\
\hline P0CF03 & U1-poneritoxin-Da2a & FLGGLIGPLMSLIPGLLK & 1.001 & 19.722 \\
\hline COHLM2 & Alpha-conotoxin & SGCCKHPACGKNRC & 1.729 & 39.130 \\
\hline $\mathrm{P} 0 \mathrm{C} 424$ & Conotoxin & CCAPSACRLGCRPCCR & 1.348 & 2.967 \\
\hline $\mathrm{COHK} 43$ & Lasioglossin & VNWKKILGKIIKVAK & 1.252 & 3.071 \\
\hline $\mathrm{COHK} 42$ & Lasioglossin & VNWKKVLGKIIKVAK & 1.169 & 3.071 \\
\hline P30259 & Protamine & $\begin{array}{l}\text { GCKKRKARKRPKCKKARKRP- } \\
\text { KCKRRKVAKKKC }\end{array}$ & 1.278 & 4.289 \\
\hline Q8WMD3 & Protamine & $\begin{array}{l}\text { MARYRRCRSRSRCRRRRRRCH- } \\
\text { RRRRRCCRRRRRRRACCRRYRCRRR }\end{array}$ & 1.043 & 21.567 \\
\hline Q16228 & Peripherin & WRWRRACRRPGRPFWRV & 1.533 & 61.163 \\
\hline Q9U8M9 & Alcohol dehydrogenase & AGLGGIGLDTNREIVKSGPK & 1.079 & 20.531 \\
\hline A0A1C8YA26 & beta-amylase & FLGCRVQLAIKISGI & 1.072 & 22.358 \\
\hline A0A0A9FN30 & Uncharacterized & MFRSLRKELKSKLL & 1.052 & 22.845 \\
\hline A0A0A9M1Q7 & Uncharacterized & MGRKFKWKLWT & 1.448 & 14.309 \\
\hline A0A0A9U210 & Uncharacterized & MTRIRRRRRHLLLLR & 1.066 & 22.612 \\
\hline A0A0D3HK27 & Uncharacterized & MFGGSGPLKLL & 1.027 & 22.008 \\
\hline A0A0E9SZ00 & Uncharacterized & MCTRWRVLLTCVRRR & 1.299 & 28.711 \\
\hline A0A0K1NW40 & Uncharacterized & KAIALALGKSGCK & 1.226 & 22.678 \\
\hline $\mathrm{A} 0 \mathrm{~A} 2 \mathrm{P} 2 \mathrm{~N} 8 \mathrm{~A} 3$ & Uncharacterized & MGGKSDFRFCHVKKKVL & 1.082 & 11.138 \\
\hline $\mathrm{A} 0 \mathrm{~A} 2 \mathrm{P} 2 \mathrm{Q} 2 \mathrm{Y} 8$ & Uncharacterized & MLKLWLRIKLLRKAL & 1.225 & 35.601 \\
\hline A0A3D5SU75 & Uncharacterized & PCPCGSGKKYKHCHGKLS & 1.040 & 1.854 \\
\hline A0A3Q7GQZ6 & Uncharacterized & GLAYRLVNLHFCKTKR & 1.073 & 22.656 \\
\hline A0A5K0UXG7 & Uncharacterized & ALLKSKPKLLRSGL & 1.662 & 22.694 \\
\hline A0A5K1B3V0 & Uncharacterized & VIRIGCKWKRTA & 1.416 & 6.260 \\
\hline A0A5K1BN05 & Uncharacterized & LGCGHGLPGIFACLK & 1.030 & 3.071 \\
\hline A0A5K1D9T8 & Uncharacterized & AKALGKRLRIKGRFQS & 0.999 & 61.036 \\
\hline A0A5K1DCQ4 & Uncharacterized & LGCGHGLPGIYACLK & 1.233 & 3.071 \\
\hline A0A5K1F988 & Uncharacterized & EKFKIHKSGKRWM & 1.062 & 46.811 \\
\hline A0A5K1FWL9 & Uncharacterized & FRARLLRTAFR & 1.115 & 22.722 \\
\hline E4Z311 & Uncharacterized & IKGILLRKIIKVR & 1.138 & 35.514 \\
\hline E9I8P2 & Uncharacterized & MLKKFLGKSGRRILR & 1.173 & 8.156 \\
\hline E9JAR4 & Uncharacterized & KLVLRRILALCIIAVCK & 1.259 & 22.923 \\
\hline S7IKV4 & Uncharacterized & SGLFCKGCSKL & 1.030 & 60.153 \\
\hline
\end{tabular}

the negative dataset than in the positive dataset. We considered stratified sampling and ten-fold cross-validation to eliminate the overfitting problem due to an imbalanced dataset. Third, we used motifs that are unique to the antibiofilm peptides not as privileged information but as a discovered entity while cross-validating the training dataset. This unbiased approach not only improved the performance of the model but also enabled the identification of truly discerning motifs which changed the performance compared to the "without motif' model. Fourth, we developed SVR-based regression models for the prediction of the efficacy, i.e., the MBIC and MBEC values of novel peptides that were classified as ABPs by our classification model. Fifth, we have used sequence alignment and secondary structure predictions to predict putative mechanisms of action of antibiofilm hits. Lastly, our work identified two broad classes of peptides: those peptides that have known previously known bioactivity but not antibiofilm activity, i.e., those that may be considered for drug re-purposing; and those peptides without any previously reported bioactivity, i.e., those that may be considered as novel drug candidates.

The two-tiered model enabled the classification and prediction of antibiofilm activity. Our SVM-based model with 572 features performed exceptionally well with an MCC of 0.91 , which is significantly higher than current models. The higher performance is due to considering the physicochemical properties and motifs along with the compositions of peptides. Consistent with previously published studies, our model showed that the ABPs are characterized by the abundance of positively charged amino acids $\mathrm{K}$ and $\mathrm{R}$, and higher 
bioRxiv preprint doi: https://doi.org/10.1101/2021.09.28.462235; this version posted September 28, 2021. The copyright holder for this preprint (which was not certified by peer review) is the author/funder, who has granted bioRxiv a license to display the preprint in perpetuity. It is made available under aCC-BY-NC-ND 4.0 International license.

$\mathrm{L}$ Prediction of secondary structure of novel antibiofilm peptide hits, and alignment of sequences with known antibiofilm peptides

Table 2. Sequence Alignment Scores of Newly Found Antibiofilm Peptides Along With Secondary Structure

\begin{tabular}{|l|l|l|l|l|l|l|}
\hline Peptide Name & Melittin & LL-37 & Coprisin & RT2 & $\mathbf{1 0 1 8}$ & Secondary Structure \\
\hline Q16228 & 90 & 160 & 40 & 230 & 150 & coil \\
P82420 & 210 & 120 & 0 & 40 & 40 & coil-helix-coil \\
P69034 & 200 & 140 & 90 & 60 & 70 & coil-helix-coil \\
P0CF03 & 190 & 120 & 10 & 20 & 30 & coil-helix-coil \\
P69036 & $\mathbf{1 8 0}$ & 50 & 90 & 60 & 50 & coil-helix-coil \\
C0HK43 & $\mathbf{1 7 0}$ & $\mathbf{1 7 0}$ & 70 & 50 & 90 & coil-helix-coil \\
C0HK42 & $\mathbf{1 7 0}$ & 160 & 70 & 50 & 90 & coil-helix-coil \\
C0HLM2 & 10 & 40 & $\mathbf{1 7 0}$ & 30 & 20 & coil \\
P0C424 & 20 & 0 & $\mathbf{1 6 0}$ & 110 & 40 & coil \\
P85874 & 140 & $\mathbf{1 6 0}$ & 30 & 50 & 90 & coil-helix-coil \\
P82419 & $\mathbf{1 5 0}$ & 140 & 0 & 40 & 50 & coil-helix-coil \\
P17238 & $\mathbf{1 3 0}$ & 120 & 50 & 0 & 80 & coil-helix-coil \\
A0A1C8YA26 & $\mathbf{1 3 0}$ & 40 & $\mathbf{1 3 0}$ & 100 & 80 & coil-helix-coil \\
P30259 & $\mathbf{1 1 0}$ & 50 & 80 & 0 & 20 & coil-helix \\
Q8WMD3 & 80 & 40 & 60 & 60 & $\mathbf{9 0}$ & coil-sheet-coil \\
Q9U8M9 & $\mathbf{9 0}$ & 70 & 50 & 60 & 0 & coil-helix-coil \\
\hline
\end{tabular}

Note: high scores are denoted in red and low scores in green; highest value highlighted in bold; secondary structure evaluated using the Pep2D server.

Table 3. Sequence Alignment Scores of Newly Found Uncharacterized Antibiofilm Peptides Along With Secondary Structure

\begin{tabular}{|l|l|l|l|l|l|l|}
\hline Peptide Name & Melittin & LL-37 & Coprisin & RT2 & $\mathbf{1 0 1 8}$ & Secondary Structure \\
\hline E9I8P2 & 30 & 230 & 40 & 0 & 60 & coil \\
A0A0A9M1Q7 & 50 & 130 & 30 & $\mathbf{2 2 0}$ & 60 & coil-helix-coil \\
A0A0K1NW40 & 30 & 50 & $\mathbf{2 0 0}$ & 70 & 50 & coil-helix-coil \\
A0A5K1F988 & 30 & $\mathbf{1 9 0}$ & 40 & 180 & 50 & coil \\
E4Z311 & 90 & 110 & 50 & 10 & $\mathbf{1 9 0}$ & coil-helix-coil \\
A0A5K1DCQ4 & $\mathbf{1 9 0}$ & 20 & 70 & 60 & 30 & coil \\
A0A5K1BN05 & $\mathbf{1 9 0}$ & 40 & 50 & 20 & 30 & coil-sheet-coil \\
A0A0A9U210 & $\mathbf{1 8 0}$ & 90 & 50 & 10 & 150 & coil-helix-coil \\
A0A2P2Q2Y8 & 120 & 90 & 10 & 80 & $\mathbf{1 8 0}$ & coil-helix-coil \\
A0A0E9SZ00 & $\mathbf{1 7 0}$ & 60 & 90 & 90 & 90 & coil-helix-coil \\
A0A0D3HK27 & $\mathbf{1 4 0}$ & 80 & 30 & 10 & 90 & coil \\
A0A5K0UXG7 & $\mathbf{1 4 0}$ & 70 & 110 & 80 & 10 & coil-helix-coil \\
A0A5K1B3V0 & 50 & $\mathbf{1 5 0}$ & 50 & 50 & 140 & coil \\
E9JAR4 & 100 & 80 & $\mathbf{1 5 0}$ & 0 & 80 & coil-helix-coil \\
A0A3Q7GQZ6 & 50 & $\mathbf{1 4 0}$ & 70 & 0 & 30 & coil-sheet-coil \\
A0A3D5SU75 & 40 & 70 & $\mathbf{1 3 0}$ & 20 & 20 & coil-sheet-coil \\
A0A0A9FN30 & 60 & $\mathbf{1 2 0}$ & 50 & 20 & 60 & coil-helix-coil \\
A0A5K1D9T8 & 20 & $\mathbf{1 1 0}$ & 10 & 20 & 80 & coil-helix-coil \\
S7IKV4 & 50 & $\mathbf{1 1 0}$ & 90 & 20 & 40 & coil \\
A0A2P2N8A3 & 40 & 60 & $\mathbf{1 1 0}$ & 20 & 40 & coil-sheet-coil \\
A0A5K1FWL9 & 30 & $\mathbf{5 0}$ & $\mathbf{5 0}$ & 40 & 0 & coil-helix-coil \\
\hline
\end{tabular}

Note: high scores are denoted in red and low scores in green; highest value highlighted in bold; secondary structure evaluated using the Pep2D server. 

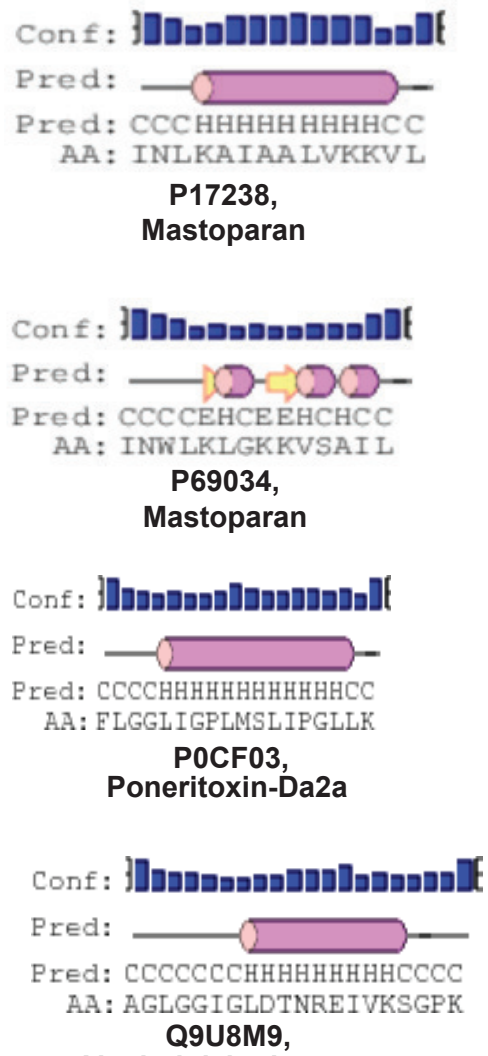

Alcohol dehydrogenase
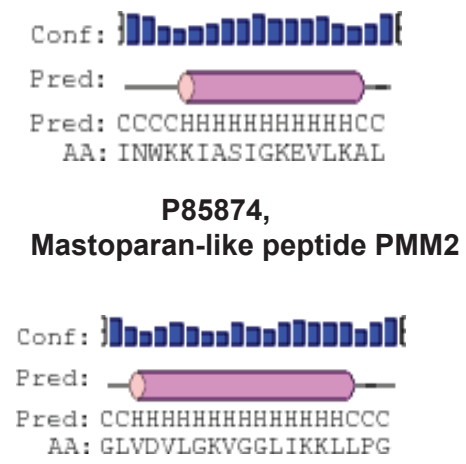

P82420,

Poneritoxin
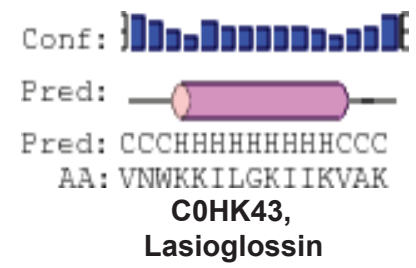

Conf : \}]

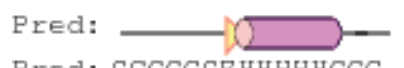

Pred: CCCCCCEHHHHHCCC

A.A : FLGCRVQLAIKISGI A0A1C8YA26, Beta - amylase

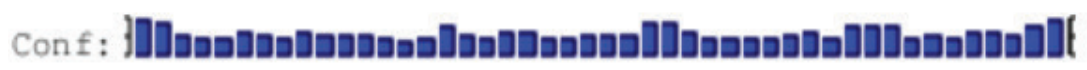

Pred:

Pred: CCCCEEEC CCEEEECCCEEEECC CEEEE CCCEC CCEEEECCEEECC

AA: MARYRRCRSRSRCRRRRRRCHRRRRRCCRRRRRRRACCRRYRCRRR

Q8MwD3,

Protamine
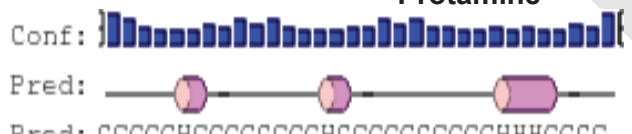

Pred: CCCCCHCCCCCCCCHCCCCCCCCCCHHHCCCC

AA: GCKKRKARKRPKCKKARKRPKCKRRKVAKKKC

P30259,

Protamine

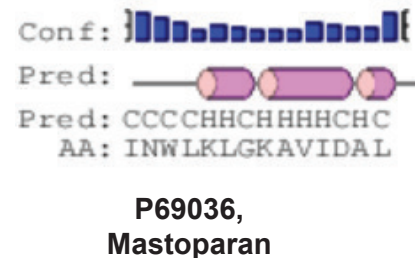

Conf : \}

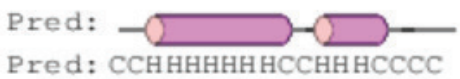

AA: GLVDVLGKVGGLI KKLLP

P82419,

Poneritoxin

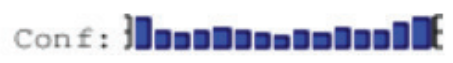

Pred: $\longrightarrow$

Pred: CCCCHHHCEEHHCCC

AA: VNWKKVLGKIIKVAK

COHK42,

Lasioglossin

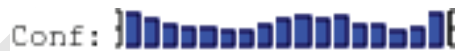

Pred:

Pred: CCCCCHCCCCCCCCCCC

AA: WRWRRACRRP GRPFWRV

Q16228,

Peripherin

Conf : |llnanananumant

Pred:

Pred: CCCCCCCCCCCCCCCC

AA: CCAPSACRLGCRPCCR

P0C424,

Conotoxin

Fig. 9. 2D structures of some newly found antibiofilm peptides; The $2 \mathrm{D}$ structures were evaluated using the PEP2D server.

hydrophobicity due to $\mathrm{W}$ and $\mathrm{I}$.

Our SVR-based model predicted the efficacy of ABPs with high confidence. To our knowledge, no previous studies have attempted to predict peptide efficacy using machine learning approaches. To this end, we built a regression model using the MBIC and MBEC values curated from the literature that have experimentally determined these values. In this work, we were careful to distinguish the biological significance of MBIC and MBEC values, as the former represents efficacy against biofilm formation, and the latter represents efficacy against pre-formed biofilms. An antibiofilm peptide with a lower MBIC but high MBEC may not effectively eradicate pre-formed biofilm. For instance, Dermaseptin-AC is useful in the inhibition of biofilm (MBIC $32 \mu \mathrm{M}$ ) formed by Staphylococcus aureus but is not effective in eradicat- ing preformed biofilm (MBEC $256 \mu \mathrm{M}$ ) [51]. Therefore, in this work, we developed models to predict both MBIC and MBEC for ABPs.

One important limitation of using MBIC/MBEC values from literature is that the peptides were not all tested against a single organism or using a single experimental technique but against a wide range of microorganisms (gram positive and gram negative bacteria, fungi), and using both dilution, platebased or other techniques. This key limitation notwithstanding, the regression model performed very well with an RMSE of $10-25 \%$ of the mean MBIC/MBEC values for most peptides in the training set. We expect the effectiveness of our model to increase given more adequate MBIC/MBEC measurements on a wide range of ABPs. As an independent validation of our regression model, the predicted MBIC of these 
bioRxiv preprint doi: https://doi.org/10.1101/2021.09.28.462235; this version posted September 28, 2021. The copyright holder for this preprint (which was not certified by peer review) is the author/funder, who has granted bioRxiv a license to display the preprint in perpetuity. It is made available under aCC-BY-NC-ND 4.0 International license.

L Prediction of secondary structure of novel antibiofilm peptide hits, and alignment of sequences with known antibiofilm peptides

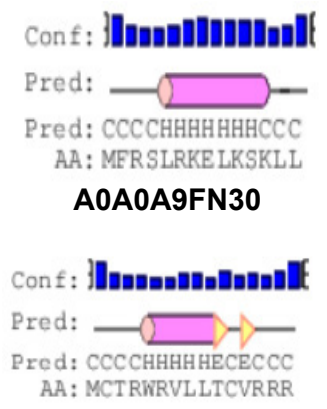

AOAOE9SZOO

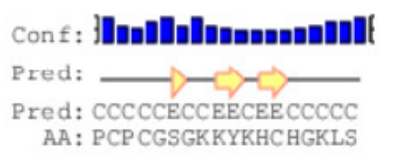

A0A3D5SU75

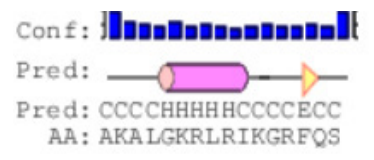

A0A5K1D9T8
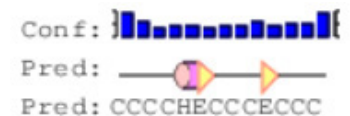

AA: EKF KIHKS GKRWM

A0A5K1F988

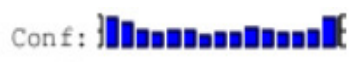

Pred:

AA: MLKKELGKSGRRI LR

E918P2
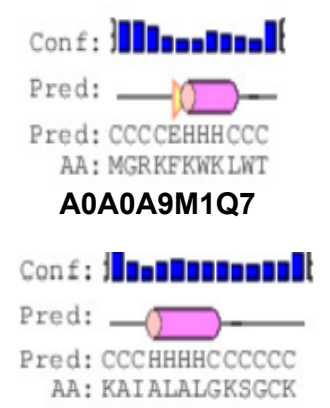

AOAOK1NW40

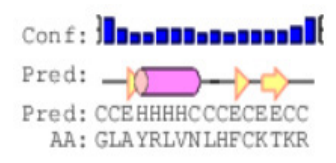

A0A3Q7GQZ6
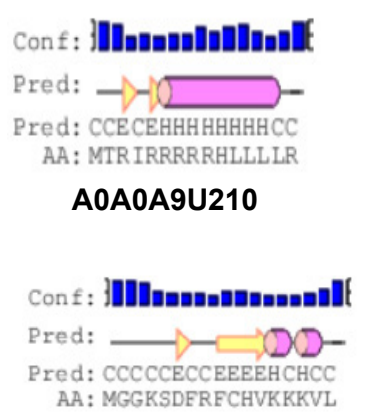

A0A2P2N8A3

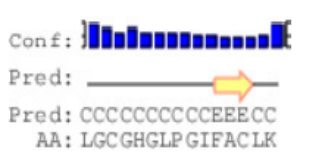

A0A5K1BN05

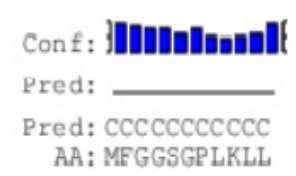

AOAOD3HK27

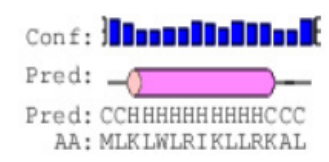

A0A2P2Q2Y8

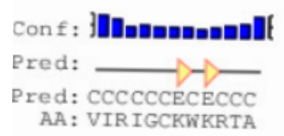

A0A5K1B3V0

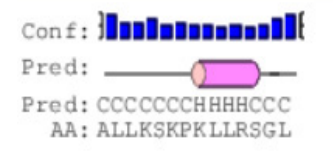

A0A5K0UXG7

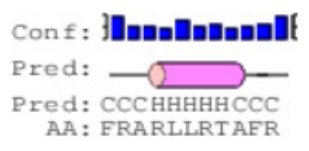

A0A5K1FWL9

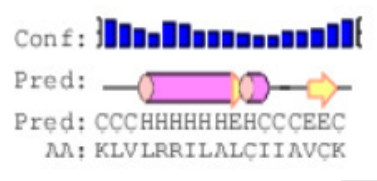

E9JAR4

Fig. 10. 2D structures of uncharacterized peptides; The 2D structures were evaluated using the PEP2D server.

peptides matched well with experimentally determined antimicrobial activity (MIC). For instance, the peptide COHK43 is active against gram-negative bacteria at concentrations of 1-14 $\mu \mathrm{M}$ as reported in the DRAMP database (MIC $1.4 \mu \mathrm{M}$ against $E$. coli, MIC $14.1 \mu \mathrm{M}$ against $P$. aeruginosa) while our model predicted an MBIC/MBEC value between 1-8 $\mu \mathrm{M}$. The identification of a number of host defense peptides, which are considered to be a physiologically relevant response to biofilms, through a mechanism-agnostic sequence search further bolsters confidence in our approach [52]. In vitro biofilm inhibition and in vivo virulence assays beyond the scope of this work are warranted to confirm the validity and translational potential of the peptide hits. Despite these limitations, our work has clearly demonstrated not only the feasibility of our sequence-based, mechanism-agnostic machine learning pipeline to predict efficacious antibiofilm peptides, but has also unearthed the vast diversity in sequences that have the potential to eradicate biofilms.

\section{ACKNOWLEDGMENTS}

This work was supported by an award from the NIH (R15AI138146). Computational resources were made pos- sible by the San José State University Computer Engineering department HPC and the Santa Clara University WAVE HPC.

\section{AUTHOR CONTRIBUTIONS}

B.B., A.K.R., and D.C.A. designed the research, analyzed the data, and wrote the manuscript. B.B. collected data from databases and literature, performed all experiments, and prepared the figures. T.D. developed and optimized the regression model. All authors approved the final version of the manuscript.

\section{DATA AVAILABILITY}

The datasets generated and analyzed in this study can be found in the Antibiofilm repository at github. com/davidanastasiu/antibiofilm. 
bioRxiv preprint doi: https://doi.org/10.1101/2021.09.28.462235; this version posted September 28, 2021. The copyright holder for this preprint (which was not certified by peer review) is the author/funder, who has granted bioRxiv a license to display the preprint in perpetuity. It is made available under aCC-BY-NC-ND 4.0 International license.

\section{BIBLIOGRAPHY}

[1] J W Costerton, K J Cheng, G G Geesey, T I Ladd, J C Nickel, M Dasgupta, and T J Marrie. Bacterial biofilms in nature and disease. Annual Review of Microbiology, 41(1):435-464, 1987. doi: 10.1146/annurev.mi.41.100187.002251. PMID: 3318676

[2] Nelson S. Torres, Daniel Montelongo-Jauregui, Johnathan J. Abercrombie, Anand Srinivasan, Jose L. Lopez-Ribot, Anand K. Ramasubramanian, and Kai P. Leung. Antimicrobial and antibiofilm activity of synergistic combinations of a commercially available small compound library with colistin against pseudomonas aeruginosa. Frontiers in Microbiology, 9: 2541, 2018. ISSN 1664-302X. doi: 10.3389/fmicb.2018.02541.

[3] Anand K. Ramasubramanian and José L. Lopez-Ribot. Nano-biofilm arrays as a novel universal platform for microscale microbial culture and high-throughput downstream applications. Current Medicinal Chemistry, 26(14):2529-2535, 2019. ISSN 0929-8673/1875-533X. doi: 10.2174/0929867326666190107155953.

[4] Anand Srinivasan, Nelson S. Torres, Kai P. Leung, Jose L. Lopez-Ribot, and Anand K. Ramasubramanian. nbiochip, a lab-on-a-chip platform of mono- and polymicrobial biofilms for high-throughput downstream applications. $m S$ phere, 2(3), 2017. doi: 10.1128/mSphere. 00247-17.

[5] César de la Fuente-Núñez, Fany Reffuveille, Lucía Ferna nde, and Robert EW Hancock. Bacterial biofilm development as a multicellular adaptation: antibiotic resistance and new therapeutic strategies. Current Opinion in Microbiology, 16(5):580-589, 2013. ISSN 13695274. doi: https://doi.org/10.1016/j.mib.2013.06.013. Antimicrobials â $€ \notin$ Genomics.

[6] Christopher G. Pierce, Anand Srinivasan, Anand K. Ramasubramanian, and José L. LópezRibot. From biology to drug development: New approaches to combat the threat of fungal biofilms. Microbiology Spectrum, 3(3), 2015

[7] David M. P. De Oliveira, Brian M. Forde, Timothy J. Kidd, Patrick N. A. Harris, Mark A. Schembri, Scott A. Beatson, David L. Paterson, and Mark J. Walker. Antimicrobial resistance in eskape pathogens. Clinical Microbiology Reviews, 33(3), 2020. ISSN 0893-8512. doi: 10.1128/CMR.00181-19.

[8] Mahlapuu Margit, Hakansson Joakim, Ringstad Lovisa, and Bjorn Camilla. Antimicrobial peptides: An emerging category of therapeutic agents. Frontiers in Cellular and Infection Microbiology, 6:194, 2016. ISSN 2235-2988. doi: 10.3389/fcimb.2016.00194.

[9] Guangshun Wang, Xia Li, and Zhe Wang. APD3: the antimicrobial peptide database as a tool for research and education. Nucleic Acids Research, 44(D1):D1087-D1093, 112015. ISSN 0305-1048. doi: 10.1093/nar/gkv1278.

[10] Réka Spohn, Lejla Daruka, Viktória Lázár, Ana Martins, Fanni Vidovics, Gábor Grézal, Orsolya Méhi, Bálint Kintses, Mónika Számel, Pramod K. Jangir, Bálint Csörgő, Ádám Györkei, Zoltán Bódi, Anikó Faragó, László Bodai, Imre Földesi, Diána Kata, Gergely Maróti, Bernadett Pap, Roland Wirth, Balázs Papp, and Csaba Pál. Integrated evolutionary analysis reveals antimicrobial peptides with limited resistance. Nature Communications, 10(1):4538, Oct 2019. ISSN 2041-1723. doi: 10.1038/s41467-019-12364-6.

[11] Alexandre Prehn Zavascki, Luciano Zubaran Goldani, Jian Li, and Roger L. Nation. Polymyxin $b$ for the treatment of multidrug-resistant pathogens: a critical review. Journal of Antimicrobial Chemotherapy, 60(6):1206-1215, 09 2007. ISSN 0305-7453. doi: 10.1093/jac/dkm357.

[12] Dean E. Sheard, Neil M. O'Brien-Simpson, John D. Wade, and Frances Separovic. Combating bacterial resistance by combination of antibiotics with antimicrobial peptides. Pure and Applied Chemistry, 91(2):199-209, 2019. doi: doi:10.1515/pac-2018-0707.

[13] Sneh Lata, B. K. Sharma, and G. P. S. Raghava. Analysis and prediction of antibacterial peptides. BMC Bioinformatics, 8(1):263, Jul 2007. ISSN 1471-2105. doi: $10.1186 /$ 1471-2105-8-263.

[14] Xuan Xiao, Pu Wang, Wei-Zhong Lin, Jian-Hua Jia, and Kuo-Chen Chou. iamp-2l: A twolevel multi-label classifier for identifying antimicrobial peptides and their functional types. Analytical Biochemistry, 436(2):168-177, 2013. ISSN 0003-2697. doi: https://doi.org/10. 1016/j.ab.2013.01.019.

[15] Prabina Kumar Meher, Tanmaya Kumar Sahu, Varsha Saini, and Atmakuri Ramakrishna Rao. Predicting antimicrobial peptides with improved accuracy by incorporating the compositional, physico-chemical and structural features into chou's general pseaac. Scientific Reports, 7(1):42362, Feb 2017. ISSN 2045-2322. doi: 10.1038/srep42362.

[16] Pratiti Bhadra, Jielu Yan, Jinyan Li, Simon Fong, and Shirley W. I. Siu. Ampep: Sequencebased prediction of antimicrobial peptides using distribution patterns of amino acid properties and random forest. Scientific Reports, 8(1):1697, Jan 2018. ISSN 2045-2322. doi: 10.1038/s41598-018-19752-w.

[17] Ernest Y. Lee, Benjamin M. Fulan, Gerard C. L. Wong, and Andrew L. Ferguson. Mapping membrane activity in undiscovered peptide sequence space using machine learning Proceedings of the National Academy of Sciences, 113(48):13588-13593, 2016. ISSN 0027-8424. doi: 10.1073/pnas.1609893113.

[18] C. D. Fjell, H. Jenssen, P. Fries, P. Aich, P. Griebel, K. Hilpert, R. E. Hancock, and A. Cherkasov. Identification of novel host defense peptides and the absence of alphadefensins in the bovine genome. Proteins, 73(2):420-430, Nov 2008

[19] Evan F. Haney, Yoan Brito-Sánchez, Michael J. Trimble, Sarah C. Mansour, Artem Cherkasov, and Robert E. W. Hancock. Computer-aided discovery of peptides that specifically attack bacterial biofilms. Scientific Reports, 8(1):1871, Jan 2018. ISSN 2045-2322. doi: 10.1038/s41598-018-19669-4.

[20] Mariagrazia Di Luca, Giuseppe Maccari, Giuseppantonio Maisetta, and Giovanna Batoni. Baamps: the database of biofilm-active antimicrobial peptides. Biofouling, 31(2):193-199, 2015. doi: 10.1080/08927014.2015.1021340. PMID: 25760404.

[21] Daniel Pletzer and Robert E. W. Hancock. Antibiofilm peptides: Potential as broad-spectrum agents. Journal of Bacteriology, 198(19):2572-2578, 2016. ISSN 0021-9193. doi: 10.1128/ JB.00017-16.

[22] Sudheer Gupta, Ashok K. Sharma, Shubham K. Jaiswal, and Vineet K. Sharma. Prediction of biofilm inhibiting peptides: An in silico approach. Frontiers in Microbiology, 7:949, 2016. ISSN 1664-302X. doi: 10.3389/fmicb.2016.00949.

[23] A. Sharma, P. Gupta, R. Kumar, and A. Bhardwaj. dpabbs: A novel in silico approach for predicting and designing anti-biofilm peptides. Scientific Reports, 6(21839), 2016. doi: https://doi.org/10.1038/srep21839.
[24] Fereshteh Fallah Atanaki, Saman Behrouzi, Shohreh Ariaeenejad, Amin Boroomand, and Kaveh Kavousi. Bipep: Sequence-based prediction of biofilm inhibitory peptides using a combination of nmr and physicochemical descriptors. ACS Omega, 5(13):7290-7297, 2020. doi: 10.1021/acsomega.9b04119.

[25] The UniProt Consortium. Uniprot: the universal protein knowledgebase in $2021 . \quad \mathrm{Nu}-$ cleic Acids Research, 49(D1):D480-D489, 11 2020. ISSN 0305-1048. doi: 10.1093/nar/ gkaa1100.

[26] Akanksha Rajput, Amit Kumar Gupta, and Manoj Kumar. Prediction and analysis of quorum sensing peptides based on sequence features. PLOS ONE, 10(3):1-16, 03 2015. doi: 10.1371/journal.pone.0120066.

[27] NCBI Resource Coordinators. Database resources of the national center for biotechnology information. Nucleic acids research, 44(D1):D7-D19, Jan 2016. ISSN 1362-4962. doi: 10.1093/nar/gkv1290. 26615191[pmid].

[28] C. Nagant, B. Pitts, K. Nazmi, M. Vandenbranden, J. G. Bolscher, P. S. Stewart, and J.-P. Dehaye. Identification of peptides derived from the human antimicrobial peptide II-37 active against biofilms formed by pseudomonas aeruginosa using a library of truncated fragments. Antimicrobial Agents and Chemotherapy, 56(11):5698-5708, 2012. ISSN 0066-4804. doi: 10.1128/AAC.00918-12.

[29] Xinyue Kang, Fanyi Dong, Cheng Shi, Shicai Liu, Jian Sun, Jiaxin Chen, Haiqi Li, Hanmei Xu, Xingzhen Lao, and Heng Zheng. Dramp 2.0, an updated data repository of antimicrobial peptides. Scientific Data, 6(1):148, Aug 2019. ISSN 2052-4463. doi: 10.1038/s41597-019-0154-y.

[30] Dongsheng Cao. propy3. pypi. https://pypi.org/project/propy3/, 2020.

[31] Peter J. A. Cock, Tiago Antao, Jeffrey T. Chang, Brad A. Chapman, Cymon J. Cox, Andrew Dalke, Iddo Friedberg, Thomas Hamelryck, Frank Kauff, Bartek Wilczynski, and Michiel J. L. de Hoon. Biopython: freely available python tools for computational molecular biology and bioinformatics. Bioinformatics, 25(11):1422-1423, 03 2009. ISSN 1367-4803. doi: 10.1093/bioinformatics/btp163.

[32] Nan Xiao, Dong-Sheng Cao, Min-Feng Zhu, and Qing-Song Xu. protr/protrweb: R package and web server for generating various numerical representation schemes of protein sequences. Bioinformatics, 31(11):1857-1859, 01 2015. ISSN 1367-4803. doi: 10.1093/bioinformatics/btv042.

[33] Celine Vens, Marie-Noëlle Rosso, and Etienne G. J. Danchin. Identifying discriminative classification-based motifs in biological sequences. Bioinformatics, 27(9):1231-1238, 03 2011. ISSN 1367-4803. doi: 10.1093/bioinformatics/btr110.

[34] F. Pedregosa. Scikit-learn: Machine learning in python. scikit-learn: Machine learning in python., 2011.

[35] X. Y. Ng, B. A. Rosdi, and S. Shahrudin. Prediction of antimicrobial peptides based on sequence alignment and support vector machine-pairwise algorithm utilizing $\mathrm{lz}$-complexity. BioMed Research International, 2015(212715), 2015. doi: https://doi.org/10.1155/2015/ 212715 .

[36] S. Gupta, P. Kapoor, K. Chaudhary, A. Gautam, R. Kumar, and G. P. Raghava. In silico approach for predicting toxicity of peptides and proteins. PLoS One, 8(9):e73957, 2013.

[37] Balachandran Manavalan, Tae H. Shin, Myeong O. Kim, and Gwang Lee. Aippred: Sequence-based prediction of anti-inflammatory peptides using random forest. Frontiers in Pharmacology, 9:276, 2018. ISSN 1663-9812. doi: 10.3389/fphar.2018.00276.

[38] Liyang Wang, Dantong Niu, Xiaoya Wang, Qun Shen, and Yong Xue. A novel machine learning strategy for prediction of antihypertensive peptides derived from food with high efficiency. bioRxiv, 2020. doi: 10.1101/2020.08.12.248955.

[39] Fábio Madeira, Young Mi Park, Joon Lee, Nicola Buso, Tamer Gur, Nandana Madhusoodanan, Prasad Basutkar, Adrian R N Tivey, Simon C Potter, Robert D Finn, and Rodrigo Lopez. The embl-ebi search and sequence analysis tools apis in 2019. Nucleic acids research, 47(W1):W636-W641, July 2019. ISSN 0305-1048. doi: 10.1093/nar/gkz268.

[40] Nathan W. Schmidt and Gerard C.L. Wong. Antimicrobial peptides and induced membrane curvature: Geometry, coordination chemistry, and molecular engineering. Current Opinion in Solid State and Materials Science, 17(4):151-163, 2013. ISSN 1359-0286. doi: https://doi.org/10.1016/j.cossms.2013.09.004. Membrane spatial organization, shape, and remodeling: Materials science and biology.

[41] Yeon-Hee Kim, Sang Moo Kim, and Si Young Lee. Antimicrobial activity of protamine against oral microorganisms. Biocontrol Science, 20(4):275-280, 2015. doi: 10.4265/bio.20.275.

[42] Hamed Memariani, Mojtaba Memariani, and Mohammad Reza Pourmand. Venom-derived peptide mastoparan-1 eradicates planktonic and biofilm-embedded methicillin-resistant staphylococcus aureus isolates. Microbial Pathogenesis, 119:72-80, 2018. ISSN 08824010. doi: https://doi.org/10.1016/j.micpath.2018.04.008.

[43] J. Orivel, V. Redeker, J. P. Le Caer, F. Krier, A. M. Revol-Junelles, A. Longeon, A. Chaffotte, A. Dejean, and J. Rossier. Ponericins, new antibacterial and insecticidal peptides from the venom of the ant Pachycondyla goeldii. J Biol Chem, 276(21):17823-17829, May 2001.

[44] Anicet Ebou, Dominique Koua, Audrey Addablah, Solange Kakou-Ngazoa, and Sébastien Dutertre. Combined proteotranscriptomic-based strategy to discover novel antimicrobial peptides from cone snails. Biomedicines, 9(4), 2021. ISSN 2227-9059. doi: 10.3390/ biomedicines 9040344

[45] Xinya Hemu and James P. Tam. Macrocyclic antimicrobial peptides engineered from $\omega$ conotoxin. Current pharmaceutical design, 23(14):2131-2138, 2017. ISSN 1873-4286. doi: 10.2174/1381612822666161027120518. 28245769[pmid].

[46] Harinder Singh, Sandeep Singh, and Gajendra Pal Singh Raghava. Peptide secondary structure prediction using evolutionary information. bioRxiv, 2019. doi: 10.1101/558791.

[47] Nigare Raheem and Suzana K. Straus. Mechanisms of action for antimicrobial peptides with antibacterial and antibiofilm functions. Frontiers in Microbiology, 10:2866, 2019. ISSN 1664-302X. doi: 10.3389/fmicb.2019.02866.

[48] M. Wieczorek, H. Jenssen, J. Kindrachuk, W. R. Scott, M. Elliott, K. Hilpert, J. T. Cheng, R. E. Hancock, and S. K. Straus. Structural studies of a peptide with immune modulating and direct antimicrobial activity. Chem Biol, 17(9):970-980, Sep 2010

[49] J. Overhage, A. Campisano, M. Bains, E. C. Torfs, B. H. Rehm, and R. E. Hancock. Human host defense peptide LL-37 prevents bacterial biofilm formation. Infect Immun, 76(9):41764182, Sep 2008

[50] M. Xiong, Y. Bao, X. Xu, H. Wang, Z. Han, Z. Wang, Y. Liu, S. Huang, Z. Song, J. Chen, 
bioRxiv preprint doi: https://doi.org/10.1101/2021.09.28.462235; this version posted September 28, 2021. The copyright holder for this preprint (which was not certified by peer review) is the author/funder, who has granted bioRxiv a license to display the preprint in perpetuity. It is made available under aCC-BY-NC-ND 4.0 International license.

$\mathrm{L}$ Prediction of secondary structure of novel antibiofilm peptide hits, and alignment of sequences with known antibiofilm peptides

R. M. Peek, L. Yin, L. F. Chen, and J. Cheng. with pH-responsive helix-coil conformation transitionable antimicrobial polypeptides. Proc Natl Acad Sci U S A, 114(48):12675-12680, 112017.

[51] Z. Gong, X. Pei, S. Ren, X. Chen, L. Wang, C. Ma, X. Xi, T. Chen, C. Shaw, and M. Zhou. Identification and rational design of a novel antibacterial peptide dermaseptin-ac from the skin secretion of the red-eyed tree frog agalychnis callidryas. Antibiotics., 9(5), 2020. doi: https://doi.org/10.3390/antibiotics9050243.

[52] R. E. W. Hancock, M. A. Alford, and E. F. Haney. Antibiofilm activity of host defence peptides: complexity provides opportunities. Nat Rev Microbiol, Jun 2021.

[53] M. Schiffer and A. B. Edmundson. Use of helical wheels to represent the structures of proteins and to identify segments with helical potential. Biophysical journal, 7(2):121-135, Mar 1967. ISSN 0006-3495. doi: 10.1016/S0006-3495(67)86579-2.

[54] Don Armstrong and Raphael Zidovetzki, Dec 2001.

[55] Andrew M. Waterhouse, James B. Procter, David M. A. Martin, Michèle Clamp, and Geoffrey J. Barton. Jalview version 2-a multiple sequence alignment editor and analysis workbench. Bioinformatics, 25(9):1189-1191, 01 2009. ISSN 1367-4803. doi: 10.1093/bioinformatics/btp033. 


\section{Supplementary Note 1: Dataset statistics}

Table 4 presents the number of peptides for training, validation and out-of-sample test sets for both the positive and negative datasets. The table also contains details of the dataset used for training and evaluating the regression models.

Table 4. Dataset Distribution of Our Machine Learning Models

\begin{tabular}{|l|l|l|l|l|}
\hline Dataset & Type & Training & Validation & Out-of-Sample Test \\
\hline \hline \multirow{3}{*}{ Classification } & Positive & 175 & 19 & 48 \\
\cline { 2 - 6 } & Negative & 1741 & 194 & 485 \\
\hline \multirow{2}{*}{ MBIC Classification } & $\leq 64 \mu \mathrm{M}$ & 128 & 32 & N/A \\
\cline { 2 - 6 } & $>64 \mu \mathrm{M}$ & 14 & 4 & N/A \\
\hline \multirow{3}{*}{ MBIC Regression } & $\leq 64 \mu \mathrm{M}$ & 128 & 32 & N/A \\
\cline { 2 - 6 } & $\leq 64 \mu \mathrm{M}$ & 33 & 9 & N/A \\
\hline Candidate & & \multicolumn{5}{|l}{135015} \\
\hline
\end{tabular}

\section{Supplementary Note 2: Characterization of Peptides}

Fig. 11 presents the ten dipeptides with the highest composition percentage from the negative dataset. Interestingly, most of the dipeptides in the top ten set contain leucine, a non-polar amino acid.

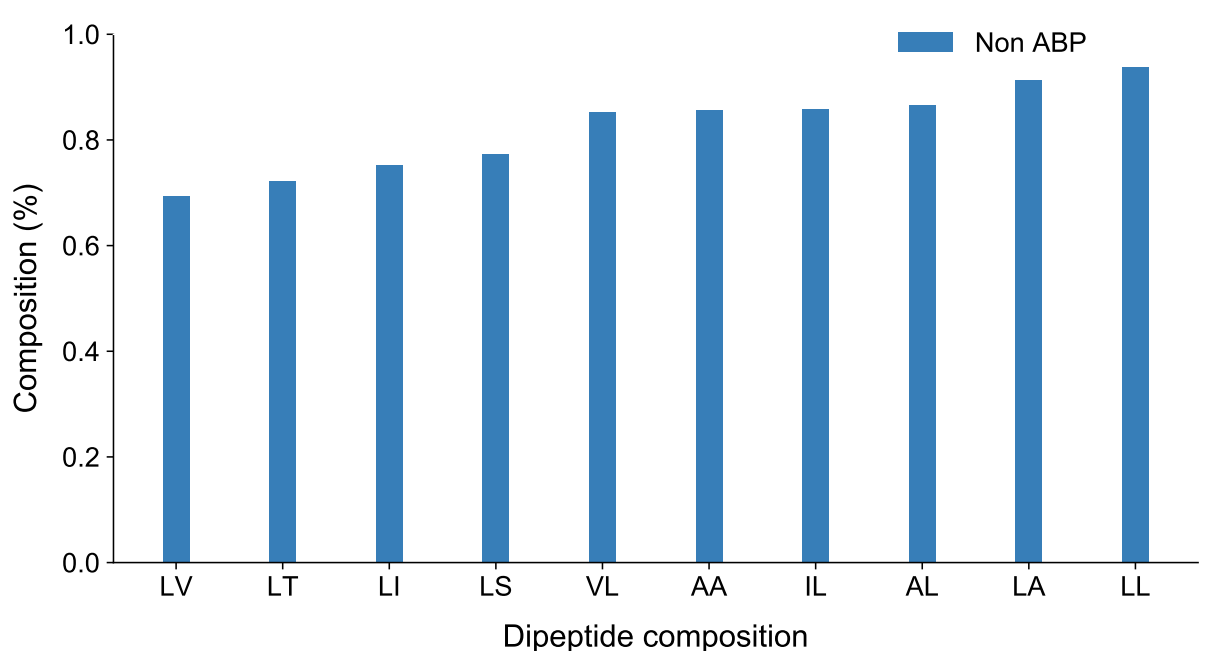

Fig. 11. Dipeptide composition of the negative dataset; all the dipepetides contain the non-polar amino acid leucine;

\section{Supplementary Note 3: Performance of Machine Learning Models}

Table 5 presents results from our evaluation of different machine learning models based on individual features while Table 6 displays the performance of different models when we combine two features together. Finally, Table 7 showcases the performance of our models when we combine more than two features. Our best performing model combines the AAC, DPC, CTD and Motif features. 
bioRxiv preprint doi: https://doi.org/10.1101/2021.09.28.462235; this version posted September 28,2021 . The copyright holder for this preprint (which was not certified by peer review) is the author/funder, who has granted bioRxiv a license to display the preprint in perpetuity. It is made available under aCC-BY-NC-ND 4.0 International license.

L Prediction of secondary structure of novel antibiofilm peptide hits, and alignment of sequences with known antibiofilm peptides

Table 5. Performance Evaluation of Different Machine Learning Techniques with Individual Features

\begin{tabular}{|l|l|l|l|l|l|l|}
\hline Feature & Model & Sensitivity & Specificity & Accuracy & F1 Score & MCC \\
\hline \hline \multirow{2}{*}{ AAC } & SVM & 72.91 & 99.79 & 97.37 & 83.33 & 82.93 \\
& RF & 68.75 & 100 & 97.18 & 81.48 & 81.66 \\
& XGBoost & 75.11 & 99.38 & 97.18 & 82.75 & 81.76 \\
\hline \multirow{2}{*}{ DPC } & SVM & 85.41 & 98.35 & 97.17 & 84.35 & 82.99 \\
& RF & 72.91 & 99.17 & 96.81 & 80.45 & 79.24 \\
& XGBoost & 79.16 & 98.76 & 96.99 & 82.60 & 81.06 \\
\hline \multirow{2}{*}{ CTD } & SVM & 83.33 & 99.38 & 97.93 & 86.94 & 87.91 \\
& RF & 70.83 & 99.79 & 97.18 & 81.92 & 81.62 \\
& XGBoost & 85.41 & 98.96 & 97.74 & 87.23 & 86.02 \\
\hline
\end{tabular}

Table 6. Performance Evaluation of Different Machine Learning Techniques with a Combination of Two Features

\begin{tabular}{|l|l|l|l|l|l|l|}
\hline Features & Model & Sensitivity & Specificity & Accuracy & F1 Score & MCC \\
\hline \hline \multirow{2}{*}{ AAC \& DPC } & SVM & 81.25 & 98.96 & 97.33 & 84.78 & 83.33 \\
& RF & 77.08 & 99.79 & 97.74 & 86.08 & 85.52 \\
& XGBoost & 81.25 & 99.38 & 97.74 & 86.66 & 85.76 \\
\hline DPC \& CTD & SVM & 77.08 & 99.79 & 97.74 & 86.04 & 85.52 \\
& RF & 70.83 & 100 & 97.37 & 82.92 & 82.97 \\
& XGBoost & 79.16 & 99.17 & 97.37 & 84.44 & 83.23 \\
\hline CTD \& AAC & SVM & 85.41 & 99.17 & 97.93 & 88.17 & 87.09 \\
& RF & 72.91 & 100 & 97.56 & 84.33 & 84.26 \\
& XGBoost & 79.16 & 99.58 & 97.74 & 86.36 & 85.56 \\
\hline
\end{tabular}

Table 7. Performance Evaluation of Different Machine Learning Techniques with a Combination of Three or More Features

\begin{tabular}{|c|c|c|c|c|c|c|}
\hline Features & Model & Sensitivity & Specificity & Accuracy & F1 Score & MCC \\
\hline $\begin{array}{l}\text { AAC \& DPC \& } \\
\text { CTD }\end{array}$ & $\begin{array}{l}\text { SVM }(c=100, \\
\text { gamma=0.01) } \\
\text { RF (n- } \\
\text { estimator=100) } \\
\text { XGBoost (n- } \\
\text { estimator=100, } \\
\text { gamma=0.5) }\end{array}$ & $\begin{array}{l}85.41 \\
70.83 \\
81.25\end{array}$ & $\begin{array}{l}98.96 \\
100 \\
99.58\end{array}$ & $\begin{array}{l}97.94 \\
97.37 \\
97.93\end{array}$ & $\begin{array}{l}88.42 \\
82.92 \\
87.64\end{array}$ & $\begin{array}{l}87.29 \\
82.97 \\
86.84\end{array}$ \\
\hline $\begin{array}{l}\text { AAC \& DPC \& } \\
\text { CTD \& motif }\end{array}$ & $\begin{array}{l}\text { SVM }(\mathrm{c}=150, \\
\text { gamma=0.05, } \\
\text { Motif=ALL) } \\
\text { RF (with } \\
\text { Motif=BETTS- } \\
\text { RUSSELL) } \\
\text { XGBoost (with } \\
\text { Motif=BETTS- } \\
\text { RUSSELL) }\end{array}$ & $\begin{array}{l}\mathbf{8 5 . 4 8} \\
72.91 \\
85.41\end{array}$ & $\begin{array}{l}99.79 \\
100 \\
99.38\end{array}$ & $\begin{array}{l}98.49 \\
97.56 \\
98.12\end{array}$ & $\begin{array}{l}91.11 \\
84.33 \\
89.13\end{array}$ & $\begin{array}{l}90.53 \\
84.26 \\
88.20\end{array}$ \\
\hline
\end{tabular}


bioRxiv preprint doi: https://doi.org/10.1101/2021.09.28.462235; this version posted September 28, 2021. The copyright holder for this preprint (which was not certified by peer review) is the author/funder, who has granted bioRxiv a license to display the preprint in perpetuity. It is made available under aCC-BY-NC-ND 4.0 International license.

Table 8. Performance Comparison of Our Method with the Dataset from [22]

\begin{tabular}{|l|l|l|l|l|l|}
\hline $\begin{array}{l}\text { Validation dataset } \\
\text { performance }\end{array}$ & Specificity & Sensitivity & Accuracy & F1 Score & MCC \\
\hline $\begin{array}{l}\text { Reported in Gupta et } \\
\text { al. [22] }\end{array}$ & 97.75 & 91.67 & 97.19 & N/A & 0.84 \\
\hline $\begin{array}{l}\text { Achieved with our } \\
\text { model }\end{array}$ & $\mathbf{9 9 . 7 1}$ & 86.11 & $\mathbf{9 8 . 4 6}$ & $\mathbf{9 1 . 1 7}$ & $\mathbf{0 . 9 0}$ \\
\hline
\end{tabular}

\section{Supplementary Note 4: Characterization of Peptides from the MBEC dataset}

We present the characteristics of the 57 peptides that were selected for training the regression model responsible for predicting the MBEC value of a candidate antibiofilm peptide.

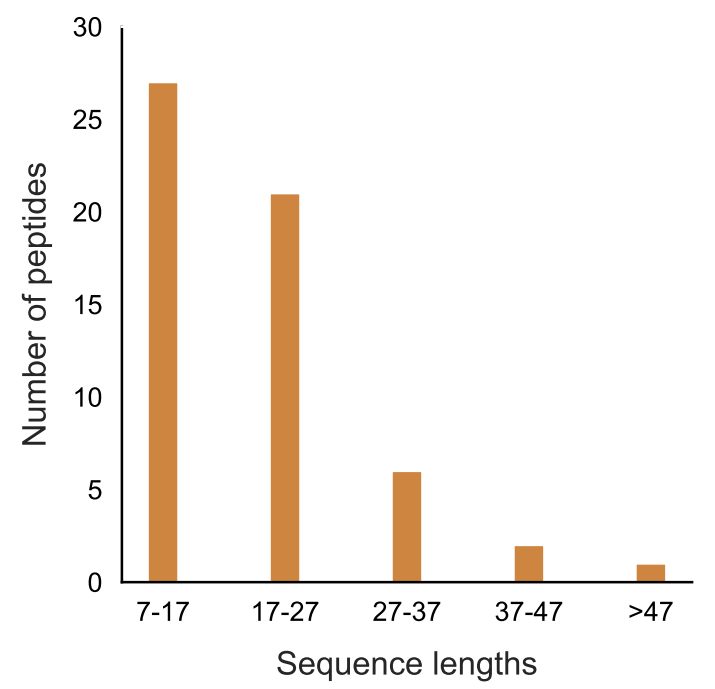

A

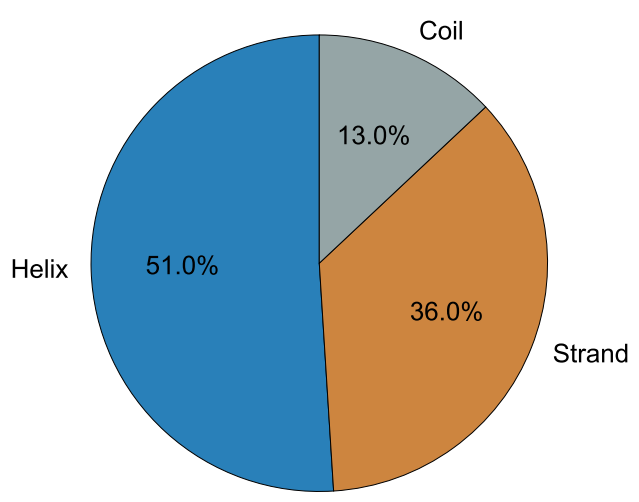

$\mathrm{B}$

Fig. 12. Performance and characteristics of peptides with MBIC/MBEC values; (A) Number of peptides with MBEC values in different sequence ranges; (B) Percentage of helices, strands and coils in secondary structure for peptides with MBEC values;

\section{Supplementary Note 5: Newly found antibiofilm peptides}

A. Visualization. We further evaluated the structure of the peptides with probable antibiofilm activity. We evaluated helical wheel structure (Fig. 13) for the peptides which showed higher percentage of helices in secondary structure evaluation. 
bioRxiv preprint doi: https://doi.org/10.1101/2021.09.28.462235; this version posted September 28, 2021. The copyright holder for this preprint (which was not certified by peer review) is the author/funder, who has granted bioRxiv a license to display the preprint in perpetuity. It is made available under aCC-BY-NC-ND 4.0 International license.

B Alignment

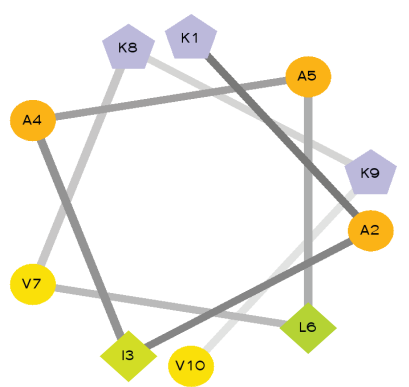

Mastoparan

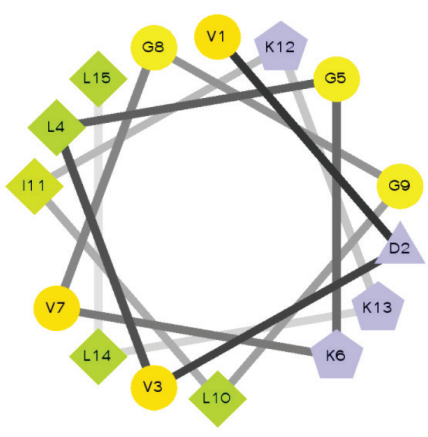

Poneritoxin

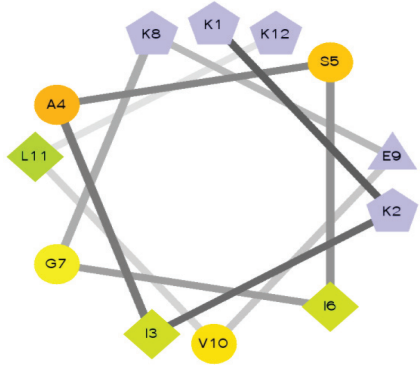

Mastoparan Like

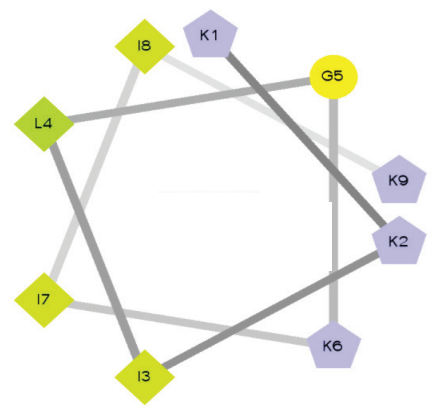

Lasioglossin

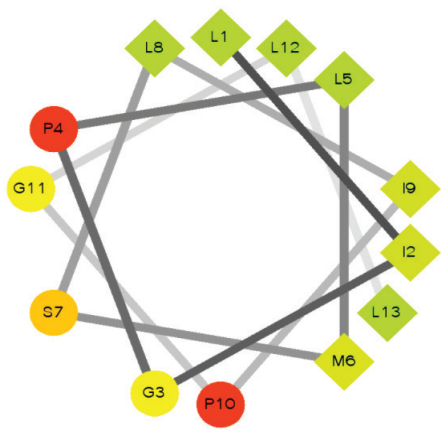

Poneritoxin-Da2a

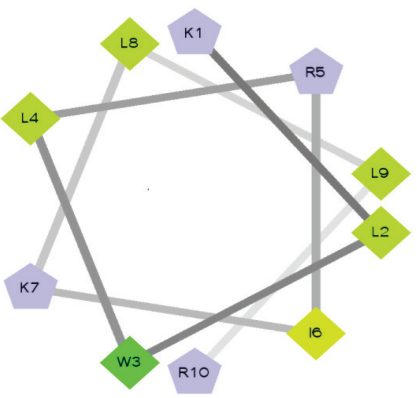

Uncharacterized

Fig. 13. The helical wheel structures of a few newly found antibiofilm peptides; (A) COHK43, Lasioglossin; (B) P82420, Poneritoxin; (C) P0CF03, Poneritoxin-Da2a; (D) Q9U8M9, alcohol dehydrogenase; (E) A0A5K1FWL9; (F) E4Z311, uncharacterized protein. Here, hydrophilic amino acids are shown in circles, hydrophobic as diamonds. Negatively charged amino acids are triangles, and positively charged are pentagons. The hydrophobic amino acids are green, and the green shade decreases to yellow as per decreasing hydrophobicity. Hydrophilic amino acids are in red and the amount of red decreases as per decreasing hydrophilicity. The highly charged amino acids are in light blue and non-polar amino acids are in dark red. The wheel structures were obtained using the software created by Don Armstrong and Raphael Zidovetzki, version 0.10 p06 12/14/2001 DLA [53, 54].

B. Alignment. We also analyzed a few newly found antibiofilm peptides against some well known antibiofilm peptides which already have an eradication effect on preformed biofilm. For example, we aligned human cathelicidin, LL-37, against the set of Mastoparan-like peptides from our list. The alignment was done using the Clustal default webservice [39]. The alignment is displayed in Fig. 14 using Jalview V2 [55]. 
bioRxiv preprint doi: https://doi.org/10.1101/2021.09.28.462235; this version posted September 28, 2021. The copyright holder for this preprint (which was not certified by peer review) is the author/funder, who has granted bioRxiv a license to display the preprint in perpetuity. It is made available under aCC-BY-NC-ND 4.0 International license.

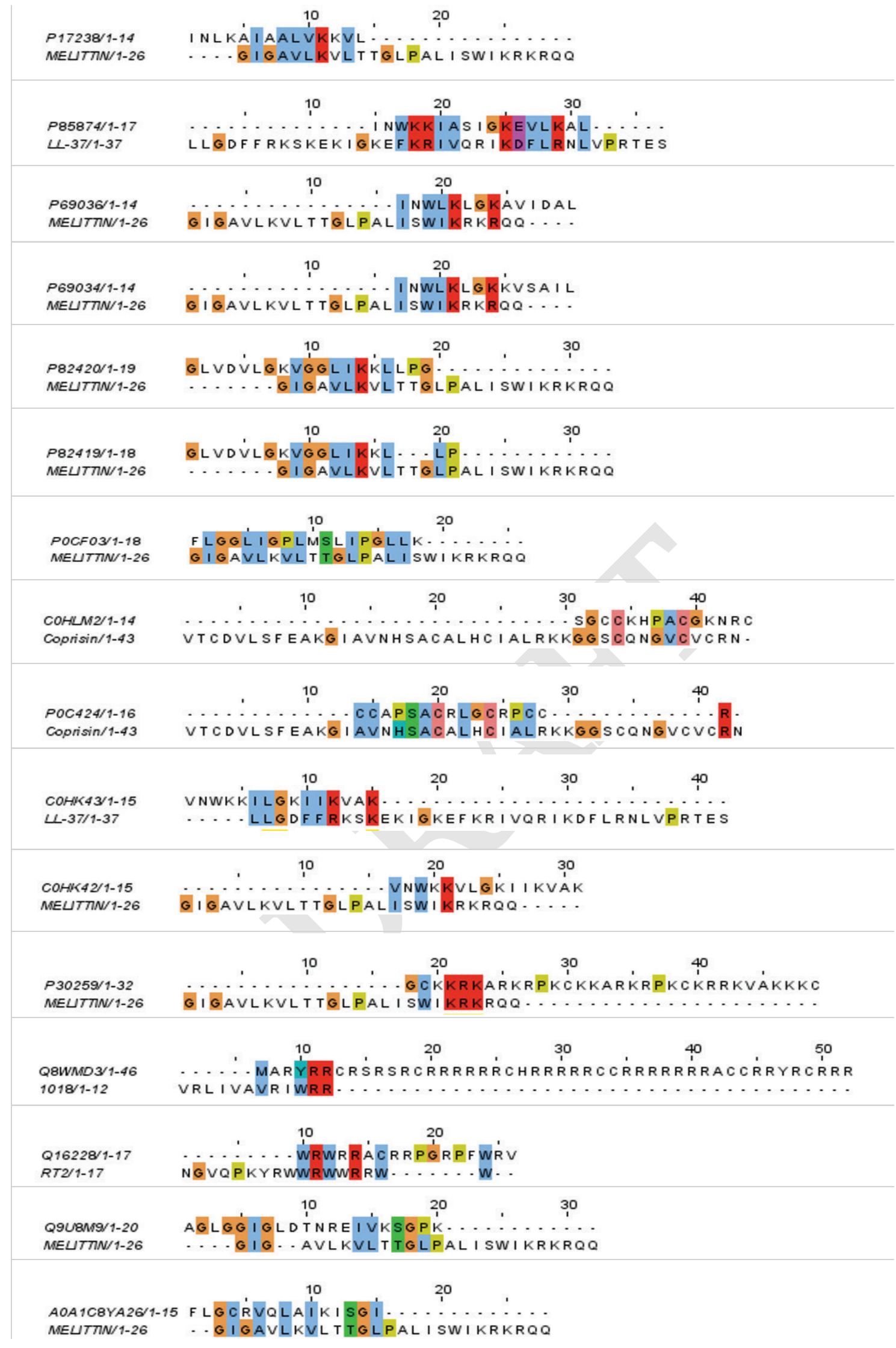

Fig. 14. Sequence alignment details, default colour scheme used as per ClustalX; Colorcode - blue: residues A, I, L, M, F, W, V, C; red: K, R; green: N, Q, S, T; magenta: E, D; yellow: P. 
bioRxiv preprint doi: https://doi.org/10.1101/2021.09.28.462235; this version posted September 28, 2021. The copyright holder for this preprint (which was not certified by peer review) is the author/funder, who has granted bioRxiv a license to display the preprint in perpetuity. It is made available under aCC-BY-NC-ND 4.0 International license.

C Peptide List

C. Peptide List. The list of probable antibiofilm peptides from our pipeline are listed in Tables 9-16. The tables contain peptide sequences and predicted MBEC values. We grouped the peptides in several MBIC value ranges.

Table 9. Newly Predicted Antibiofilm Peptides with MBIC Range 1-8 $(\mu \mathrm{M})$ from the DRAMP database

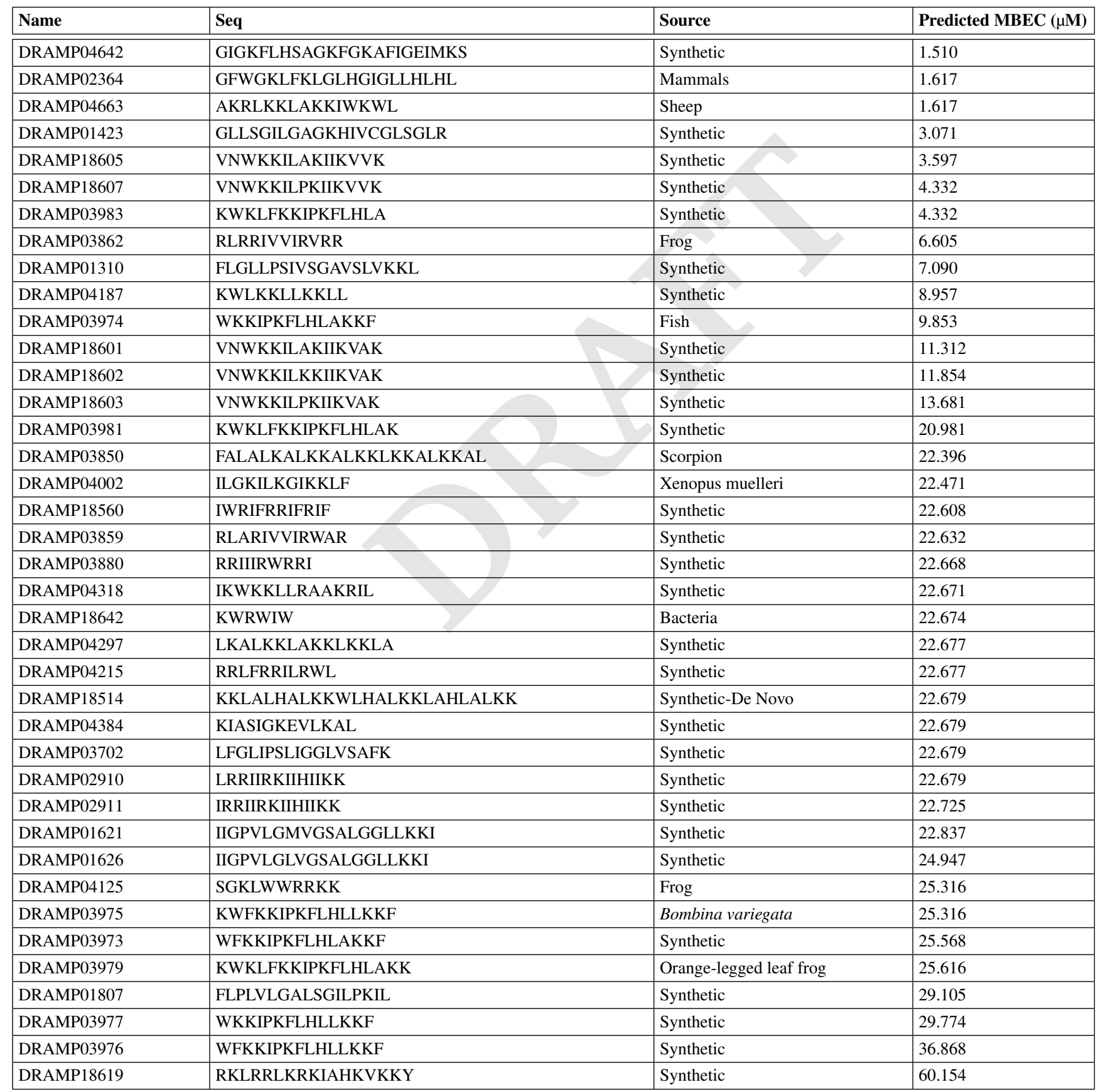


bioRxiv preprint doi: https://doi.org/10.1101/2021.09.28.462235; this version posted September 28, 2021. The copyright holder for this preprint (which was not certified by peer review) is the author/funder, who has granted bioRxiv a license to display the preprint in perpetuity. It is made available under aCC-BY-NC-ND 4.0 International license.

Table 10. Newly Predicted Antibiofilm Peptides with MBIC Range 8-16 $(\mu \mathrm{M})$ from the DRAMP Database

\begin{tabular}{|c|c|c|c|}
\hline Name & Seq & Source & Predicted MBEC $(\mu \mathrm{M})$ \\
\hline DRAMP02474 & KFFRKLKKSVKKRAK & Spider & 2.397 \\
\hline DRAMP18600 & NVWKKILGKIIKVAK & Synthetic & 2.462 \\
\hline DRAMP18568 & VSWKKSLGKIIKVVK & Synthetic & 3.071 \\
\hline DRAMP18596 & NVWKKVLGKIIKVAK & Synthetic & 3.071 \\
\hline DRAMP04228 & GRFRRLGRKFKKLFKKYGP & Synthetic & 3.071 \\
\hline DRAMP03972 & KWFKKIPKFLHLAKKF & Scorpion & 3.236 \\
\hline DRAMP02963 & GRFRRLRKKTRKRLKKIGKV & Synthetic & 4.011 \\
\hline DRAMP01126 & ILGPVISKIGGVLGGLLKNL & Synthetic & 4.332 \\
\hline DRAMP03570 & LLGDFFRKSKEKIGKEFKRIVQR & Bovine & 4.719 \\
\hline DRAMP03967 & KWKLFKKIPKFLHLAKKF & Synthetic & 4.953 \\
\hline DRAMP03969 & KWKLFKKISKFLHLAKKF & Synthetic & 4.953 \\
\hline DRAMP03970 & WKLFKKIPKFLHLAKKF & Synthetic & 6.610 \\
\hline DRAMP03971 & FKLFKKIPKFLHLAKKF & Synthetic & 10.699 \\
\hline DRAMP18563 & KSLRRVWRSWR & Synthetic & 10.791 \\
\hline DRAMP03826 & KNLRRIIRKIIHIIKKYG & Odorrana grahami (Frog) & 15.718 \\
\hline DRAMP04310 & ELAKKALKALKKALKSAR & Synthetic & 16.091 \\
\hline DRAMP04311 & ELAKKALRALKKALKSAK & Pig & 19.720 \\
\hline DRAMP03227 & GLFGKLIKKFGRKAISYAVKKARGKH & Synthetic & 19.996 \\
\hline DRAMP03980 & KWKLFKKIPLHLAKKF & 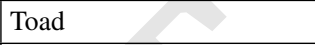 & 21.695 \\
\hline DRAMP03923 & KWKLFKKIGIGAVLKVLT & Synthetic & 22.608 \\
\hline DRAMP04260 & LALLKVLLRKIKKAL & Synthetic & 22.645 \\
\hline DRAMP18562 & KSLVRRWRSRW & +2 & 22.645 \\
\hline DRAMP18597 & VNWKKVLAKIIKVAK & Synthetic & 22.659 \\
\hline DRAMP18598 & VNWKKVLKKIIKVAK & Synthetic & 22.659 \\
\hline DRAMP18599 & VNWKKVLPKIIKVAK & Synthetic & 22.668 \\
\hline DRAMP03963 & KWKLFKKIKFLHSAKKF & Synthetic & 22.671 \\
\hline DRAMP03968 & KWKLFKKILKFLHLAKKF & Synthetic & 22.676 \\
\hline DRAMP03984 & KWKLFKKIPLAKKF & Synthetic & 22.679 \\
\hline DRAMP18570 & VNRKKILGKSIKVVK & Synthetic & 22.679 \\
\hline DRAMP18502 & 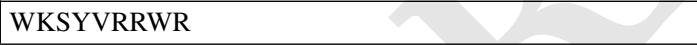 & Synthetic & 22.679 \\
\hline DRAMP04018 & ALYKKFKKKLLKSLKRLG & Bacteria & 22.679 \\
\hline DRAMP04003 & ILGKIWKIKKLF & Synthetic & 22.679 \\
\hline DRAMP04376 & INWLKLGKKIISAL & Synthetic & 22.705 \\
\hline DRAMP18507 & FSGGNCRGFRRRCFCTK & Synthetic & 22.725 \\
\hline DRAMP04614 & AVNIPFKVHFRCKSIFC & Synthetic & 22.837 \\
\hline DRAMP03865 & RWWKIWVIRWWR & Synthetic & 22.837 \\
\hline DRAMP18567 & VNWKKILGKSIKVSK & Synthetic & 23.595 \\
\hline
\end{tabular}


bioRxiv preprint doi: https://doi.org/10.1101/2021.09.28.462235; this version posted September 28, 2021. The copyright holder for this preprint (which was not certified by peer review) is the author/funder, who has granted bioRxiv a license to display the preprint in perpetuity. It is made available under aCC-BY-NC-ND 4.0 International license.

C Peptide List

Table 11. Newly Predicted Antibiofilm Peptides with MBIC Range 8-16 $\mu$ M from the DRAMP Database (Cont.)

\begin{tabular}{|l|l|l|l|}
\hline Name & Seq & Source & Predicted MBEC $(\mu$ M) \\
\hline \hline DRAMP04664 & AKRLKKLAKKIWKWK & Human & 24.958 \\
\hline DRAMP04051 & RICRIVVIRCIR & Human & 25.040 \\
\hline DRAMP03978 & KWKLFKKIPFLHLAKKF & Synthetic & 25.219 \\
\hline DRAMP03925 & KWKLFKKGAVLKVLT & Synthetic & 25.595 \\
\hline DRAMP03768 & ILSAIWSGIKS & Synthetic & 25.595 \\
\hline DRAMP03858 & RLARIVKIRVAR & Synthetic & 25.595 \\
\hline DRAMP03982 & KWKLFKKIPHLAKKF & Synthetic & 28.344 \\
\hline DRAMP18564 & KWLRRVWRWWR & Snake & 35.077 \\
\hline DRAMP18565 & KRLRRVWRRWR & Synthetic & 39.599 \\
\hline DRAMP03964 & KWKLFKKIPKFLHSAKKF & 39.927 \\
\hline DRAMP03924 & KWKLFKKGIGAVLKV & Synthetic & 44.372 \\
\hline DRAMP03575 & FKRIVQRIKDFLR & Synthetic & 48.038 \\
\hline DRAMP02872 & GRFKRFRKKFKKLFKKLS & AnTomato & 50.828 \\
\hline DRAMP18501 & WKSYVRRWRS & Synthetic & 53.153 \\
\hline DRAMP03829 & GLKKLLGKLLKKLGKLLLK & Synthetic & 54.066 \\
\hline DRAMP18499 & WKSYVRRWRSR & Synthetic & 63.560 \\
\hline
\end{tabular}

Table 12. Newly Predicted Antibiofilm Peptides with MBIC Range 16-32 $(\mu \mathrm{M})$ from the DRAMP Database

\begin{tabular}{|l|l|l|l|}
\hline Name & Seq & Source & Predicted MBEC $(\mu$ M $)$ \\
\hline \hline DRAMP03777 & IWSAIWSGIKGLL & Urodacus yaschenkoi $($ scorpion $)$ & 35.514 \\
\hline DRAMP04390 & INWKKGKEVLKAL & Synthetic & 22.679 \\
\hline DRAMP03966 & KLKLFKKIGIGKFLHSAKKF & Synthetic & 7.220 \\
\hline DRAMP02914 & RICRIIFLRVCR & Sheep & 14.287 \\
\hline DRAMP04377 & INWLKLGKKLLSAL & Synthetic & 22.679 \\
\hline DRAMP04113 & KWKSFIKKLASKFLHSAKKF & Synthetic & 22.680 \\
\hline DRAMP04115 & KWKSFIKKLTKKFLHSAKKF & Synthetic & 45.279 \\
\hline DRAMP04127 & RGKRWWRRKK & 49.900 \\
\hline DRAMP04054 & RLCRIVWVIRVCR & Synthetic & 47.017 \\
\hline DRAMP18401 & ILSAIWSGIKGLL & Synthetic & 35.514 \\
\hline DRAMP03965 & KAKLFKKIGIGKFLHSAKKF & 5.068 \\
\hline DRAMP04102 & KWKSFIKKLTSKFLHLAKKF & Scorpion & 25.740 \\
\hline DRAMP04103 & KWKSFIKKLTSKFLHSAKKF & Synthetic & 45.279 \\
\hline DRAMP04104 & KFKSFIKKLTSKFLHSAKKF & Synthetic & 45.279 \\
\hline DRAMP04106 & KWKSFKKKLTSKFLHSAKKF & Synthetic & 45.279 \\
\hline DRAMP04119 & KWKSFIKKLTSKFLHSKKKF & Synthetic & 45.279 \\
\hline DRAMP04112 & KWKSFIKKLLSKFLHSAKKF & Synthetic & 22.380 \\
\hline DRAMP18723 & KWKLFKKI & Synthetic & 48.126 \\
\hline DRAMP18566 & VNWKKSLGKSIKVVK & Synthetic & 4.953 \\
\hline DRAMP01134 & ILGPVIKTIGGVLGGLLKNL & Moth & 19.866 \\
\hline
\end{tabular}


bioRxiv preprint doi: https://doi.org/10.1101/2021.09.28.462235; this version posted September 28, 2021. The copyright holder for this preprint (which was not certified by peer review) is the author/funder, who has granted bioRxiv a license to display the preprint in perpetuity. It is made available under aCC-BY-NC-ND 4.0 International license.

Table 13. Newly Predicted Antibiofilm Peptides with MBIC Range $>32(\mu \mathrm{M})$ from the DRAMP Database

\begin{tabular}{|l|l|l|l|}
\hline Name & Seq & Source & Predicted MBEC $(\mu$ M $)$ \\
\hline \hline DRAMP04343 & IGKLFKRIVKRILKFLRKL & Synthetic & 35.719 \\
\hline DRAMP04126 & SGKRWWRRKK & Synthetic & 49.900 \\
\hline DRAMP04339 & IGKKFKRIVQRIKKFLRKL & Synthetic & 3.556 \\
\hline DRAMP04340 & IGKKFKRIVKRIKKFLRKL & 3.556 \\
\hline DRAMP04345 & IGKKWKRIVKRIKKFLRKL & Synthetic & 3.556 \\
\hline DRAMP04346 & IGKKFKRIVKRIKKWLRKL & Synthetic & 3.556 \\
\hline DRAMP18614 & VRRFAWWWAFLRR & Synthetic & 22.940 \\
\hline DRAMP03876 & RRWWWRWRRW & 49.900 \\
\hline DRAMP03877 & KKWWWKWKKW & Synthetic & 49.900 \\
\hline DRAMP03878 & RRWWRRWRRW & Synthetic & 49.900 \\
\hline DRAMP03879 & RRFFFRFRF & Synthetic & 49.900 \\
\hline DRAMP18457 & KRWWKWWRRC & Synthetic & 15.828 \\
\hline DRAMP18508 & KFAKKFKWFAKAAFKFFKK & Synthetic & 49.900 \\
\hline DRAMP18643 & KWWWRW & Synthetic & 49.900 \\
\hline DRAMP04001 & ILGKIWKGIKSLF & Synthetic & 7.590 \\
\hline DRAMP04069 & CFKFKFKFGSGFKFKFKFC & Synthetic & 22.791 \\
\hline DRAMP04070 & CWKWKWKWGSGWKWKWKWC & 22.791 \\
\hline DRAMP03869 & RRWVIWRR & Synthetic & 40.529 \\
\hline DRAMP18558 & FIKRIARLLRKIF & Synthetic & 34.455 \\
\hline
\end{tabular}

Table 14. Newly Predicted Antibiofilm Peptides with MBIC Range 1-8 $(\mu \mathrm{M})$ from the UniProt database

\begin{tabular}{|l|l|l|l|}
\hline Name & Seq & Source & Predicted MBEC $(\mu \mathbf{M})$ \\
\hline \hline sp|P0CF03| & FLGGLIGPLMSLIPGLLK & Ant & 19.723 \\
\hline tr|A0A5K1B3V0| & VIRIGCKWKRTA & Nymphaea colorata $($ plant $)$ & 6.260 \\
\hline tr|A0A0E9SZ00| & MCTRWRVLLTCVRRR & Anguilla anguilla $($ eel $)$ & 28.711 \\
\hline tr|A0A2P2N8A3| & MGGKSDFRFCHVKKKVL & 11.138 \\
\hline tr|A0A0A9M1Q7| & MGRKFKWKLWT & Rhizophora mucronata (plant) & 14.310 \\
\hline sp|C0HK43| & VNWKKILGKIIKVAK & Arundo donax (plant) & 3.071 \\
\hline tr|A0A0A9U210| & MTRIRRRRRHLLLLR & Lasioglossum laticeps (bee) & 22.612 \\
\hline sp|P17236| & FLPLILGKLVKGLL & Arundo donax (plant) & 36.241 \\
\hline tr|A0A2P2Q2Y8| & MLKLWLRIKLLRKAL & Oriental hornet & 35.601 \\
\hline tr|A0A5K1FWL9| & FRARLLRTAFR & Rhizophora mucronata (plant) & 22.722 \\
\hline sp|P82419| & GLVDVLGKVGGLIKKLLP & 28.502 \\
\hline sp|C0HLD5| & FLSLIPKIAGGIASLVKNL & Ant & 23.319 \\
\hline sp|P82420| & GLVDVLGKVGGLIKKLLPG & Frog & 27.711 \\
\hline tr|E4Z311| & Ant & 35.514 \\
\hline
\end{tabular}


bioRxiv preprint doi: https://doi.org/10.1101/2021.09.28.462235; this version posted September 28, 2021. The copyright holder for this preprint (which was not certified by peer review) is the author/funder, who has granted bioRxiv a license to display the preprint in perpetuity. It is made available under aCC-BY-NC-ND 4.0 International license.

A Positive Dataset

Table 15. Newly Predicted Antibiofilm Peptides with MBIC Range 8-16 $(\mu \mathrm{M})$ from the UniProt database

\begin{tabular}{|c|c|c|c|}
\hline Name & Seq & Source & Predicted MBEC $(\mu \mathrm{M})$ \\
\hline $\operatorname{trl}|A 0 A 3 D 5 S U 75|$ & PCPCGSGKKYKHCHGKLS & Rhodocyclaceae bacterium & 1.854 \\
\hline sp|P0C424| & CCAPSACRLGCRPCCR & Conus marmoreus (marble cone) & 2.968 \\
\hline $\operatorname{tr|A0A5K1BN05|~}$ & LGCGHGLPGIFACLK & Nymphaea colorata (plant) & 3.071 \\
\hline $\operatorname{tr}|A 0 A 5 K 1 D C Q 4|$ & LGCGHGLPGIYACLK & Nymphaea colorata (plant) & 3.071 \\
\hline splC0HK42| & VNWKKVLGKIIKVAK & Lasioglossum laticeps (bee) & 3.071 \\
\hline sp|P30259| & GCKKRKARKRPKCKKARKRPKCKRRKVAKKKC & Catshark & 4.290 \\
\hline sp|P14215| & RRWCFRVCYRGFCYRKCR & Atlantic horseshoe crab & 6.030 \\
\hline sp|P14216| & RRWCFRVCYKGFCYRKCR & Atlantic horseshoe crab & 6.030 \\
\hline $\operatorname{tr|A0A0G3VIX2|~}$ & AVPSWRIKSWNR & Bacteria & 7.090 \\
\hline tr|E9I8P2| & MLKKFLGKSGRRILR & Solenopsis invicta (ant) & 8.156 \\
\hline sp|P69135| & KWCFRVCYRGICYRRCR & Asian horseshoe crab & 18.171 \\
\hline sp|Q8WMD3| & $\begin{array}{l}\text { MARYRRCRSRSRCRRRRRRCHRRRRRCCRRRRRRRA } \\
\text { CCRRYRCRRR }\end{array}$ & Bat & 21.567 \\
\hline $\operatorname{tr}|A 0 A 0 D 3 H K 27|$ & MFGGSGPLKLL & Oryza barthii (plant) & 22.009 \\
\hline $\operatorname{tr|A0A1C8YA26|~}$ & FLGCRVQLAIKISGI & $\begin{array}{l}\begin{array}{l}\text { Triticum aestivum } \mathrm{x} \text { Aegilops } \\
\text { sharonensis (plant) }\end{array} \\
\end{array}$ & 22.359 \\
\hline $\operatorname{trl}$ A0A3Q7GQZ6| & GLAYRLVNLHFCKTKR & Solanum lycopersicum (tomato) & 22.657 \\
\hline $\operatorname{trl} \mathrm{A} 0 \mathrm{~A} 0 \mathrm{~K} 1 \mathrm{NW} 40 \mathrm{I}$ & KAIALALGKSGCK & Lycium cestroides (plants) & 22.679 \\
\hline sp|P0C022| & INLLKIAKGIIKSL & Wasp & 22.679 \\
\hline sp|P85874| & INWKKIASIGKEVLKAL & Wasp & 22.679 \\
\hline sp|P69034| & INWLKLGKKVSAIL & Wasp & 22.679 \\
\hline sp|P69036| & INWLKLGKAVIDAL & Wasp & 22.679 \\
\hline sp|P85443| & GLLDFLKAAGKGLVTNL & 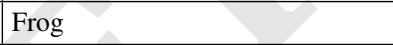 & 22.691 \\
\hline $\operatorname{trl}$ A0A5K0UXG7| & ALLKSKPKLLRSGL & Nymphaea colorata (plant) & 22.694 \\
\hline $\operatorname{tr|E9JAR4|~}$ & KLVLRRILALCIIAVCK & Solenopsis invicta (ant) & 22.924 \\
\hline sp|P82282| & IIGPVLGMVGSALGGLLKKIG & Toad & 23.278 \\
\hline sp|P82285| & IIGPVLGLVGSALGGLLKKIG & Toad & 23.278 \\
\hline sp|P85982| & IFGAILPLALGALKNLIK & Frog & 23.712 \\
\hline LFB0040 & FKCRRWAWRMKKLGA & Synthetic & 25.902 \\
\hline sp|P0C1R0| & ILGTILGLLKSL & Wasp & 32.702 \\
\hline $\operatorname{tr|A0A5K0UVL7|~}$ & ILLIKVGCCKIK & Nymphaea colorata (plant) & 38.404 \\
\hline LFB0017 & FKCRRWQWR & Lactoferrin, source: cow & 38.492 \\
\hline sp|COHLM2| & SGCCKHPACGKNRC & $\begin{array}{l}\text { Alpha-conotoxin, source: conus } \\
\text { purpurascens }\end{array}$ & 39.130 \\
\hline $\operatorname{trlA0A0K0LBU6|~}$ & GGYCGGAFRQRCICYRK & Androctonus bicolor (scorpion) & 46.616 \\
\hline tr|A0A5K1F988I & EKFKIHKSGKRWM & Nymphaea colorata (plant) & 46.812 \\
\hline tr|I7DAN2| & KKSGKIKSAYKR & Rhea americana (bird) & 50.828 \\
\hline $\operatorname{tr|S7IKV4|~}$ & SGLFCKGCSKL & Chlamydia psittaci (bacteria) & 60.154 \\
\hline $\operatorname{tr|Q16228|}$ & WRWRRACRRPGRPFWRV & Human & 61.163 \\
\hline
\end{tabular}

Table 16. Newly Predicted Antibiofilm Peptides with MBIC Range 16-32 $(\mu \mathrm{M})$ from the UniProt database

\begin{tabular}{|l|l|l|l|}
\hline Name & Seq & Source & Predicted MBEC $(\mu M)$ \\
\hline \hline sp|P0C005| & GLLKRIKTLL & Wasp & 22.679 \\
\hline sp|P17238| & INLKAIAALVKKVL & Hornet & 22.679 \\
\hline tr|Q9U8M9| & AGLGGIGLDTNREIVKSGPK & Scaptomyza graminum (insect) & 20.318 \\
\hline
\end{tabular}

\section{Supplementary Note 6: Dataset}

A. Positive Dataset. The details of our positive dataset, including the peptide sequence and its length, are given in Tables 1721. 
bioRxiv preprint doi: https://doi.org/10.1101/2021.09.28.462235; this version posted September 28, 2021. The copyright holder for this preprint (which was not certified by peer review) is the author/funder, who has granted bioRxiv a license to display the preprint in perpetuity. It is made available under aCC-BY-NC-ND 4.0 International license.

Table 17. Peptide List for our Positive Dataset

\begin{tabular}{|c|c|c|}
\hline Name & Seq & Seq Length \\
\hline BREVININ-1GHA & FLGAVLKVAGKLVPAAICKISKKC & 24 \\
\hline DERMASEPTIN-AC4 & SLWGKLKEMAAAAGKAALNAVNGLVNQ & 27 \\
\hline RPDEF1ALPHA & GFGCPNDYSCSNHCRDSIGCRGGYCKYHVICTCYGCKKRRSIQE & 44 \\
\hline KASSINIATUERIN-3 & FIQHLIPLIPHAIQGIKDIF & 20 \\
\hline AGELAIA-MP & INWLKLGKAIIDAL & 14 \\
\hline CCL20 & $\begin{array}{l}\text { SNFDCCLGYTDRILHPKFIVGFTRQLANEGCDINAIIFHTKKKLSVCANPKQTWVKYIVRLLS } \\
\text { KKVKNM }\end{array}$ & 69 \\
\hline CHICKEN & RFGRFLRKIRRFRPKVTITIQGSARFG & 27 \\
\hline CITROPIN & GLFDVIKKVASVIGGL & 16 \\
\hline COLISTIN & KTKKKLLKKT & 10 \\
\hline CON10 & FWSFLVKAASKILPSLIGGGDDNKSSS & 27 \\
\hline COPRISIN & VTCDVLSFEAKGIAVNHSACALHCIALRKKGGSCQNGVCVCRN & 43 \\
\hline DATUCIN & TFPKCAPTRPPGPKPCDINNFKSKFWHIWRA & 31 \\
\hline DERMASEPTIN-PH & ALWKEVLKNAGKAALNEINNLV & 22 \\
\hline DERMASEPTIN-PT9 & GLWSKIKDAAKTAGKAALGFVNEMV & 25 \\
\hline DHVAR4 & KRLFKKLLFSLRKY & 14 \\
\hline ENTEROCIN & $\begin{array}{l}\text { LGSCVANKIKDEFFAMISISAIVKAAQKKAWKELAVTVLRFAKANGLKTNAIIVAGQLALWAV } \\
\text { QCGLS } \\
\end{array}$ & 68 \\
\hline ESCULENTIN & GIFSKLAGKKIKNLLISGLKG & 21 \\
\hline GL13K & GKIIKLKASLKLL & 13 \\
\hline GRAMICIDIN & VKLFPVKLFP & 10 \\
\hline HSO2 & KWAVRIIRKFIKGFIS & 16 \\
\hline HUMAN defensin & GIINTLQKYYCRVRGGRCAVLSCLPKEEQIGKCSTRGRKCCRRKK & 45 \\
\hline HYICIN & NKGCSACAIGAACLADGPIPDFEVAGITGTFGIAS & 35 \\
\hline INDOLICIDIN & ILPWKWPWWPWRR & 13 \\
\hline JAPONICIN-2LF & FIVPSIFLLKKAFCIALKKC & 20 \\
\hline LL-37 & LLGDFFRKSKEKIGKEFKRIVQRIKDFLRNLVPRTES & 37 \\
\hline MP-C & LNLKALLAVAKKIL & 14 \\
\hline MORONECIDIN- & FFRNLWKGAKAAFRAGHAAWRA & 22 \\
\hline MYXINIDIN & 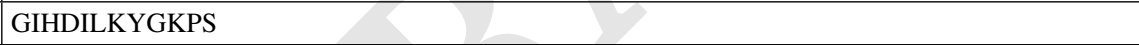 & 12 \\
\hline NA-CATH & GLLSGILGAGKKIVF & 15 \\
\hline NISIN & ITSISLCTPGCKTGALMGCNMKTATCHCSIHVSK & 34 \\
\hline PARACENTRIN & EVASFDKSKLK & 11 \\
\hline PHYLLOSEPTIN-1 & FLSLIPHIVSGVASIAKHF & 19 \\
\hline PHYLLOSEPTIN-CO & FLSMIPKIAGGIASLVKNL & 19 \\
\hline PHYLLOSEPTIN-PHA & FLSLIPAAISAVSALANHF & 19 \\
\hline PLEUROCIDIN & GWGSFFKKAAHVGKHVGKAALTHYL & 25 \\
\hline POLYBIA-MP-II & INWLKLGKMVIDAL & 14 \\
\hline POLYMYXIN & KTKKKFLKKT & 10 \\
\hline PROTEGRIN & RGGRLCYCRRRFCVCVGR & 18 \\
\hline SA-CATH & KFFKKLKKSVKKHVKKFFKKPKVIGVSIPF & 30 \\
\hline SAAP-148 & LKRVWKRVFKLLKRYWRQLKKPVR & 24 \\
\hline SMAP-29-APD & RGLRRLGRKIAHGVKKYGPTVLRIIRIAG & 29 \\
\hline TACHYPLESIN & KWCFRVCYRGICYRKCR & 17 \\
\hline TEMPORIN-1OLA & FLPFLKSILGKIL & 13 \\
\hline
\end{tabular}


bioRxiv preprint doi: https://doi.org/10.1101/2021.09.28.462235; this version posted September 28, 2021. The copyright holder for this preprint (which was not certified by peer review) is the author/funder, who has granted bioRxiv a license to display the preprint in perpetuity. It is made available under aCC-BY-NC-ND 4.0 International license.

A Positive Dataset

Table 18. Peptide List for our Positive Dataset (Cont.)

\begin{tabular}{|c|c|c|}
\hline Name & Seq & Seq Length \\
\hline TEMPORIN-B & LLPIVGNLLKSLL & 13 \\
\hline TEMPORIN-1CEB & ILPILSLIGGLLGK & 14 \\
\hline TEMPORIN-GHC & FLQHIIGALTHIF & 13 \\
\hline TEMPORIN-GHD & FLQHIIGALSHFF & 13 \\
\hline TEMPORIN-PTA & FFGSVLKLIPKIL & 13 \\
\hline TETRAF2W-RK & WWWLRKIW & 8 \\
\hline TOAP1 & FIGMIPGLIGGLISAFK & 17 \\
\hline TOAP2 & FFGTLFKLGSKLIPGVMKLFSKKKER & 26 \\
\hline TSAP-2 & FLGMIPGLIGGLISAFK & 17 \\
\hline UYCT3 & ILSAIWSGIKSLF & 13 \\
\hline VLL-28 & VLLVTLTRLHQRGVIYRKWRHFSGRKYR & 28 \\
\hline ZMD32 & RTCQSQSHRFRGPCLRRSNCANVCRTEGFPGGRCRGFRRRCFCTTHC & 47 \\
\hline BMAP-27 & GRFKRFRKKFKKLFKKLSPVIPLLHL & 26 \\
\hline BMAP-28 & GGLRSLGRKILRAWKKYGPIIVPIIRI & 27 \\
\hline SMAP-29 & RGLRRLGRKIAHGVKKYGPTVLRIIRIA & 28 \\
\hline KSL & KKVVFKVKFK & 10 \\
\hline F2-5-12W & RWGRWLRKIRRWRPK & 15 \\
\hline LL-31 & LLGDFFRKSKEKIGKEFKRIVQRIKDFLRNL & 31 \\
\hline LL7-31 & RKSKEKIGKEFKRIVQRIKDFLRNL & 25 \\
\hline LL13-37 & IGKEFKRIVQRIKDFLRNLVPRTES & 25 \\
\hline LL7-37 & RKSKEKIGKEFKRIVQRIKDFLRNLVPRTES & 31 \\
\hline LL-19 & LLGDFFRKSKEKIGKEFKR & 19 \\
\hline LL-25 & LLGDFFRKSKEKIGKEFKRIVQRIK & 25 \\
\hline LL-13 & LLGDFFRKSKEKI & 13 \\
\hline LL13-31 & IGKEFKRIVQRIKDFLRNL & 19 \\
\hline LL7-25 & RKSKEKIGKEFKRIVQRIK & 19 \\
\hline LL13-25 & IGKEFKRIVQRIK & 13 \\
\hline LL19-37 & RIVQRIKDFLRNLVPRTES & 19 \\
\hline KSL-W & KKVVFWVKFK & 10 \\
\hline KS-30 & KSKEKIGKEFKRIVQRIKDFLRNLVPRTES & 30 \\
\hline KR-20 & KRIVQRIKDFLRNLVPRTES & 20 \\
\hline KR-12 & KRIVQRIKDFLR & 12 \\
\hline LACTOFERRICIN-(17-30) & FKCRRWQWRMKKLG & 14 \\
\hline LACTOFERRAMPIN & WKLLSKAQEKFGKNKSR & 17 \\
\hline MUC7-12-MER-L & RKSYKCLHKRCR & 12 \\
\hline G10KHC & KKHRKHRKHRKHGGSGGSKNLRRIIRKGIHIIKKYG & 36 \\
\hline MUC7-12-MER-L4 & RKSYKALHKRAR & 12 \\
\hline MUC7-20-MER & LAHQKPFIRKSYKCLHKRCR & 20 \\
\hline HSN5 & AKRHHGYKRKFH & 12 \\
\hline MAGAININ-II & GIGKFLHSAKKFGKAFVGEIMNS & 23 \\
\hline LYS-A1 & KIFGAIWPLALGALKNLIK & 19 \\
\hline AAP2 & FHFFHHFFHFFHHF & 14 \\
\hline CSP & SGSLSTFFRLFNRSFTQALGK & 21 \\
\hline CSPC16 & TFFRLFNRSFTQALGK & 16 \\
\hline G2 & KNLRIIRKGIHIIKKY & 16 \\
\hline C16G2 & TFFRLFNRSFTQALGKGGGKNLRIIRKGIHIIKKY & 35 \\
\hline M8G2 & TFFRLFNRGGGKNLRIIRKGIHIIKKY & 27 \\
\hline S6L3-33 & FKKFWKWFRRF & 11 \\
\hline C16-33 & TRRRLFNRSFTQALGKSGGGFKKFWKWFRRF & 31 \\
\hline M8-33 & TFFRLFNRSGGGFKKFWKWFRRF & 23 \\
\hline CECROPIN-A-(1-7)-MELITTIN & KWKLFKKIGAVLKVL & 15 \\
\hline HH15 & KRFRIRVRVIRK & 12 \\
\hline
\end{tabular}


bioRxiv preprint doi: https://doi.org/10.1101/2021.09.28.462235; this version posted September 28, 2021. The copyright holder for this preprint (which was not certified by peer review) is the author/funder, who has granted bioRxiv a license to display the preprint in perpetuity. It is made available under aCC-BY-NC-ND 4.0 International license.

Table 19. Peptide List for our Positive Dataset (Cont.)

\begin{tabular}{|c|c|c|}
\hline Name & Seq & Seq Length \\
\hline $\mathrm{BAC} 2 \mathrm{~A}$ & RLARIVVIRVAR & 12 \\
\hline 1026 & VQWRIRVRVIKK & 12 \\
\hline 1029 & \begin{tabular}{|l} 
KQFRIRVRV \\
\end{tabular} & 9 \\
\hline 1036 & VQFRIRVRIVIRK & 13 \\
\hline 1037 & KRFRIRVRV & 9 \\
\hline $\mathrm{HH} 2$ & VQLRIRVAVIRA & 12 \\
\hline 1002 & VQRWLIVWRIRK & 12 \\
\hline 1003 & IVWKIKRWWVGR & 12 \\
\hline 1004 & RFWKVRVKYIRF & 12 \\
\hline 1008 & RIKWIVRFR & 9 \\
\hline HH7 & VRLRIRVAVRRA & 12 \\
\hline 1010 & IRWRIRVWVRRI & 12 \\
\hline 1011 & RRWVVWRIVQRR & 12 \\
\hline 1012 & IFWRRIVIVKKF & 12 \\
\hline 1013 & VRLRIRVA & 8 \\
\hline 1016 & LRIRWIFKR & 9 \\
\hline HH8 & VRLRIRVAVIRK & 12 \\
\hline 1020 & VRLRIRWWVLRK & 12 \\
\hline HH10 & KRFRIRVAVRRA & 12 \\
\hline 1035 & KRWRWIVRNIRR & 12 \\
\hline 1031 & WRWRVRVWR & 9 \\
\hline IMB-2 & TFFRLFNRGGGWGSFFKKAAHVGKL & 25 \\
\hline BAC8C & 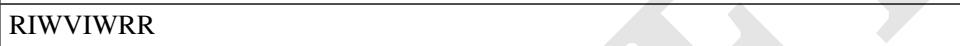 & 8 \\
\hline PTP-7 & FLGALFKALSKLL & 13 \\
\hline HOLOTHURIOIDIN-1 & HLGHHALDHLLK & 12 \\
\hline HOLOTHURIOIDIN-2 & ASHLGHHALDHLLK & 14 \\
\hline TN-AFP1 & LMCTHPLDCSN & 11 \\
\hline COPRISIN-BAAMP & VTCDVLSFEAKGIAVNH & 17 \\
\hline HISTATIN & DSHAKRHHGYKRKFHEKHHSHRGY & 24 \\
\hline HST & AKRHHGYKRKFHGGG & 15 \\
\hline DF17-6K & KKKKKKAAFAAWAAFAA & 17 \\
\hline DF21-10K & KKKKKKKKKKAAFAAWAAFAA & 21 \\
\hline CWR11 & CWFWKWWRRRRR & 12 \\
\hline CHRYSOPHSIN-1 & FFGWLIKGAIHAGKAIHGLIHRRRH & 25 \\
\hline RK1 & RWKRWWRRKK & 10 \\
\hline RK2 & RKKRWWRRKK & 10 \\
\hline (IRIK) & IRIKIRIK & 8 \\
\hline (IRVK) & IRVKIRVKIRVK & 12 \\
\hline ALPHA-DEFENSIN-3 & DCYCRIPACIAGERRYGTCIYQGRLWAFCC & 30 \\
\hline BETA-DEFENSIN-1 & DHYNCVSSGGQCLYSACPIFTKIQGTCYRGKAKCCK & 36 \\
\hline MAGAININ-I & GIGKFLHSAGKFGKAFVGEIMKS & 23 \\
\hline RIP & YSPWTNF & 7 \\
\hline K4-S4(1â€“"13)A & ALWKTLLKKVLKA & 13 \\
\hline DD13-RIP & ALWKTLLKKVLKAYSPWTNF & 20 \\
\hline $2 \mathrm{C}-4$ & RWRWRWF & 7 \\
\hline SM6(L1)2C & FIKHFIHRFGGGRWRWRWF & 19 \\
\hline SM6(L3)2C & FIKHFIHRFSATRWRWRWF & 19 \\
\hline SM6(L1)B33 & FIKHFIHRFGGGFKKFWKWFRRF & 23 \\
\hline NRC-16 & GWKKWLRKGAKHLGQAAIK & 19 \\
\hline GK7 & GQIINLK & 7 \\
\hline (RW)2-NH2 & RWRW & 4 \\
\hline (RW)3-NH2 & RWRWRW & 6 \\
\hline
\end{tabular}


bioRxiv preprint doi: https://doi.org/10.1101/2021.09.28.462235; this version posted September 28, 2021. The copyright holder for this preprint (which was not certified by peer review) is the author/funder, who has granted bioRxiv a license to display the preprint in perpetuity. It is made available under aCC-BY-NC-ND 4.0 International license.

A Positive Dataset

Table 20. Peptide List for our Positive Dataset (Cont.)

\begin{tabular}{|c|c|c|}
\hline Name & Seq & Seq Length \\
\hline$(\mathrm{RW}) 4-\mathrm{NH} 2$ & RWRWRWRW & 8 \\
\hline LASIO-III & VNWKKILGKIIKVVK & 15 \\
\hline MELITTIN & GIGAVLKVLTTGLPALISWIKRKRQQ & 26 \\
\hline MELIMINE & TLISWIKNKRKQRPRVSRRRRRRGGRRRR & 29 \\
\hline MELIMINE-CYSN & CTLISWIKNKRKQRPRVSRRRRRRGGRRRR & 30 \\
\hline MELIMINE-CYSC & TLISWIKNKRKQRPRVSRRRRRRGGRRRRC & 30 \\
\hline MELIMINE-CYS13 & TLISWIKNKRKQCRPRVSRRRRRRGGRRRR & 30 \\
\hline K4-S4(1-15)A & LWKTLLKKVLKAAA & 14 \\
\hline BETA6-20-G3K6 & NEEGFFSARGHRPLDGGGKKKKKK & 24 \\
\hline HEPCIDIN & ICIFCCGCCHRSKCGMCCKT & 20 \\
\hline NA-CATH-BAAMP & KRFKKFFKKLKNSVKKRAKKFFKKPKVIGVTFPF & 34 \\
\hline NA-CATH-ATRA1-ATRA1 & KRFKKFFKKLKNSVKKRFKKFFKKLKVIGVTFPF & 34 \\
\hline LACTOFERRICIN-B-(17-41) & FKCRRWQWRMKKLGAPSITCVRRAF & 25 \\
\hline SCRAMBLED & GLKLRFEFSKIKGEFLKTPEVRFRDIKLKDNRISVQR & 37 \\
\hline R-FV-I16 & RFRRLFRIRVRVLKKI & 16 \\
\hline FV7 & FRIRVRV & 7 \\
\hline VSL2 & AFKAFWKFVKFVK & 13 \\
\hline VS2 & KWFWKFVKFVK & 11 \\
\hline L-K6 & IKKILSKIKKLLK & 13 \\
\hline HLF1-11 & GRRRRSVQWCA & 11 \\
\hline FS3 & YAPWTNF & 7 \\
\hline TET-213 & KRWWKWWRRC & 10 \\
\hline 1010CYS & IRWRIRVWVRRIC & 13 \\
\hline TET-20 & KRWRIRVRVIRKC & 13 \\
\hline TET-26 & WIVVIWRRKRRRC & 13 \\
\hline FS8 & $\sqrt{2}+3$ & 7 \\
\hline CHROMOFUNGIN & RILSILRHQNLLKELQDLAL & 20 \\
\hline CECROPIN-B & KWKVFKKIEKMGRNIRNGIVKAGPAIAVLGEAKAL & 35 \\
\hline MAGAININ & GIGLFLHSAGLFGLAFVGEIMKS & 23 \\
\hline CYSLASIO-III & CVNWKKILGKIIKVVK & 16 \\
\hline DASAMP1 & FFGKVLKLIRKIF & 13 \\
\hline BMAP-18 & GRWKRWRKKWKKLWKKLS & 18 \\
\hline BACTENECIN & RLCRIVVIRVCR & 12 \\
\hline CA-MA & KWKLFKKIGIGKFLHSAKKF & 20 \\
\hline RTA3 & RPAFRKAAFRVMRACV & 16 \\
\hline DHVAR5 & LLLFLLKKRKKRKY & 14 \\
\hline KABT-AMP & GIWKKWIKKWLKKLLKKLWKKG & 22 \\
\hline $\mathrm{P} 10$ & LAREYKKIVEKLKRWLRQVLRTLR & 24 \\
\hline P60.4AC & IGKEFKRIVERIKRFLRELVRPLR & 24 \\
\hline OSIP108 & MLCVLQGLRE & 10 \\
\hline S-OSIP108 & ELRLVCMGQL & 10 \\
\hline [CYC2]OSIP108 & MLCVLQGLREGG & 12 \\
\hline [CYC3]OSIP108 & MLCVLQGLREC & 11 \\
\hline 1018 & VRLIVAVRIWRR & 12 \\
\hline HE1 & RRWIRVAVILRV & 12 \\
\hline HE2 & VRLIRAVRAWRV & 12 \\
\hline HE3 & VRWARVARILRV & 12 \\
\hline HE4 & VRLIWAVRIWRR & 12 \\
\hline HE10 & VRLIVRIWRR & 10 \\
\hline HE12 & RFKRVARVIW & 10 \\
\hline GL13KR1 & IGIKLLKSKLKAL & 13 \\
\hline (IKIK)2 & IKIKIKIK & 8 \\
\hline
\end{tabular}


bioRxiv preprint doi: https://doi.org/10.1101/2021.09.28.462235; this version posted September 28, 2021. The copyright holder for this preprint (which was not certified by peer review) is the author/funder, who has granted bioRxiv a license to display the preprint in perpetuity. It is made available under aCC-BY-NC-ND 4.0 International license.

Table 21. Peptide List for our Positive Dataset (Cont.)

\begin{tabular}{|c|c|c|}
\hline Name & Seq & Seq Length \\
\hline RI1012 & FKKVIVIRRWFI & 12 \\
\hline RI1002 & KRIRWVILWRQV & 12 \\
\hline LJK1 & VFLRRIRVIVIR & 12 \\
\hline RIJK1 & RIVIVRIRRLFV & 12 \\
\hline LJK2 & VFWRRIRVWVIR & 12 \\
\hline RIJK2 & RIVWVRIRRWFV & 12 \\
\hline LJK3 & VQLRAIRVRVIR & 12 \\
\hline RIJK3 & RIVRVRIARLQV & 12 \\
\hline LJK4 & VQLRRIRVWVIR & 12 \\
\hline RIJK4 & RIVWVRIRRLQV & 12 \\
\hline LJK5 & VQWRAIRVRVIR & 12 \\
\hline RIJK5 & RIVRVRAIRWQV & 12 \\
\hline LJK6 & VQWRRIRVWVIR & 12 \\
\hline RIJK6 & RIVWVRIRRWQV & 12 \\
\hline NAL-P-113 & AKRRRGYKRKFKK & 13 \\
\hline $\mathrm{P} 15$ & GTPGPQGIAGQRGVV & 15 \\
\hline P15-CSP & GTPGPQGIAGQRGVVAEAAAKEAAAKEAAAKASGSLSTFFRLFNRSFTQALGK & 53 \\
\hline C-GG-NT-DHVAR5 & CGGLLLFLLKKRKKRKY & 17 \\
\hline KT2 & NGVQPKYKWWKWWKKWW & 17 \\
\hline RT2 & NGVQPKYRWWRWWRRWW & 17 \\
\hline LF11-322 & PFWRIRIRR & 9 \\
\hline LF11-324 & 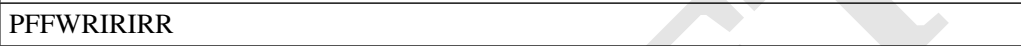 & 10 \\
\hline 6-MO-LF11-227 & 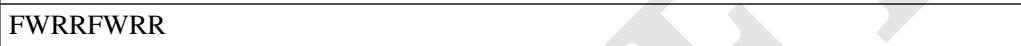 & 8 \\
\hline LF11-215 & FWRIRIRR & 8 \\
\hline D-ATRA-1A & KRAKKFFKKLK & 11 \\
\hline ATRA-2 & KRAKKFFKKPK & 11 \\
\hline ATRA-1 & KRFKKFFKKLK & 11 \\
\hline ALL & LKLLKKLLKKLLKLL & 15 \\
\hline SEG5D & KKKLLLLLLLLLLKKK & 15 \\
\hline SEG6D & LLLLLKKKKKKLLLL & 15 \\
\hline G10 & KNLRRIIRKGIHIIKKYG & 18 \\
\hline LIN-SB056 & WKKIRVRLSA & 10 \\
\hline LIN-SB056-1 & KWKIRVRLSA & 10 \\
\hline MYXINIDIN2 & KIKWILKYWKWS & 12 \\
\hline MYXINIDIN3 & RIRWILRYWRWS & 12 \\
\hline GH12 & GLLWHLLHHLLH & 12 \\
\hline PA-MAP & LAAKLTKAATKLTAALTKLAAALT & 24 \\
\hline HSAFP1 & DGVKLCDVPSGTWSGHCGSSSKCSQQCKDREHFAYGGACHYQFPSVKCFCKRQC & 54 \\
\hline HSLIN06 & EHFAYGGAKHYQFPSVKKFKKRQK & 24 \\
\hline Verine & RRRWWWWV & 8 \\
\hline Phylloseptin-PTa & FLSLIPKIAGGIAALAKHL & 19 \\
\hline
\end{tabular}

B. MBEC Dataset. Antibiofilm peptides with MBEC values are listed in Table 22. The pathogens against which the MBEC values are effective are also listed in the 'pathogen' column. The MBEC values are listed in $\mu \mathrm{M}$. 
bioRxiv preprint doi: https://doi.org/10.1101/2021.09.28.462235; this version posted September 28,2021 . The copyright holder for this preprint (which was not certified by peer review) is the author/funder, who has granted bioRxiv a license to display the preprint in perpetuity. It is made available under aCC-BY-NC-ND 4.0 International license.

B MBEC Dataset

Table 22. Antibiofilm Peptides and MBEC $(\mu \mathrm{M})$ Values

\begin{tabular}{|c|c|c|c|c|}
\hline Name & Seq & MBEC $(\mu \mathbf{M})$ & Pathogen & Source \\
\hline BREVININ-1GHA & FLGAVLKVAGKLVPAAICKISKKC & 16 & S. aureus & [56] \\
\hline DERMASEPTIN-AC4 & SLWGKLKEMAAAAGKAALNAVNGLVNQ & 256 & S. aureus & [57] \\
\hline KASSINIATUERIN-3 & FIQHLIPLIPHAIQGIKDIF & 64 & S. aureus & [58] \\
\hline CCL20 & $\begin{array}{l}\text { SNFDCCLGYTDRILHPKFIVGFTRQLANEGCDINAIIFH } \\
\text { TKKKLSVCANPKQTWVKYIVRLLSKKVKNM } \\
\end{array}$ & 128 & P. aeruginosa & [59] \\
\hline COPRISIN & $\begin{array}{l}\text { VTCDVLSFEAKGIAVNHSACALHCIALRKKGGSCQNG } \\
\text { VCVCRN }\end{array}$ & 4.49 & P. aeruginosa & [60] \\
\hline DERMASEPTIN-PH & ALWKEVLKNAGKAALNEINNLV & 128 & S. aureus & [61] \\
\hline DERMASEPTIN-PT9 & GLWSKIKDAAKTAGKAALGFVNEMV & 32 & S. aureus & [62] \\
\hline ESCULENTIN & GIFSKLAGKKIKNLLISGLKG & 6 & P. aeruginosa & [63] \\
\hline GL13K & GKIIKLKASLKLL & 22.47 & P. aeruginosa & [64] \\
\hline HUMAN defensin & $\begin{array}{l}\text { GIINTLQKYYCRVRGGRCAVLSCLPKEEQIGKCSTRGR } \\
\text { KCCRRKK }\end{array}$ & 3.1 & MRSE & [65] \\
\hline INDOLICIDIN & ILPWKWPWWPWRR & 335.7 & MRSA & [66] \\
\hline LL-37 & LLGDFFRKSKEKIGKEFKRIVQRIKDFLRNLVPRTES & 20 & P. aeruginosa & [67] \\
\hline NISIN & ITSISLCTPGCKTGALMGCNMKTATCHCSIHVSK & 183.1 & $M R S A$ & [66] \\
\hline PHYLLOSEPTIN-1 & FLSLIPHIVSGVASIAKHF & 5 & S. aureus & [68] \\
\hline PLEUROCIDIN & GWGSFFKKAAHVGKHVGKAALTHYL & 23.62 & S. mutans & [69] \\
\hline BMAP-27 & GRFKRFRKKFKKLFKKLSPVIPLLHL & 6.2 & P. aeruginosa & [70] \\
\hline BMAP-28 & GGLRSLGRKILRAWKKYGPIIVPIIRI & 6.5 & P. aeruginosa & [70] \\
\hline SMAP-29 & RGLRRLGRKIAHGVKKYGPTVLRIIRIA & 6.25 & P. aeruginosa & [70] \\
\hline KSL & KKVVFKVKFK & 400 & S. mutans & [71] \\
\hline F2-5-12W & RWGRWLRKIRRWRPK & 40 & S.epidermidis & [72] \\
\hline LL-31 & LLGDFFRKSKEKIGKEFKRIVQRIKDFLRNL & 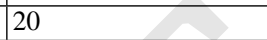 & P. aeruginosa & [67] \\
\hline LL13-37 & IGKEFKRIVQRIKDFLRNLVPRTES & 100 & P. aeruginosa & [67] \\
\hline LL7-37 & RKSKEKIGKEFKRIVQRIKDFLRNLVPRTES & 50 & P. aeruginosa & [67] \\
\hline KSL-W & KKVVFWVKFK & 191.16 & MRSA & [73] \\
\hline MUC7-12-MER-L & RKSYKCLHKRCR & 12.5-50; median 50 & S. mutans & [74] \\
\hline MUC7-12-MER-L4 & RKSYKALHKRAR & $50 ;$ median $>50$ & S. mutans & [74] \\
\hline MUC7-20-MER & LAHQKPFIRKSYKCLHKRCR & $6.25-25 ;$ median 25 & S. mutans & [74] \\
\hline HSN5 & AKRHHGYKRKFH & 12.5-50; median $>50$ & S. mutans & [74] \\
\hline MAGAININ-II & GIGKFLHSAKKFGKAFVGEIMNS & $25-50 ;$ median $>50$ & S. mutans & [74] \\
\hline C16G2 & TFFRLFNRSFTQALGKGGGKNLRIIRKGIHIIKKY & 25 & S. mutans & [75] \\
\hline BAC8C & RIWVIWRR & 108.13 & S. mutans & [76] \\
\hline PTP-7 & FLGALFKALSKLL & 40 & S. aureus & [77] \\
\hline CHRYSOPHSIN-1 & FFGWLIKGAIHAGKAIHGLIHRRRH & 11.07 & S. aureus & [78] \\
\hline $2 \mathrm{C}-4$ & RWRWRWF & 50 & $\begin{array}{l}\text { S. mutans and } \\
\text { other oral } \\
\text { streptococci }\end{array}$ & [79] \\
\hline SM6(L1)2C & FIKHFIHRFGGGRWRWRWI & 50 & $\begin{array}{l}\text { S. mutans and } \\
\text { other oral } \\
\text { streptococci }\end{array}$ & [79] \\
\hline SM6(L3)2C & FIKHFIHRFSATRWRWRWF & 50 & $\begin{array}{l}\text { S. mutans and } \\
\text { other oral } \\
\text { streptococci }\end{array}$ & [79] \\
\hline SM6(L1)B33 & FIKHFIHRFGGGFKKFWKWFRRF & 50 & S. mutans & [79] \\
\hline$(\mathrm{RW}) 4-\mathrm{NH} 2$ & RWRWRWRW & 100 & E.coli & [80] \\
\hline MELITTIN & GIGAVLKVLTTGLPALISWIKRKRQQ & 50 & S.mutans & [75] \\
\hline R-FV-I16 & RFRRLFRIRVRVLKKI & 64 & P. aeruginosa & [81] \\
\hline L-K6 & IKKILSKIKKLLK & 6.25 & S. mutans & [82] \\
\hline CA-MA & KWKLFKKIGIGKFLHSAKKF & 361.54 & MRSA & [66] \\
\hline P10 & LAREYKKIVEKLKRWLRQVLRTLR & 32 & $M R S A$ & [83] \\
\hline 1018 & VRLIVAVRIWRR & 6.51 & P. aeruginosa & [?] \\
\hline HE4 & VRLIWAVRIWRR & 6.16 & P. aeruginosa & [84] \\
\hline HE10 & VRLIVRIWRR & 7.32 & P. aeruginosa & [84] \\
\hline DJK5 & VQWRAIRVRVIR & 1.61 & P. aeruginosa & [85] \\
\hline DJK6 & VQWRRIRVWVIR & 1.5 & P. aeruginosa & {$[85]$} \\
\hline KT2 & NGVQPKYKWWKWWKKWW & 1 & E. coli & [86] \\
\hline RT2 & NGVQPKYRWWRWWRRWW & 1 & E. coli & [86] \\
\hline DI-MB-LF11-322 & PFWRIRIRR & 246.38 & P. aeruginosa & [87] \\
\hline LF11-324 & PFFWRIRIRR & 55.33 & P. aeruginosa & [87] \\
\hline 6-MO-LF11-227 & FWRRFWRR & 489.01 & P. aeruginosa & [87] \\
\hline LF11-215 & FWRIRIRR & 133.41 & P. aeruginosa & [87] \\
\hline P60.4AC & IGKEFKRIVERIKRFLRELVRPLR & 32 & $M R S A$ & [83] \\
\hline
\end{tabular}


bioRxiv preprint doi: https://doi.org/10.1101/2021.09.28.462235; this version posted September 28, 2021. The copyright holder for this preprint (which was not certified by peer review) is the author/funder, who has granted bioRxiv a license to display the preprint in perpetuity. It is made available under aCC-BY-NC-ND 4.0 International license.

\section{APPENDIX BIBLIOGRAPHY}

[56] Qi Chen, Peng Cheng, Chengbang Ma, Xinping Xi, Lei Wang, Mei Zhou, Huimin Bian, and Tianbao Chen. Evaluating the bioactivity of a novel broad-spectrum antimicrobial peptide brevinin-1gha from the frog skin secretion of hylarana guentheri and its analogues. Toxins, 10(10), 2018. ISSN 2072-6651. doi: 10.3390/toxins10100413.

[57] Zijian Gong, Xinjie Pei, Shen Ren, Xiaoling Chen, Lei Wang, Chengbang Ma, Xinping Xi, Tianbao Chen, Chris Shaw, and Mei Zhou. Identification and rational design of a novel antibacterial peptide dermaseptin-ac from the skin secretion of the red-eyed tree frog agalychnis callidryas. Antibiotics, 9(5), 2020. ISSN 2079-6382. doi: 10.3390/antibiotics9050243.

[58] H. Wang, H. He, X. Chen, M. Zhou, M. Wei, X. Xi, C. Ma, Q. Du, T. Chen, C. Shaw, and L. Wang. A novel antimicrobial peptide (kassinatuerin-3) isolated from the skin secretion of the african frog, kassina senegalensis. Biology (Basel), 9(7), Jul 2020.

[59] Gopal Ramamourthy, Mauricio Arias, Leonard T. Nguyen, Hiroaki Ishida, and Hans J. Vogel. Expression and purification of chemokine mip-3 $\alpha$ (ccl20) through a calmodulin-fusion protein system. Microorganisms, 7(1), 2019. ISSN 2076-2607. doi: 10.3390/microorganisms7010008.

[60] In-sok Hwang, Jae-Sam Hwang, Ji Hong Hwang, Hyemin Choi, Eunjung Lee, Yangmee Kim, and Dong Gun Lee. Synergistic effect and antibiofilm activity between the antimicrobial peptide coprisin and conventional antibiotics against opportunistic bacteria. Current Microbiology, 66(1):56-60, Jan 2013. ISSN 1432-0991. doi: 10.1007/s00284-012-0239-8.

[61] Linyuan Huang, Dong Chen, Lei Wang, Chen Lin, Chengbang Ma, Xinping Xi, Tianbao Chen, Chris Shaw, and Mei Zhou. Dermaseptin-ph: A novel peptide with antimicrobial and anticancer activities from the skin secretion of the south american orange-legged leaf frog, pithecopus (phyllomedusa) hypochondrialis. Molecules, 22(10), 2017. ISSN 1420-3049. doi: 10.3390/molecules22101805.

[62] Miaoran Li, Xinping Xi, Chengbang Ma, Xiaoling Chen, Mei Zhou, James F. Burrows, Tianbao Chen, and Lei Wang. A novel dermaseptin isolated from the skin secretion of phyllomedusa tarsius and its cationicity-enhanced analogue exhibiting effective antimicrobial and anti-proliferative activities. Biomolecules, 9(10), 2019. ISSN 2218-273X. doi: 10.3390/biom9100628.

[63] Vincenzo Luca, Annarita Stringaro, Marisa Colone, Alessandro Pini, and Maria Luisa Mangoni. Esculentin(1-21), an amphibian skin membrane-active peptide with potent activity on both planktonic and biofilm cells of the bacterial pathogen pseudomonas aeruginosa. Cellular and Molecular Life Sciences, 70(15):2773-2786, Aug 2013. ISSN 1420-9071. doi: 10.1007/s00018-013-1291-7.

[64] Helmut Hirt and Sven-Ulrik Gorr. Antimicrobial peptide gl13k is effective in reducing biofilms of pseudomonas aeruginosa. Antimicrobial Agents and Chemotherapy, 57(10):4903-4910, 2013. doi: 10.1128/AAC.00311-13

[65] J. M. Sutton and T. A. Pritts. Human beta-defensin 3: a novel inhibitor of Staphylococcus-produced biofilm production. Commentary on "Human $\beta$-defensin 3 inhibits antibiotic-resistant Staphylococcus biofilm formation". J Surg Res, 186(1):99-100, Jan 2014.

[66] E. Mataraci and S. Dosler. In vitro activities of antibiotics and antimicrobial cationic peptides alone and in combination against methicillin-resistant Staphylococcus aureus biofilms. Antimicrob Agents Chemother, 56(12):6366-6371, Dec 2012.

[67] C. Nagant, B. Pitts, K. Nazmi, M. Vandenbranden, J. G. Bolscher, P. S. Stewart, and J.-P. Dehaye. Identification of peptides derived from the human antimicrobial peptide II-37 active against biofilms formed by pseudomonas aeruginosa using a library of truncated fragments. Antimicrobial Agents and Chemotherapy, 56(11):5698-5708, 2012. doi: 10.1128/AAC.00918-12.

[68] Ruowen Zhang, Mei Zhou, L. Wang, S. McGrath, Tianbao Chen, Xiaohui Chen, and C. Shaw. Phylloseptin-1 (psn-1) from phyllomedusa sauvagei skin secretion: a novel broad-spectrum antimicrobial peptide with antibiofilm activity. Molecular immunology, 47 11-12:2030-7, 2010.

[69] R. Tao, Z. Tong, Y. Lin, Y. Xue, W. Wang, R. Kuang, P. Wang, Y. Tian, and L. Ni. Antimicrobial and antibiofilm activity of pleurocidin against cariogenic microorganisms. Peptides, 32(8):1748-1754, Aug 2011.

[70] A. Pompilio, M. Scocchi, S. Pomponio, F. Guida, A. Di Primio, E. Fiscarelli, R. Gennaro, and G. Di Bonaventura. Antibacterial and anti-biofilm effects of cathelicidin peptides against pathogens isolated from cystic fibrosis patients. Peptides, 32(9):1807-1814, Sep 2011.

[71] Y. Liu, L. Wang, X. Zhou, S. Hu, S. Zhang, and H. Wu. Effect of the antimicrobial decapeptide KSL on the growth of oral pathogens and Streptococcus mutans biofilm. Int J Antimicrob Agents, 37 (1):33-38, Jan 2011.

[72] E. M. Molhoek, A. van Dijk, E. J. Veldhuizen, H. P. Haagsman, and F. J. Bikker. A cathelicidin-2-derived peptide effectively impairs Staphylococcus epidermidis biofilms. Int J Antimicrob Agents, 37 (5):476-479, May 2011.

[73] Purushottam V. Gawande, Kai P. Leung, and Srinivasa Madhyastha. Antibiofilm and antimicrobial efficacy of dispersinb®-ksl-w peptide-based wound gel against chronic wound infection associated bacteria. Current Microbiology, 68(5):635-641, May 2014. ISSN 1432-0991. doi: 10.1007/s00284-014-0519-6.

[74] Guo-Xian Wei, Alexander N. Campagna, and Libuse A. Bobek. Effect of muc7 peptides on the growth of bacteria and on streptococcus mutans biofilm. Journal of Antimicrobial Chemotherapy, 57 (6):1100-1109, 04 2006. ISSN 0305-7453. doi: 10.1093/jac/dkl120.

[75] R. Sullivan, P. Santarpia, S. Lavender, E. Gittins, Z. Liu, M. H. Anderson, J. He, W. Shi, and R. Eckert. Clinical efficacy of a specifically targeted antimicrobial peptide mouth rinse: Targeted elimination of <i>streptococcus mutans</i> and prevention of demineralization. Caries Research, 45(5):415-428, 2011. ISSN 0008-6568. doi: 10.1159/000330510.

[76] Y. Ding, W. Wang, M. Fan, Z. Tong, R. Kuang, W. Jiang, and L. Ni. Antimicrobial and anti-biofilm effect of Bac8c on major bacteria associated with dental caries and Streptococcus mutans biofilms. Peptides, 52:61-67, Feb 2014.

[77] R. Kharidia and J. F. Liang. The activity of a small lytic peptide PTP-7 on Staphylococcus aureus biofilms. J Microbiol, 49(4):663-668, Aug 2011.

[78] W. Wang, R. Tao, Z. Tong, Y. Ding, R. Kuang, S. Zhai, J. Liu, and L. Ni. Effect of a novel antimicrobial peptide chrysophsin-1 on oral pathogens and Streptococcus mutans biofilms. Peptides, 33(2): 212-219, Feb 2012

[79] Jian He, Daniel K. Yarbrough, Jens Kreth, Maxwell H. Anderson, Wenyuan Shi, and Randal Eckert. Systematic approach to optimizing specifically targeted antimicrobial peptides against <i>streptococcus mutans<ii>. Antimicrobial Agents and Chemotherapy, 54(5):2143-2151, 2010. doi: 10.1128/AAC.01391-09.

[80] Shuyu Hou, Zhigang Liu, Anne W. Young, Sheron L. Mark, Neville R. Kallenbach, and Dacheng Ren. Effects of trp- and arg-containing antimicrobial-peptide structure on inhibition of <i>escherichia coli</i> planktonic growth and biofilm formation. Applied and Environmental Microbiology, 76(6):1967-1974, 2010. doi: 10.1128/AEM.02321-09.

[81] Wei Xu, Xin Zhu, Tingting Tan, Weizhong Li, and Anshan Shan. Design of embedded-hybrid antimicrobial peptides with enhanced cell selectivity and anti-biofilm activity. PLOS ONE, 9(6):1-13, 06 2014. doi: 10.1371/journal.pone.0098935.

[82] D. Shang, H. Liang, S. Wei, X. Yan, Q. Yang, and Y. Sun. Effects of antimicrobial peptide L-K6, a temporin-1CEb analog on oral pathogen growth, Streptococcus mutans biofilm formation, and anti-inflammatory activity. Appl Microbiol Biotechnol, 98(20):8685-8695, Oct 2014.

[83] Elisabeth M. Haisma, Anna de Breij, Heelam Chan, Jaap T. van Dissel, Jan W. Drijfhout, Pieter S. Hiemstra, Abdoelwaheb El Ghalbzouri, and Peter H. Nibbering. LI-37-derived peptides eradicate multidrug-resistant staphylococcus aureus from thermally wounded human skin equivalents. Antimicrobial Agents and Chemotherapy, 58(8):4411-4419, 2014. doi: 10.1128/AAC.02554-14.

[84] César de la Fuente-Núñez, Sarah C. Mansour, Zhejun Wang, Lucy Jiang, Elena B.M. Breidenstein, Melissa Elliott, Fany Reffuveille, David P. Speert, Shauna L. Reckseidler-Zenteno, Ya Shen, Markus Haapasalo, and Robert E.W. Hancock. Anti-biofilm and immunomodulatory activities of peptides that inhibit biofilms formed by pathogens isolated from cystic fibrosis patients. Antibiotics, 3(4):509-526, 2014. ISSN 2079-6382. doi: 10.3390/antibiotics3040509.

[85] C. de la Fuente-Núñez, F. Reffuveille, S. C. Mansour, S. L. Reckseidler-Zenteno, D. Hernández, G. Brackman, T. Coenye, and R. E. Hancock. D-enantiomeric peptides that eradicate wild-type and multidrug-resistant biofilms and protect against lethal Pseudomonas aeruginosa infections. Chem Biol, 22(2):196-205, Feb 2015.

[86] Thitiporn Anunthawan, César de la Fuente-Núñez, Robert E.W. Hancock, and Sompong Klaynongsruang. Cationic amphipathic peptides kt2 and rt2 are taken up into bacterial cells and kill planktonic and biofilm bacteria. Biochimica et Biophysica Acta (BBA) - Biomembranes, 1848(6):1352-1358, 2015. ISSN 0005-2736. doi: https://doi.org/10.1016/j.bbamem.2015.02.021.

[87] Susana Sánchez-Gómez, Raquel Ferrer-Espada, Philip S. Stewart, Betsey Pitts, Karl Lohner, and Guillermo Martínez de Tejada. Antimicrobial activity of synthetic cationic peptides and lipopeptides derived from human lactoferricin against pseudomonas aeruginosa planktonic cultures and biofilms. BMC Microbiology, 15(1):137, Jul 2015. ISSN 1471-2180. doi: 10.1186/s12866-015-0473-x. 